\title{
Use of peptide microarrays for mapping viral B cell epitopes
}

\author{
Dissertation \\ zur Erlangung des Doktorgrades \\ der Mathematisch-Naturwissenschaftlichen Fakultäten \\ der Georg-August-Universität zu Göttingen
}

vorgelegt von

Ahmed Abd El Wahed Aly Abou El Nasr (geb. Port Said)

Aus Port Said, Ägypten

Göttingen 2011 
Referent:

Prof. Dr. Hans-Joachim Fritz

Korreferent:

Prof. Dr. Gerhard Hunsmann

Tag der mündlichen Prüfung:

15.03.2011 


\section{Contents}

\section{Abbreviations}

1 INTRODUCTION

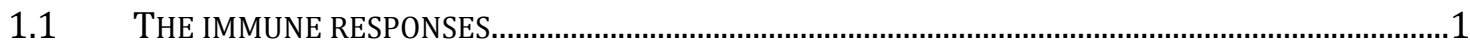

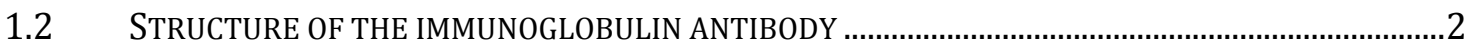

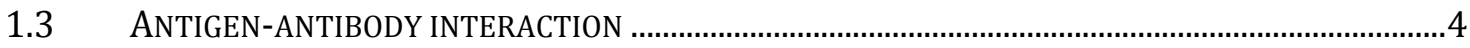

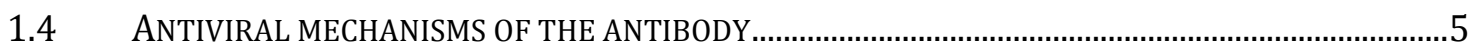

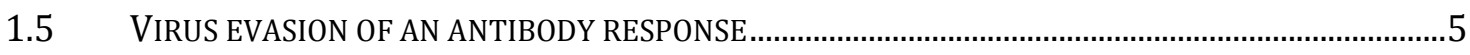

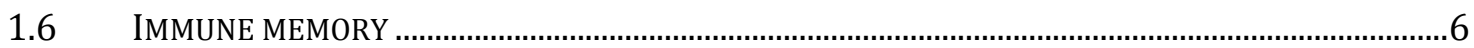

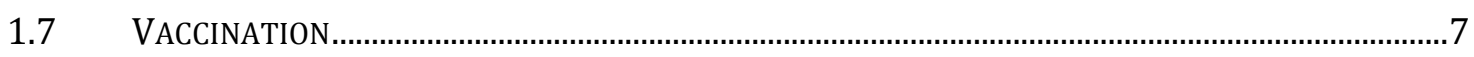

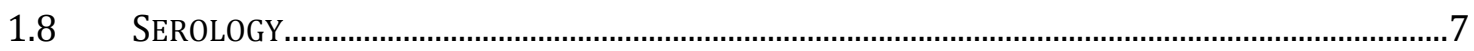

1.9 STANDARD SEROLOGICAL METHODS FOR THE DETECTION OF ANTIBODIES ....................................

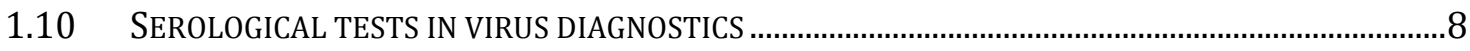

1.11 LIMITATIONS OF THE CURRENT SEROLOGICAL TESTS ............................................................

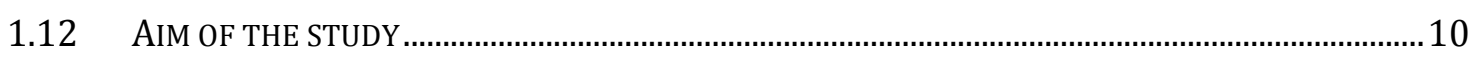

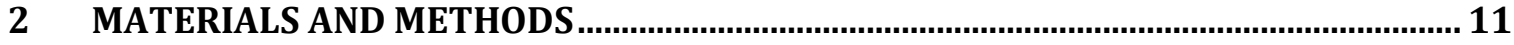

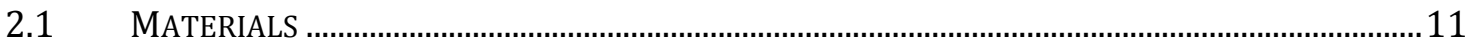

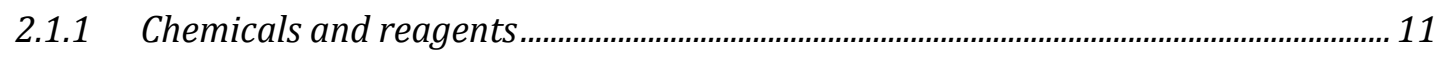

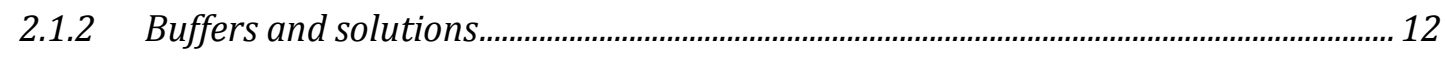

2.1.3 Antibodies.................................................................................................................... 12

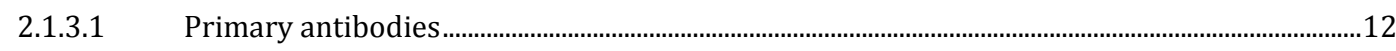

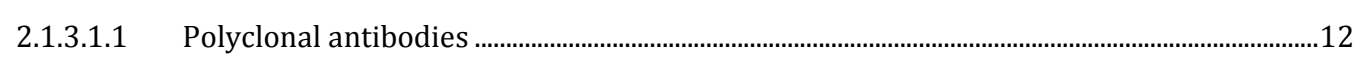

2.1.3.1.2 Monoclonal antibodies........................................................................................................................13

2.1.3.2 Polyclonal secondary antibodies......................................................................................................13

2.1.4 Microarray and miniarray chips ……............................................................................ 14

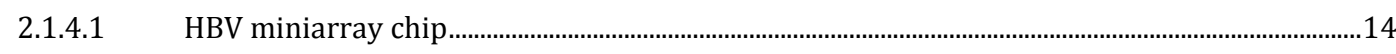

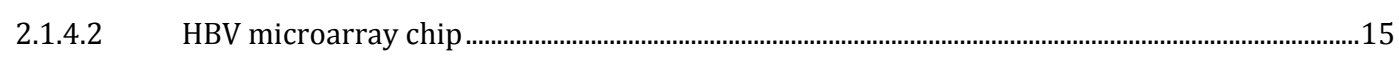

2.1.4.3 HIVenv microarray chip..................................................................................................................17

2.1.4.4 Random peptide library ...........................................................................................................................17

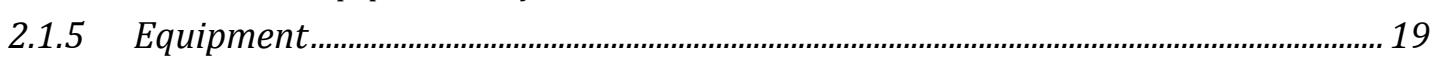

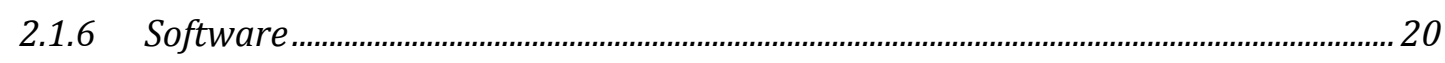

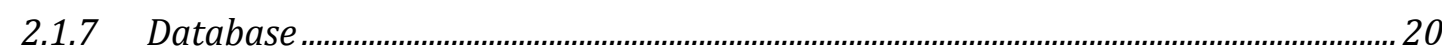

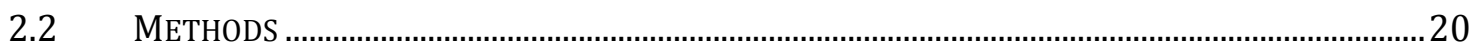

2.2.1 Microarray chip screening...............................................................................................20

2.2.1.1 General screening procedures..........................................................................................................20

2.2.1.2 Precautions during chip screening..............................................................................................................21

2.2.1.3 Scanning the chip with an Agilent microarray scanner..........................................................................22

2.2.2 Filter membrane screening procedure .............................................................................24

2.2.3 Sera from monkeys immunized with HIV/SIV ...............................................................2. 24

2.2.3.1 Sera from monkeys immunized with DNA and modified vaccinia Ankara (MVA) as vector 24 
2.2.3.1.1 SIV DNA and recombinant MVA vaccine constructs................................................................24

2.2.3.1.2 The regime of immunizing monkeys with DNA and MVA vector.............................................25

2.2.3.2 Sera from monkeys immunized with DNA and adenovirus serotype 5 (Ad5) as vector........26

2.2.3.2.1 DNA and recombinant Ad5 vaccine constructs ........................................................................26

2.2.3.2.2 The regime of immunizing monkeys with DNA and recombinant Ad5 vaccine .................27

2.2.3.3 Immunization of monkeys with single-cycle immunodeficiency virus vaccine (SCIV) and

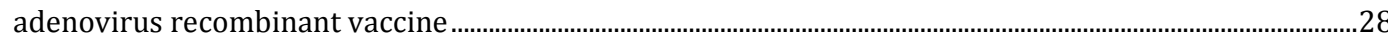

$3 \quad$ RESULTS AND DISCUSSION

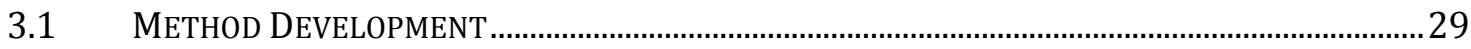

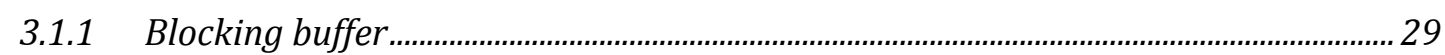

3.1.2 Peptide-cellulose conjugate (PCC) stock solution.......................................................... 30

3.1.3 Storage conditions for printed slides..............................................................................32

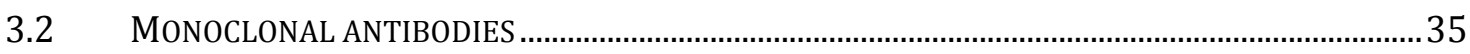

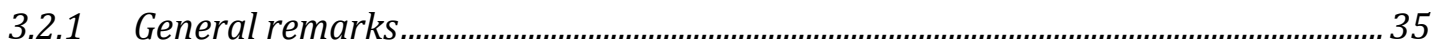

3.2.2 Reactivity of monoclonal antibodies with HIVenv and HBV chips..............................36

3.2.2.1 Reactivity of the mAbs (EVA3012, EVA329, EVA3063 and EVA328) with the HIVenv chip 36

3.2.2.2 Discrimination of HBV genotypes and serotypes with mAbs .....................................................38

3.2.2.2.1 Reactivity of 2-11B1 mAb............................................................................................................39

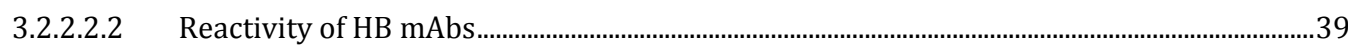

3.2.3 Results obtained with mAbs (MA18/7 and EVA3047 mAbs) on scanning chips are reproduced and expanded with a random peptide library.......................................................... 41

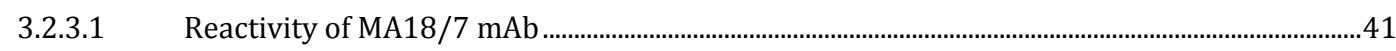

3.2.3.2 Reactivity of EVA3047 mAb .........................................................................................................................45

3.2.4 No reactive peptide found on the scanning chips with HBV and HIV mAbs except

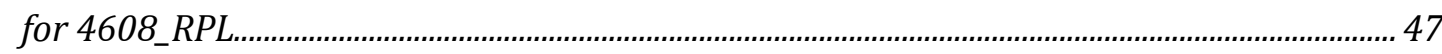

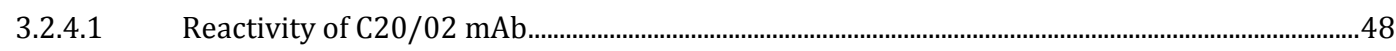

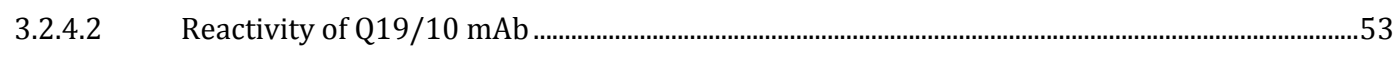

3.2.4.3 Reactivity of EVA332 mAb..........................................................................................................................55

3.2.5 No unambiguous results obtained with the random peptide library despite clear identification of target sequence on the scanning chip..............................................................56

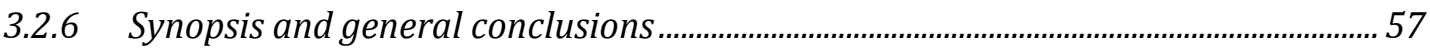

3.3 REACTIVITY OF HUMAN SERA TO THE HBV CHIPS.................................................................... 58

3.3.1 Sera from HBV-vaccinated individuals.......................................................................5 58

3.3.1.1 Epitopes detected by Engerix-B-vaccinated individuals......................................................................58

3.3.1.2 Epitopes detected by Bio-Hep-B-vaccinated individuals.................................................................60

3.3.2 Sera from $\mathrm{HBV}$-infected patients (inf-Pa) in the recovery phase ..................................61

3.3.3 Synopsis and general conclusions..................................................................................... 64

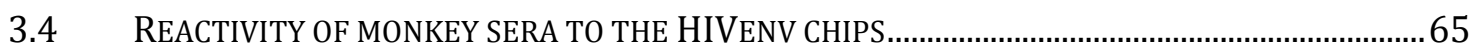

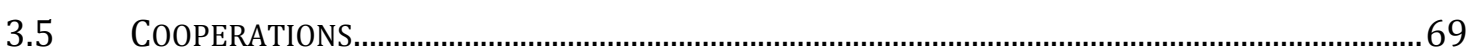

3.5.1 Neutralizing epitopes in the preS1 attachment site of hepatitis B virus are

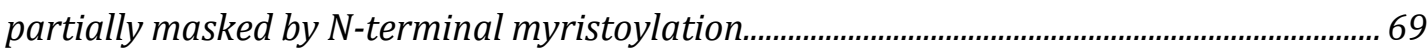

3.5.2 Performance of polyclonal sera against preS1 and preS2 domains on the HBV microarray. 
3.5.3 Identification of mimotopes of an HSV mAb, 2c using the 4608_RPL......................... 76

4 SUMMARY

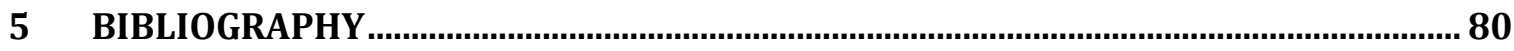

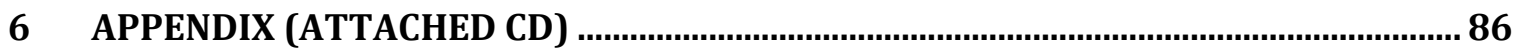

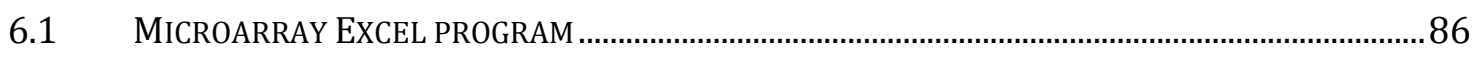

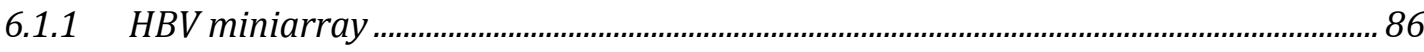

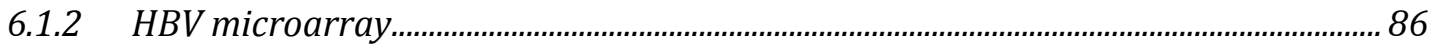

6.1.3 HIVenv microarray........................................................................................................ 86

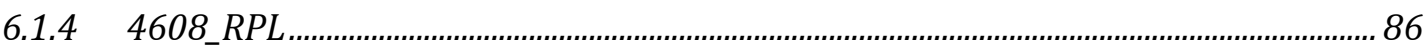

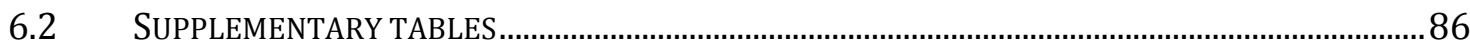

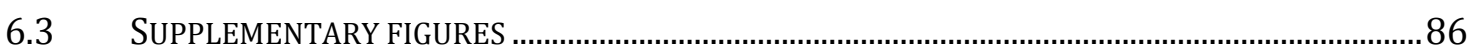

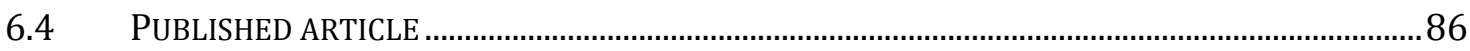

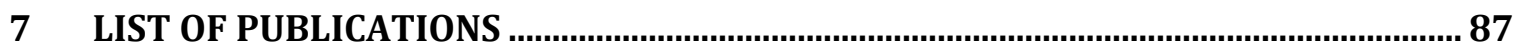

8 LIST OF PRESENTATIONS AT CONGRESSES AND MEETINGS ..................................... 87

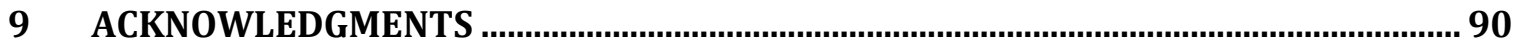

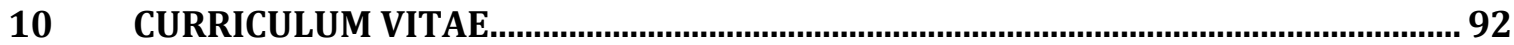




\section{Abbreviations}

4608_RPL_ random peptide library contained 4608 15-mere peptides

three-dimensional

aa

amino acids

Ad5

adenovirus serotype 5

ADCC

antibody-dependent cellular cytotoxicity

AGL

antigenic loop of HBsAg

BB

blocking buffer

BCIP

5-Bromo-4-chloro3indolylphosphate toluidine salt

BSA

bovine serum albumin

$\mathrm{C}$

constant domain of the immunoglobulin

CBS

citrate buffered saline

CDC

complement dependent cytotoxicity

CDR

complementary-determining region

CDS

color developing solution

CMV

cytomegalovirus

CST

conventional serological techniques

DMSO

dimethyl sulphoxide

DPZ

German Primate Center

e.g.

exempli graciā (for example)

E1

HIV vaccination experiment number 1

E2

HIV vaccination experiment number 2

E3

HIV vaccination experiment number 3

ELISA

enzyme-linked immunosorbent assay

EVA

European vaccine against AIDS

$\mathrm{Fab}$

fragment antigen binding

$\mathrm{Fc}$

fragment crystallizable

FcR

Fc receptors

Frs

framework regions

$\mathrm{H}$ heavy chain of the immunoglobulin

$\mathrm{HBcAg}$ hepatits B core antigen 


\begin{tabular}{|c|c|}
\hline $\mathrm{HBeAg}$ & hepatitis B e antigen \\
\hline HBsAg & hepatitis B surface antigen \\
\hline $\mathrm{HBV}$ & hepatitis B virus \\
\hline $\mathrm{HCV}$ & hepatitis $\mathrm{C}$ virus \\
\hline HIV-1 & human immunodeficiency virus type 1 \\
\hline HIVenv & HIV envelope \\
\hline HPV & human papiloma virus \\
\hline HSV & herpes simplex virus \\
\hline HZI & Helmholtz Centre for Infection Research \\
\hline i.e. & id est (that is; in other words) \\
\hline ID & Intradermally \\
\hline $\operatorname{Ig}$ & Immunoglobulin \\
\hline $\mathrm{IM}$ & Intramuscularly \\
\hline inf-Pa & HBV-infected patients \\
\hline IV & Intravenously \\
\hline $\mathrm{L}$ & light chain of the immunoglobulin \\
\hline LMS & $\begin{array}{l}\text { HBV-subviral particles bearing the } 3 \text { envelope proteins L-, M- and } \\
\text { SHBsAg }\end{array}$ \\
\hline $\mathrm{mAb}$ & monoclonal antibody \\
\hline MBS & membrane blocking solution \\
\hline MHBsAg & middle hepatitis B surface antigen \\
\hline $\min$ & Minutes \\
\hline MTT & thiazolyl blue tetrazolin bromide \\
\hline MVA & modified vaccinia Ankara \\
\hline MVAgpenv & modified vaccinia Ankara expressing HIV-1 envelop \\
\hline NIBSC & National Institute for Biological Standards and Control, UK \\
\hline PCC & peptide-cellulose conjugate \\
\hline $\mathrm{S} / \mathrm{N}$ & signal-to-noise ratio \\
\hline $\mathrm{SC}^{2}$ & spotting compound - support conjugates \\
\hline SCIV & single-cycle immunodeficiency virus vaccine \\
\hline $\sec$ & seconds \\
\hline SHBsAg & HBV small surface antigen \\
\hline SHIV & simian-human immunodeficiency virus \\
\hline SIV & simian immunodeficiency virus \\
\hline
\end{tabular}




SM skimmed milk

T-TBS Tween-Tris buffer solution

TBS Tris buffer solution

TFA trifluoroacetic acid

UMG University Medical Center Göttingen

$\mathrm{V} \quad$ variable domain of the immunoglobulin

WMB Whatman protein microarray blocking buffer

\section{Amino Acids}

$\begin{array}{ll}\text { A / Ala } & \text { Alanine } \\ \text { C / Cys } & \text { Cysteine } \\ \text { D / Asp } & \text { Aspartic Acid } \\ \text { E / Glu } & \text { Glutamic Acid } \\ \text { F / Phe } & \text { Phenylalanine } \\ \text { G / Gly } & \text { Glycine } \\ \text { H / His } & \text { Histidine } \\ \text { I / Ile } & \text { Isoleucine } \\ \text { K / Lys } & \text { Lysine } \\ \text { L / Leu } & \text { Leucine } \\ \text { M / Met } & \text { Methionine } \\ \text { N / Asn } & \text { Asparagine } \\ \text { P / Pro } & \text { Proline } \\ \text { Q / Gln } & \text { Glutamine } \\ \text { R / Arg } & \text { Arginine } \\ \text { S / Ser } & \text { Serine } \\ \text { T / Thr } & \text { Threonine } \\ \text { V / Val } & \text { Valine } \\ \text { W /Trp } & \text { Tryptophan } \\ \text { Y / Tyr } & \text { Tyrosine }\end{array}$




\section{Introduction}

\subsection{The immune responses}

The environment contains an enormous range of pathogens and toxins that attack mammalian bodies. In response to these, mammals have developed their own defense, the immune system. The immune system eliminates these pathogens and toxins and thereby protects the organism. The immune response is organized in two stages. The first line of defense is the innate immunity, which is considered as the first line of defense against invading pathogens. It reacts rapidly after invasion of pathogens by recognizing molecular patterns shared by many microbes but not present on mammalian cells. The second line of defense is the adaptive immunity. This system recognizes individual pathogens through a large repertoire of specific receptors. Moreover, the adaptive immune system has a memory, which guarantees faster and stronger responses to reinvading pathogens (figure 1) (Abbas, Lichtman et al. 2010; Bonilla and Oettgen 2010; Turvey and Broide 2010).

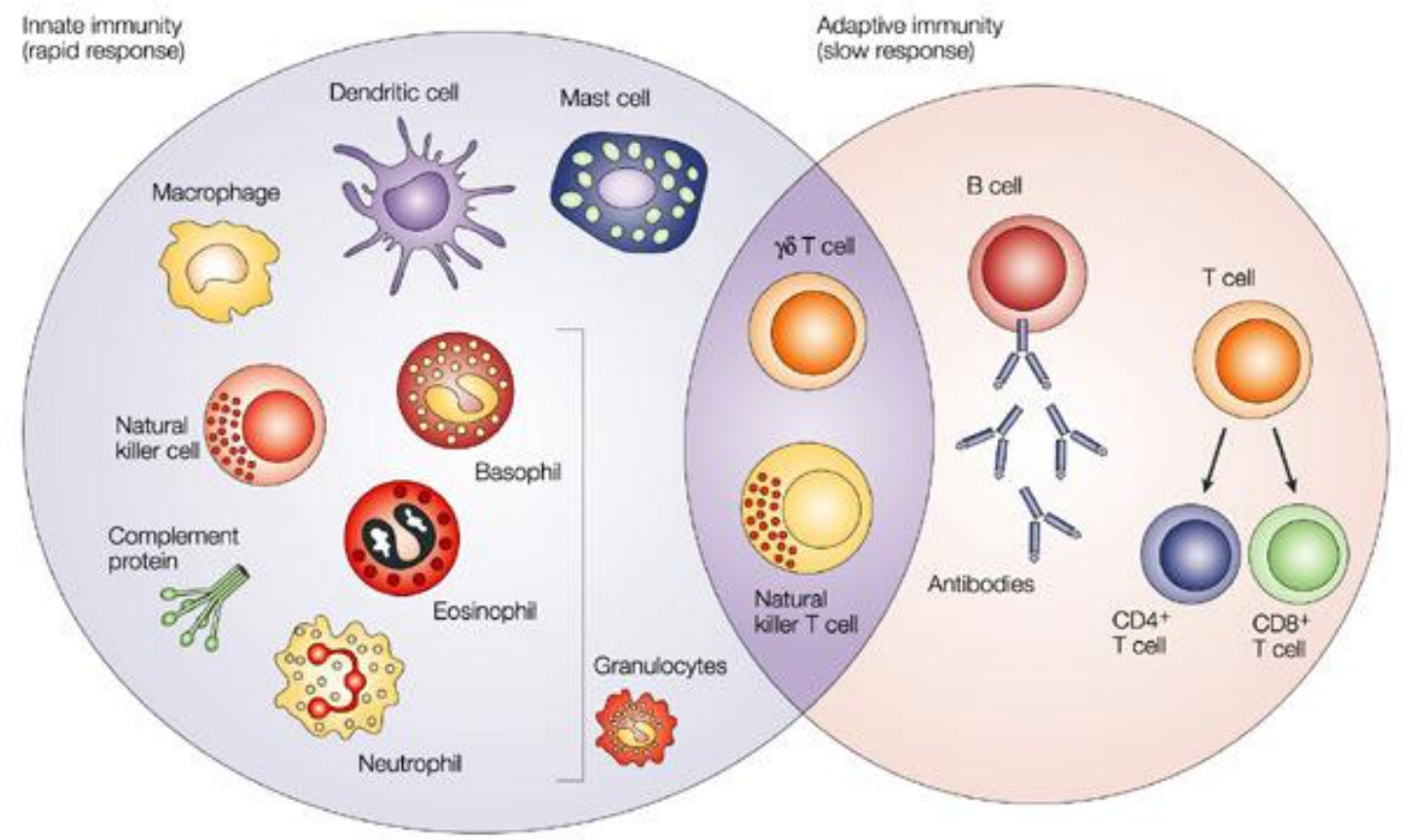

Figure 1: Major components of the innate and adaptive immunity (Dranoff 2004). 
The adaptive immunity comprises two classes of cells. $\mathrm{T}$-lymphocytes recognize intracellular microbes and function to destroy these or the infected cells. B -lymphocytes upon contact with the pathogen differentiate into plasma cells producing specific antibodies (Abbas, Lichtman et al. 2010).

\subsection{Structure of the immunoglobulin antibody}

As illustrated in figure 2, immunoglobulin (Ig) is a heterodimeric protein composed of 2 heavy $(\mathrm{H})$ and 2 light (L) chains. The L chain can either be of a $K$ or a $\lambda$ type. $H$ and $\mathrm{L}$ chains both contain an $\mathrm{NH} 2$-terminal variable (V) domain and $\mathrm{COOH}$-terminal constant (C) domain. Each V domain consists of two sandwiched $\beta$-pleated sheets kept together by a disulfide bridge between two conserved cysteine residues. Each V or $\mathrm{C}$ domain consists of approximately 110 to 130 amino acids, comprising a molecular mass of 12,000 to 13,000 kd. Both Ig L chains contain only $1 \mathrm{C}$ domain (light blue in figure 2), whereas immunoglobulin $\mathrm{H}$ chains contain either 3 or 4 such domains (dark blue in figure 2). $\mathrm{H}$ chains with $3 \mathrm{C}$ domains include a spacer hinge region (black arrow in figure 2) between the first $\left(\mathrm{C}_{\mathrm{H}} 1\right)$ and second $\left(\mathrm{C}_{\mathrm{H}} 2\right)$ domain. This hinge gives the Ig the flexibility to bind to two determinants with variable distances. (Schroeder and Cavacini 2010).
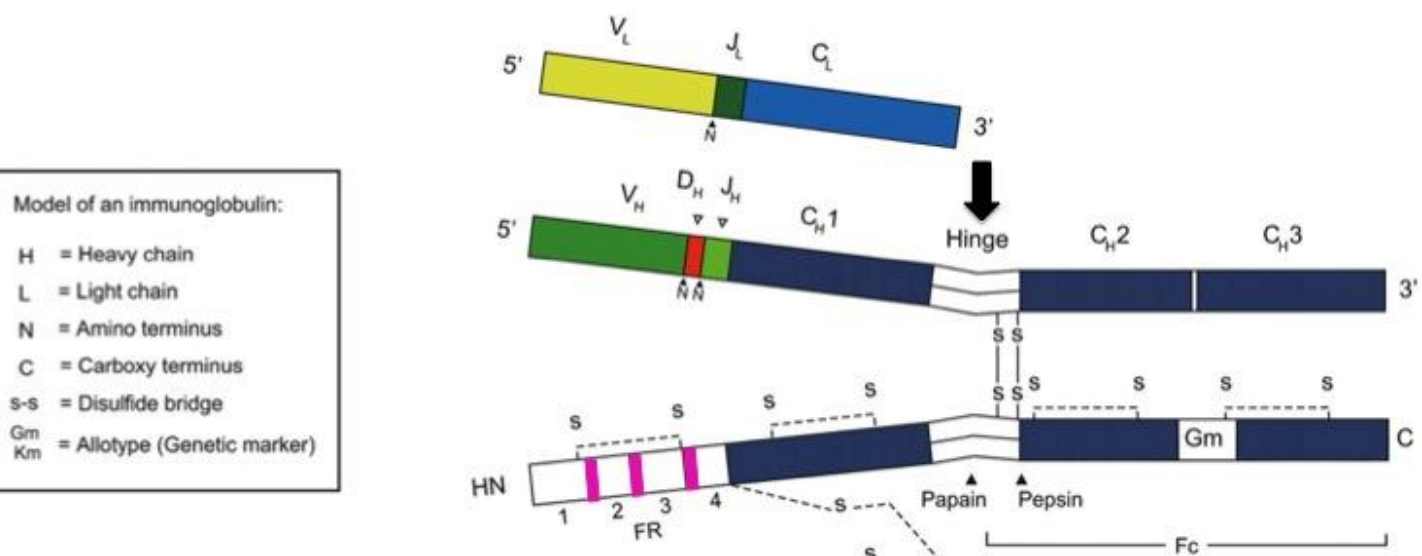

LN

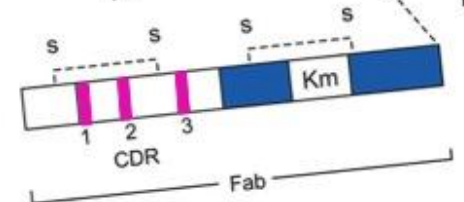

Figure 2: Two-dimensional model of an IgG molecule. For more details, see the text. Modified from (Schroeder and Cavacini 2010). 
Pepsin digests Ig into two identical Fragment Antigen Binding (Fab) arms, which still allow for bivalent binding. The Fab fragment consists of the entire $\mathrm{L}$ chain as well as the $\mathrm{V}$ and $\mathrm{C}_{\mathrm{H}} 1$ domain of the $\mathrm{H}$ chain. The other fragment of the pepain is one Fragment Crystallizable $(\mathrm{Fc})$ stem. The $\mathrm{COOH}$-terminal part of the $\mathrm{Fc}$ fragment contains a site binding to $\mathrm{Fc}$ receptors $(\mathrm{FcR})$ on effector cells. The antibody-bound pathogen can then be eliminated more effectively. (Smith, Nelson et al. 2004; Burton and Wilson 2007).

Within the $\mathrm{V}$ region of both $\mathrm{L}$ and $\mathrm{H}$ chains, there are three hypervariable regions, each 10 amino acids long. They are also called complementary-determining regions (CDRs) because these sequences form a surface complementary to a 3D structure called the antigen (the CDRs are violet in figure 2). An example of antigen-antibody $\mathrm{H}$ chain binding is shown in figure 3 where the CDRs of a monoclonal antibody bind to human immunodeficiency virus type 1 (HIV-1) gp120. The CDRs are interspaced with 4 regions of conserved sequence termed framework regions (FRs) (the white area between the violet areas in figure 2) (Schroeder and Cavacini 2010).

A plasma cell can secrete one of the five $\operatorname{Ig}$ isotypes $\operatorname{IgM}, \operatorname{IgD}, \operatorname{IgG}, \operatorname{Ig} A$ and $\operatorname{IgE}$, which differ in the Fc portion. In humans, IgA and $\operatorname{IgG}$ isotypes can be subtyped into $\operatorname{IgA} 1$ and $\operatorname{IgA} 2$, or $\operatorname{IgG} 1, \operatorname{IgG} 2, \operatorname{IgG} 3$, and $\mathrm{IgG} 4$ respectively. Each $\mathrm{C}$ domain of the $\mathrm{H}$ chain of a given isotope or subtypes has the same amino acid sequences. The $\mathrm{C}$ domains are designated by letters of the Greek alphabet corresponding to the Ig isotype. Thus IgA1 contains $\alpha 1 \mathrm{H}, \operatorname{IgA} 2 \alpha 2, \operatorname{IgD} \delta, \operatorname{IgE} \varepsilon, \operatorname{IgG} 1 \gamma 1, \operatorname{IgG} 2 \gamma 2, \operatorname{IgG} 3 \gamma 3, \operatorname{IgG} 4 \gamma 4$, and $\operatorname{IgM} \mu$. The $\operatorname{IgG}, \operatorname{Ig} A$, and $\operatorname{IgD}$ have three $\mathrm{C}_{\mathrm{H}}$ domains, while $\operatorname{IgM}$ and $\operatorname{IgE}$ have four (Abbas, Lichtman et al. 2010). The constant Fc region of the Ig isotypes or subtypes allow for the production of specific antibodies by immunizing heterologous species. Such antibodies are used as a second antibody in the analysis of humoral immune responses (e.g. with goat anti mouse $\operatorname{IgG}$, the goat is the species immunized with mouse IgG). 


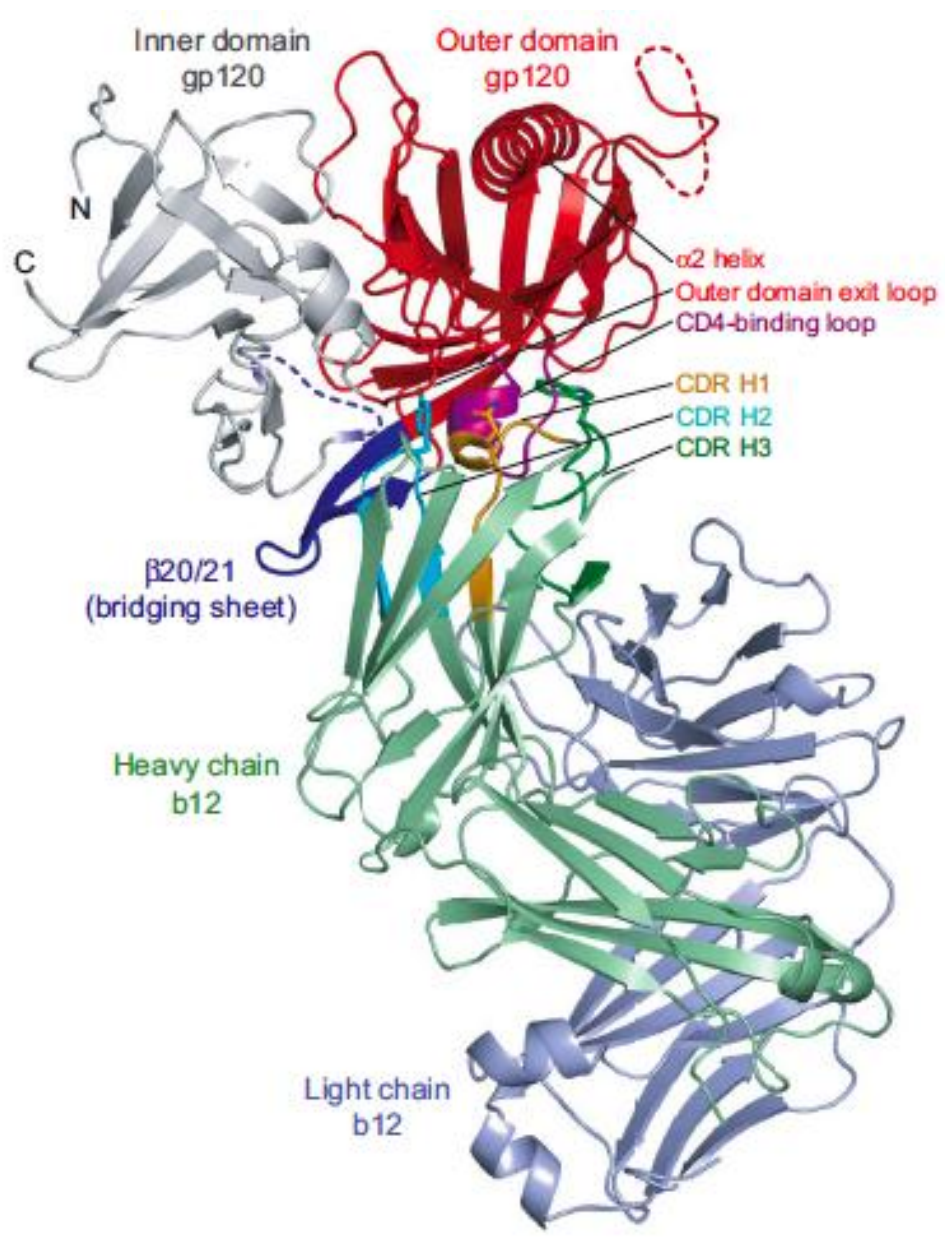

Figure 3: Interaction between a monoclonal antibody, b12 and HIV-1 gp120 core. The gp120 inner domain is grey, and the outer domain is red, except for the CD4-binding loop, which is purple. The strands and associated loops, which in the CD4-bound conformation correspond to the bridging sheet, are blue. The b12 light chain is blue-grey and the b12 heavy chain is green, with associated CDRs of the heavy chain highlighted in orange (H1), cyan (H2) and dark green (H3). The heavy-chain dominance of the binding interaction is apparent, with the nearest light-chain approach separated by $\approx 10 \mathrm{~A}{ }^{\circ}$ from gp 120 . Heavychain-only interactions are rare (Zhou, Xu et al. 2007).

\subsection{Antigen-antibody interaction}

The molecules capable of stimulating B -lymphocytes to produce antibodies are called immunogens (e.g. hepatitis B virus (HBV)), while an antigen is any compound that binds to an antibody or T cell receptor (e.g. hepatitis B surface antigen (HBsAg)). Usually antigens are much larger than the paratopes, the site of Ig binding to the antigen. Therefore, the antibody binds only to a portion of the antigen, which is called the epitope (Abbas, Lichtman et al. 2010; Schroeder and Cavacini 2010). The antigen may have several epitopes but the individual antibody binds only to one epitope. 
Affinity is the strength of binding between an individual antibody and an epitope. A serum from an immunized person has antibodies of different affinities to the same antigen, depending on the amino acids sequences of the CDRs. The antibody is specific for the epitope. It can distinguish between minor differences in the chemical structure of an epitope (Chaplin 2010). However, some antibodies may react with a different but structurally related epitope or with a mimotope. The amino acid sequence of a mimotope is completely different from the related epitope but has the same chemical properties (Slootstra, Puijk et al. 1997; Meloen, Puijk et al. 2000).

\subsection{Antiviral mechanisms of the antibody}

Neutralization of the free virus particle is the first direct effect of the antibody, which takes place either extracellularly or intracellularly. Antibodies neutralize extracellularly through different mechanisms. (1) Antibodies block the virus ligandcellular receptor thereby preventing viral attachment to the cell (Kolatkar, Bella et al. 1999). (2) Antibodies bind to the virus fusion protein inhibiting viral penetration into the cell (Mclain, Porta et al. 1995). (3) Antibodies inhibit virus release from the infected cell (Vanderplasschen, Hollinshead et al. 1997). Finally, antibodies can also block virus uncoating within the cell and thereby inhibit the virus nucleic acid release (Virgin, Mann et al. 1994).

Indirect effects of the antibody are mediated through its Fc part, which binds to FcR on the effector cell. This can activate several antiviral mechanisms. (1) Activation of the complement pathway leads to deposition of complement on the viral surface, neutralizing viral activity. (2) Activation of virus-bound complement can lead directly to virolysis (Avirutnan, Mehlhop et al. 2008). Finally, the Fc-mediated effector system can lyse virusinfected cells through either antibody-dependent cellular cytotoxicity (ADCC) or complement-dependent cytotoxicity (CDC) (Burton 2002).

The neutralizing power of the antibody depends mainly on the recognized epitope. Discrimination between neutralizing and non-neutralizing epitopes is important for vaccine production and viral diagnostics.

\subsection{Virus evasion of an antibody response}

The antibody responses against a virus can stop it from spreading through the body, 
can eliminate infectious particles and prevent reinfection. However, viruses can counteract neutralizing antibodies through evolutionary changes.

The influenza virus is a typical example for a virus evading the immune response through two distinct mechanisms. (1) An antigenic drift is due to point mutations in the hemagglutinin, and neuraminidase gens generate viral variants escaping antiviral neutralization. (2) An antigenic shift is caused by genetic reassortment of viral gene segment coding for the surface polypeptides hemagglutinin and/or neuraminidase. Thus, antibodies produced against the previously infecting virus cannot protect the host against infection with this new virus (Scholtissek 1995; Hilleman 2002; Vossen, Westerhout et al. 2002).

The antibody repertoire of the infected host exerts a high selective pressure on the infecting virus population. This pressure selects for changes in the neutralizing epitopes. Such changes can occur due to the low-fidelity of the RNA-dependent RNA polymerases. This escape mechanism is used by e.g. hepatitis $\mathbf{C}$ virus (HCV). (Alcami and Koszinowski 2000; Diamond 2003). Other viruses (e.g. HIV) evade the antiviral complement activities by encoding homologues of complement regulatory proteins or incorporate host factors blocking complement activation into their lipid envelope, such as CD46 (Burton 2002; Diamond 2003). Others (e.g. cytomegalovirus and coronavirus) encode $\mathrm{Fc}$ receptors inhibiting the Fc-dependent immune responses (Alcami and Koszinowski 2000; Tortorella, Gewurz et al. 2000).

\subsection{Immune memory}

Specific antibodies appear after the first exposure to an antigen. This primary response is slow. First IgM with low affinity are produced after one week of exposure to the antigen. After two weeks, IgG with higher affinity start to appear and an immune memory is established. Activated B cell clones differentiate into antibody secreting cell and long-lived memory cells. After subsequent exposure to the same antigen, a highaffinity $\mathrm{IgG}$ is produced within the first week of secondary response. (Abbas, Lichtman et al. 2010; Bonilla and Oettgen 2010). 


\subsection{Vaccination}

Vaccination is a unique way to employ the immune memory. Vaccines are an important tool to combat and even eradicate infectious diseases. For example, in the first three-quarters of the $20^{\text {th }}$ century, up to 300 million people died from smallpox. In contrast, due to a massive vaccination program, no one has died from the disease since 1978 (Burton 2002).

Vaccinations mimic natural infections without causing disease. As antigens, toxins, surface structures of the pathogens or their killed or attenuated forms are applied (Burton and Parren 2000). Vaccines induce antibody responses. Similar to the antibodies found after natural infection, vaccine-induce antibodies neutralize pathogens e.g. HBV, measles and influenza viruses (Ada 2001; Plotkin 2008). The titer of antibodies induced by vaccination is an indicator of protection. $\mathrm{HBV}$-vaccinated individuals with $10 \mathrm{IU} / \mathrm{l}$ of specific antibodies are considered to be protected and those with lower levels or no antibody titers should be revaccinated (Mahy and Ter Meulen 2007).

\section{$1.8 \quad$ Serology}

Serology is defined as the immunochemical analysis of antibodies or antigens present in sera or other body fluids.

\subsection{Standard serological methods for the detection of antibodies}

Antibodies are usually detected and quantified by binding to a fixed quantity of one known antigen (e.g. whole or recombinant virus or synthetic peptides) attached to a solid phase (e.g. plastic microtiter plate). Test serum or dilutions thereof are added to antigencontaining wells and incubated at room temperature. Unbound antibodies are removed by washing. A second species-specific antibody linked to an indicator is allowed to bind. The indicator can either be a radioisotope, an enzyme or fluorophore. This assay format using enzyme is called an enzyme-linked immunosorbent assay (ELISA) (Abbas, Lichtman et al. 2010). Today medical laboratories around the world are using ELISAs for routine diagnostics. Usually fully automated ELISA instruments and commercial kits are employed. 


\subsection{Serological tests in virus diagnostics}

Serology tests are important to identify both acute and chronic viral infections. Antiviral IgM is found in the serum between 5 and 10 days post-infection and is undetectable two to four months later. Thus specific IgM antibodies are not found in persistent or chronic infections. IgM and IgA cannot cross the placental barrier. Detecting them in newborns indicates congenital infection (Mahy and Ter Meulen 2007; Yinon, Farine et al. 2010).

Recent infections can also be detected by the analysis of paired serum samples, the first sample obtained in the acute phase of the disease and the second two weeks later. A four-fold or greater rise in specific IgG antibody titer strongly indicates an acute infection (Cremer, Cossen et al. 1982; Mahy and Ter Meulen 2007).

The set of antibodies against different polypeptides of a given virus indicates the stage of infection. For instance, antibodies against three HBV antigens can be found: the anti-HBs to the $\mathrm{HBsAg}$, anti-HBc to hepatits $\mathbf{B}$ core antigen ( $\mathrm{HBcAg}$ ), and anti-HBe to hepatitis B e antigen ( $\mathrm{HBeAg}$ ). In chronic $\mathrm{HBV}$ infections, the presence of anti- $\mathrm{HBc}$ and the absence of anti-HBs is found, while the presence of anti-HBc, anti-HBs and anti-HBe indicate recovery from infection (Chang and Lewin 2007).

\subsection{Limitations of the current serological tests}

Mostly, the antibody is directed against an epitope within the virus' antigen. Conventional serological techniques (CST) detect the presence or absence of serum antibodies against an antigen. In doing so they do not provide information on antibodies against individual peptide epitopes. Identifying antibodies at the epitope level is of great significance because not all antibodies are neutralizing and able to stop the infection. Besides, each epitope has its own function. For instance, there are epitopes responsible for binding the virus to the cell surface, others assist the virus into the host cell (Burton 2002). Binding antibodies to other epitopes may not have a functional consequence. Information on such individual epitopes is missed when performing diagnostics CST. Furthermore, the identification of distinct epitopes expressed during the virus' lifecycle may make it possible to detect epitopes specific for a distinct phase of the disease, track disease progression, and lead to a better understanding of the viral life cycle. This information may be exploited for new treatment approaches (Vigil, Davies et al. 2010). 
Furthermore, highly immunogenic parts of viruses are often less genetically conserved. Virus types are characterized by multiple viruses of the same gene, e.g. human papiloma virus (HPV) encodes only eight proteins but so far more than 200 types have been described (Mahy and Ter Meulen 2007; Vigil, Davies et al. 2010). These individual HPV types prefer distinct target cells and have different pathogenic potentials. The high mutation rate of the hemagglutination gene of influenza viruses enables the virus to escape the immune response to an earlier variant and may lead to the emergence of highly pathogenic influenza virus strains (Mueller, Renzullo et al. 2010). Testing for different virus variants with CST is very difficult since a separate test must be run for each variant. Such tests consume much serum and can hardly be run for individual patients. Moreover the unique pattern of activity of each patient is missed. These disadvantages of CST can be only overcome by drastic miniaturization and parallelization of serological assays.

High throughput screening of thousands of peptides in parallel make possible the discovery of new diagnostic serological markers as well as permit the detection of antibodies to multiple antigens of different pathogens in the same sample. A serum antibody titer may not contain enough information about the potential protection of a vaccinated individual. Profiling the antibody response to unique neutralizing epitopes would allow for a better protection. Finally, The detection of antibodies against functionally important virus epitopes in patients recovering from a viral disease may identify new antigens for future vaccines. 


\subsection{Aim of the study}

As explained above, the CST cannot detect important and diagnostically relevant features of the individual antibody response. This can only be achieved by peptide array technology. Such a technique would consume minute volumes of serum and could be performed in parallel with a large number of samples. Moreover, further development of this technique would increase diagnostic speed, reduce size and price of the required equipment as well as consume much less reagent and produce less waste. To explore the potential of this new area of research and development this thesis evaluates peptide microarrays deduced from HBV and HIV sequences as well as random peptide library using monoclonal antibodies and sera from vaccinees and patients. 


\section{Materials and Methods}

\subsection{Materials}

\subsubsection{Chemicals and reagents}

Material were supplied by the following distributors/companies:

\section{BD, Heidelberg:}

Difco $^{\text {TM }}$ skim milk

Enzo Life Sciences, Loerrach (Biomol):

5-Bromo-4-chloro3indolylphosphate toluidine salt (BCIP)

Jackson ImmunoResearch, USA:

Normal goat serum, normal rabbit serum

\section{Merck, Darmstadt:}

Hydrochloric acid 37\%, magnesium chloride, monopotassium phosphate, monosodium phosphate, N-N dimethylformamid, Thiazolyl Blue Tetrazolin Bromide (MTT)

\section{Roth GmbH, Kalsruhe:}

Albumin fraction V, Base Tris, Citric acid, potassium chloride, sacchsrose, sodium chloride, sodium hydroxide

\section{Sigma-Aldrich, Munich:}

$10 \mathrm{x}$ blocking buffer, ethanol (absolute, Spectranal), Tween20

\section{Whatman, USA:}

Whatman protein microarray blocking buffer 


\subsubsection{Buffers and solutions}

The composition of the buffers and solutions were:

Bovine serum albumin (BSA)

Citrate buffered saline (CBS)

Color developing solution (CDS)

Membrane blocking solution (MBS)

PBS-Buffer (1x)

Tris buffer solution (TBS)

Tween-Tris buffer solution (T-TBS) 3g Albumin fraction V in 100ml PBS

$8.0 \mathrm{~g}$ of $\mathrm{NaCl}, 0.2 \mathrm{~g}$ of $\mathrm{KCl}, 10.51 \mathrm{~g}$ of citric acid (monohydrate), $\mathrm{pH}$ to 7.0 with $\mathrm{NaOH}$

60 mg BCIP,

$50 \mathrm{mg}$ MTT, $10 \mathrm{ml} \mathrm{CBS}$

DMF (1 ml absolute and $1 \mathrm{ml} 70 \%$ [v/v] in $\left.\mathrm{H}_{2} \mathrm{O}\right), 50 \mu 1 \mathrm{MgCl}_{2}(1 \mathrm{M})$

160ml T-TBS pH 8.0, 40ml 10xblocking buffer, 10g Saccharose

$10 \mathrm{mM}$ Na2HPO4, $1.8 \mathrm{mM}$ KH2PO4 pH 7.3, $140 \mathrm{mM} \mathrm{NaCl}, 2.7 \mathrm{mM} \mathrm{KCl}$

$6.2 \mathrm{~g}$ base Tris, $0.2 \mathrm{KCL}, 8.0 \mathrm{~g} \mathrm{Nacl}$, ca.3.8ml HCL, pH 7.0

6.2g base Tris, $0.2 \mathrm{KCL}, 8.0 \mathrm{~g} \mathrm{Nacl}$, ca.3.8ml HCL, $500 \mu$ l Tween 20

\subsubsection{Antibodies}

\subsubsection{Primary antibodies}

\subsection{Polyclonal antibodies}

Dr. Angela Uy (Universitätsmedizin Göttingen) provided 72 sera samples from HBV-infected patients (table S1), 22 serum samples from individuals vaccinated with Engerix-B-vaccine (table S2), and 20 sera from $\mathrm{HBV}$-unvaccinated and $\mathrm{HBV}$ negative individuals. An additional 26 serum samples from individuals vaccinated with Engerix-B vaccine (table S3) were obtained from Prof. Dr. Wolfram Gerlich (Institute of Medical Virology, University of Giessen). Prof. Dr. Michael Roggendorf 
(Insitute of Virology, University Clinic, Essen) supplied serum samples from six HBV-infected patients vaccinated with Bio-Hep-B-vaccine (table S4).

\subsection{Monoclonal antibodies}

The chips were reacted with the monoclonal antibodies listed in table 1.

Table 1: List of monoclonal antibodies.

\begin{tabular}{|c|c|c|}
\hline Designation & Target antigen & Source \\
\hline $2 \mathrm{c}$ & $\begin{array}{l}\text { Herpes simplex } \\
\text { virus (HSV) }\end{array}$ & $\begin{array}{l}\text { Prof. Dr. Michael Roggendorf, Institute of } \\
\text { Virology, University Clinic, Essen }\end{array}$ \\
\hline $\begin{array}{l}\text { ARP301(221) } \\
\text { ARP3051 (SR3 (4D7/4)) } \\
\text { EVA3012 (4G10) } \\
\text { EVA3046 (IIIB-V3-01) } \\
\text { EVA3047 (IIIB-V3- } \\
\text { 13/IIIB-V3-34) } \\
\text { EVA3048 (IIIB-V3-21) } \\
\text { EVA3063 (2F5) } \\
\text { EVA328 (60.1.1) } \\
\text { EVA329 (136.1) } \\
\text { EVA332 (187.2.1) }\end{array}$ & HIVenv & $\begin{array}{l}\text { The European Vaccine Against AIDS } \\
\text { (EVA) program, Center of AIDS Reagent, } \\
\text { attached to the National Institute for } \\
\text { Biological Standards and Control } \\
\text { (NIBSC), UK }\end{array}$ \\
\hline $\begin{array}{l}\text { HB1 } \\
\text { HB3 } \\
\text { HB7 } \\
\text { MA18/7 } \\
\text { Q19/10 } \\
\text { C20/02 } \\
\text { 2-11B1 }\end{array}$ & HBsAg & $\begin{array}{l}\text { Prof. Dr. Wolfram Gerlich, Institute of } \\
\text { Medical Virology, University Medical } \\
\text { Center, Giessen }\end{array}$ \\
\hline
\end{tabular}

\subsubsection{Polyclonal secondary antibodies}

Secondary antibodies are listed in table 2. 
Table 2: List of secondary antibodies.

\begin{tabular}{|l|l|}
\hline \multicolumn{1}{|c|}{ Designation } & \multicolumn{1}{|c|}{ Source } \\
\hline $\mathrm{Cy}^{\mathrm{TM}}$ 3-conjugated Streptavidin, & \\
$\mathrm{Cy}^{\mathrm{TM}}$ 3-conjugated IgG fraction monoclonal mouse anti- \\
biotin, \\
$\mathrm{Cy}^{\mathrm{TM}}$ 5-conjugated AffiniPure goat anti-mouse IgG & Jackson ImmunoResearch \\
$(\mathrm{H}+\mathrm{L})$, & laboratory, USA (Dianova, \\
$\mathrm{Cy}^{\mathrm{TM}}$ 5-conjugated AffiniPure goat anti-human IgA + IgM & Hamburg) \\
$+\mathrm{IgG}^{\mathrm{Ig}}$ (H+L), & \\
$\mathrm{Cy}{ }^{\mathrm{TM}}$ 5-conjugated AffiniPure $\mathrm{F}\left(\mathrm{ab}^{\prime}\right)_{2}$ fragment goat anti- \\
human IgG (H+L)
\end{tabular}

\subsubsection{Microarray and miniarray chips}

Dr. Ronald Frank and Ulrike Beutling (Department of Chemical Biology, Helmholtz Centre for Infection Research (HZI), Braunschweig, Germany) donated the microarray chips. Peptides were synthesized via SPOT synthesis (Frank 1992), passed through the $\mathrm{SC}^{2}$ process (Dikmans, Beutling et al. 2006) and spotted onto glass microscope slides. The miniarray chip contained between 500-1000 spots measuring ca. $750 \mu \mathrm{m}$ in diameter. The microarray chip comprised 5000-10 000 spots with spot size between 200-250 $\mu \mathrm{m}$ (Dikmans, Beutling et al. 2006).

\subsubsection{HBV miniarray chip}

One-hundred thirty 15-mere peptides overlapping by twelve amino acids representing the entire aa sequence of the HBsAg genotype A2 (PubMed accession number X02763) were synthesized and spotted onto glass microscope slides to produce the HBV miniarray. Its layout is shown in figure 4. An Excel file containing the coordinates of the HBV miniarray chip is given on the supplementary CD with the file name "'HBV miniarray". 
A

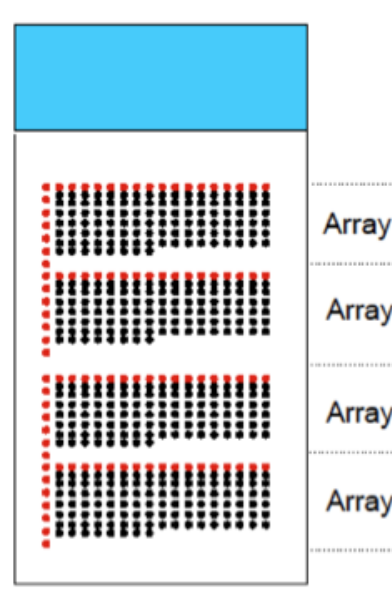

B

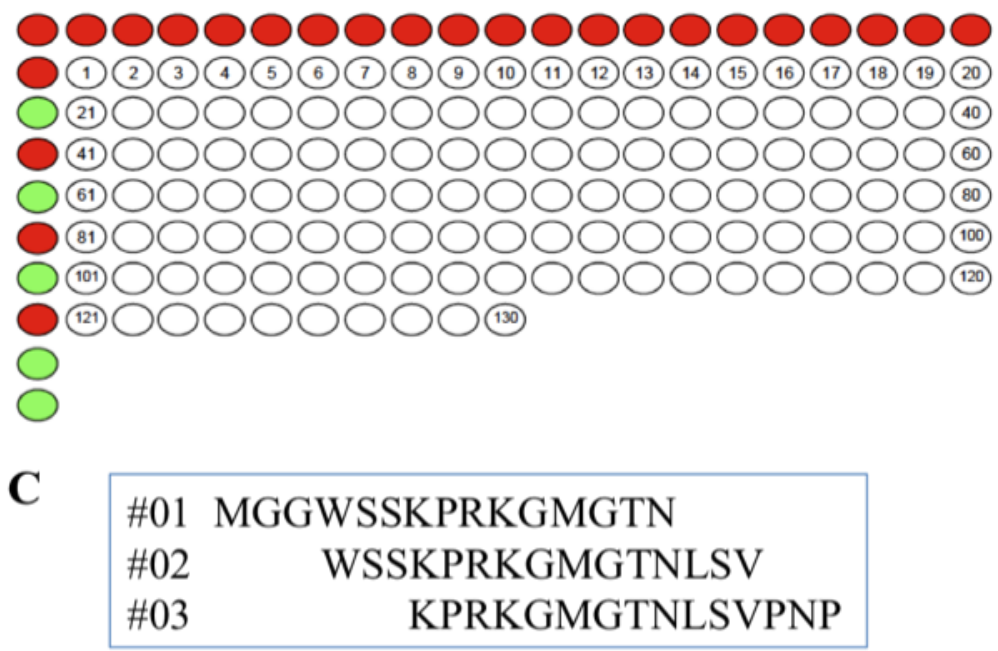

Figure 4: Layout of the HBV miniarray chip. (A) The whole chip contains four identical arrays. (B) Arrangement of spots on each array (red: biotin positive-control, green: beta-alanine negative-control, and uncolored circles: HBsAg aa sequence). (C) the aa sequences of the first three peptides to show the overlap of 12 aa (Ulrike Beutling, personal communication).

\subsubsection{HBV microarray chip}

The HBV microarray chip contains 12 identical arrays of 348 spots each (figure 5A). Two-hundred-ninety-nine of them are 15 mere peptides overlapping twelve aa, which representing the entire aa sequence of HBsAg genotype A2 (PubMed accession number X02763), preS1 and preS2 of genotype D (PubMed accession number X02496), HBsAg serotypes and HBeAg and HBcAg. In addition, four peptides as synthesis control, 40 biotin spots as a positive control, and HBsAg myristoylated $\mathrm{N}$ terminus peptides (figure 5B) were added to the chip. The Excel file named "HBV microarray" containing the coordinates of the HBV microarray chip is provided on the supplementary CD. 
A

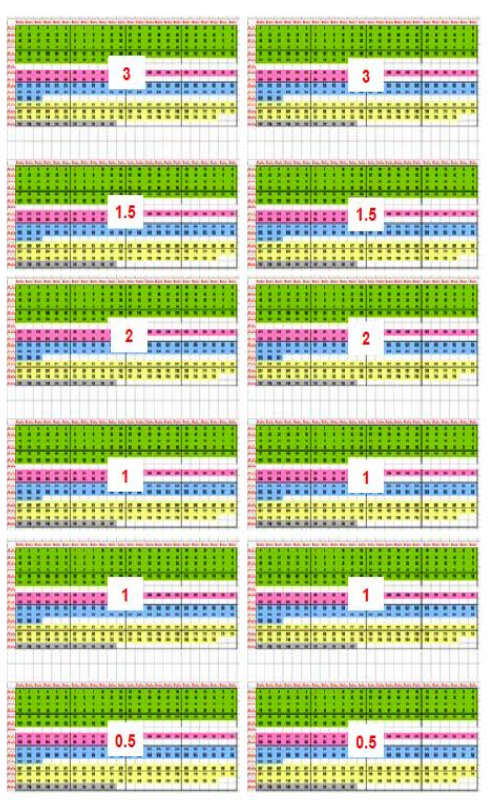

B

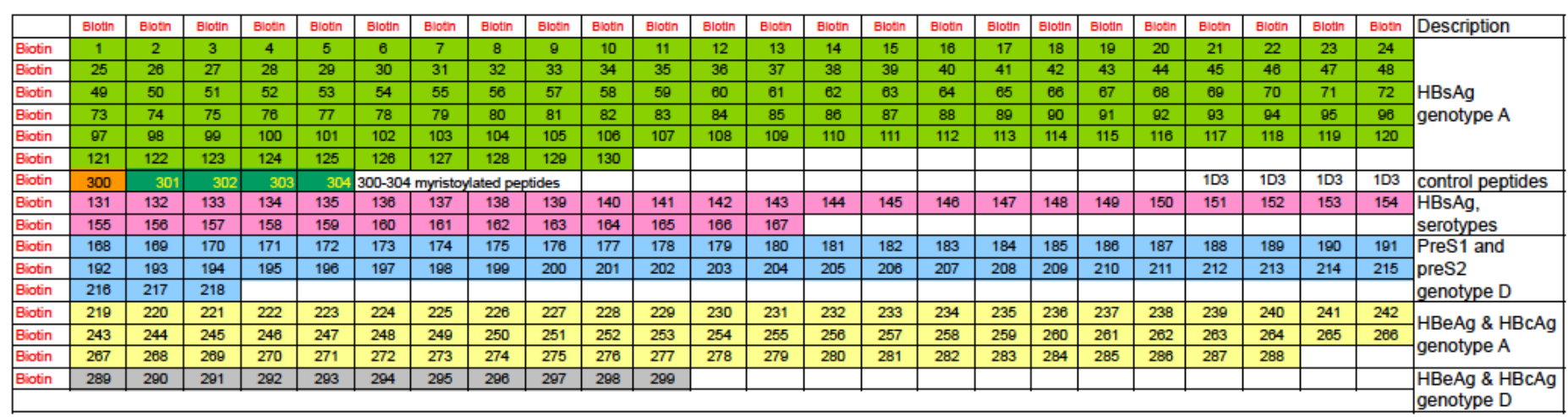

Figure 5: Layout of the HBV microarray. (A) The HBV microarray chip contains twelve arrays arranged in the same manner, however, five different peptide concentrations were applied. The variation in the peptide concentration of the spotting solution is given in red in the insert. (B) Layout of a single array of the HBV chip. $\mathrm{HBsAg}$ genotype A are given in green, HBsAg myristoylated N-terminal peptides in dark green, serotypes of HBsAg peptides in pink, peptides of the preS1 and preS2 region of HBsAg genotype D in blue, genotype A peptides of HBeAg and HBcAg in yellow, HBeAg and HBcAg genotype D peptides in grey, and biotin positive-control spots in red (Ulrike Beutling, personal communication). 


\subsubsection{HIVenv microarray chip}

The HIVenv microarray chip comprise 4896 spots arranged in 16 identical arrays (figure 6A), each containing the same 282 overlapping 15-mere peptides representing the 856 aa of the gp160 of HIV-1 (B.FR.83.HXB2_LAI_IIIB_BRU.K03455, www.hiv.lanl.gov). Thirty spots with cellulose-conjugated biotin serve as a positive control and 6 with cellulose conjugated beta-alanine as a negative control (figure 6B). An Excel file containing the coordinates of the HIVenv microarray chip is given on the supplementary CD with the file name "HIVenv microarray".

$\mathbf{A}$

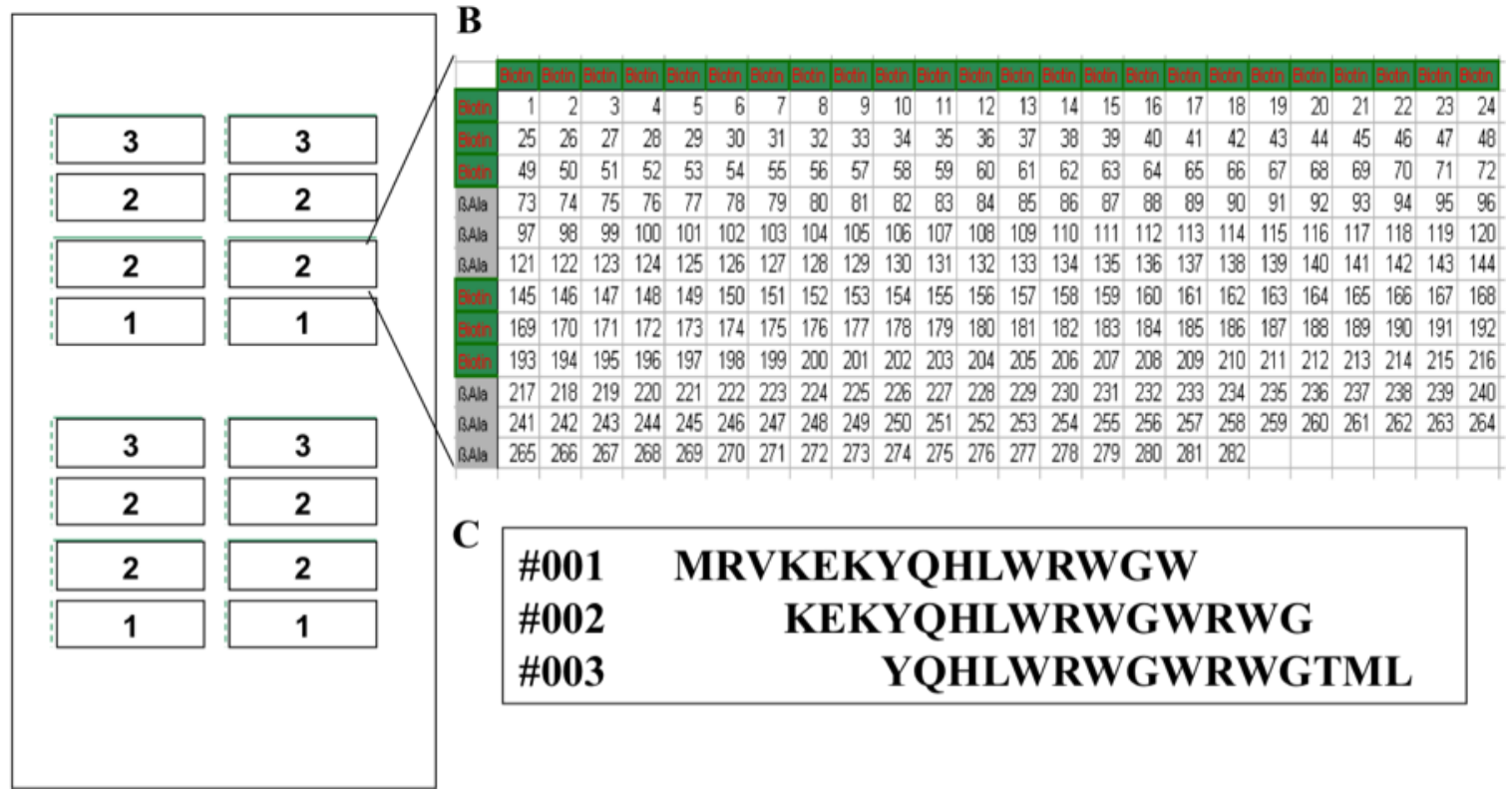

Figure 6: Layout of the HIVenv microarray chip. (A) The chip contains 16 arrays. Three different peptide concentrations were applied. The variation in the peptide concentration of the spotting solution is given. (B) Arrangement of spots on each array, green: biotin positive-control; gray: beta-alanine negativecontrol; and numbered squares: HIV gp160 aa sequence. (C) The aa sequences of the first three peptides to show the overlap of 12 aa (Ulrike Beutling, personal communication).

\subsubsection{Random peptide library}

The random peptide library contains 4608 15-mere peptides (4608_RPL). The 4608 peptides were arranged in 48 quadrants (figure 7A). Each quadrant contained 96 peptides arranged in a $12 \times 8$ pattern similar to a micro-titer plate (figure 7B). A replicate of each spot was placed below the original one (figure 7B and 7C). An Excel program called "Seek-Peptide" was developed for easy sequence identification of reactive peptides 
(figure 8). To identify the peptide sequence of a spot, the coordinates are entered into the Seek-Peptide program. The quadrants are abbreviated to Q1-Q48. The Y position of each spot is then given a capital letter while the $\mathrm{x}$ position is identified by a number e.g. Q1E7 (figure 7D). The Excel data sheet for the 4608_RPL was placed on the supplementary CD under the title "4608_RPL".

A

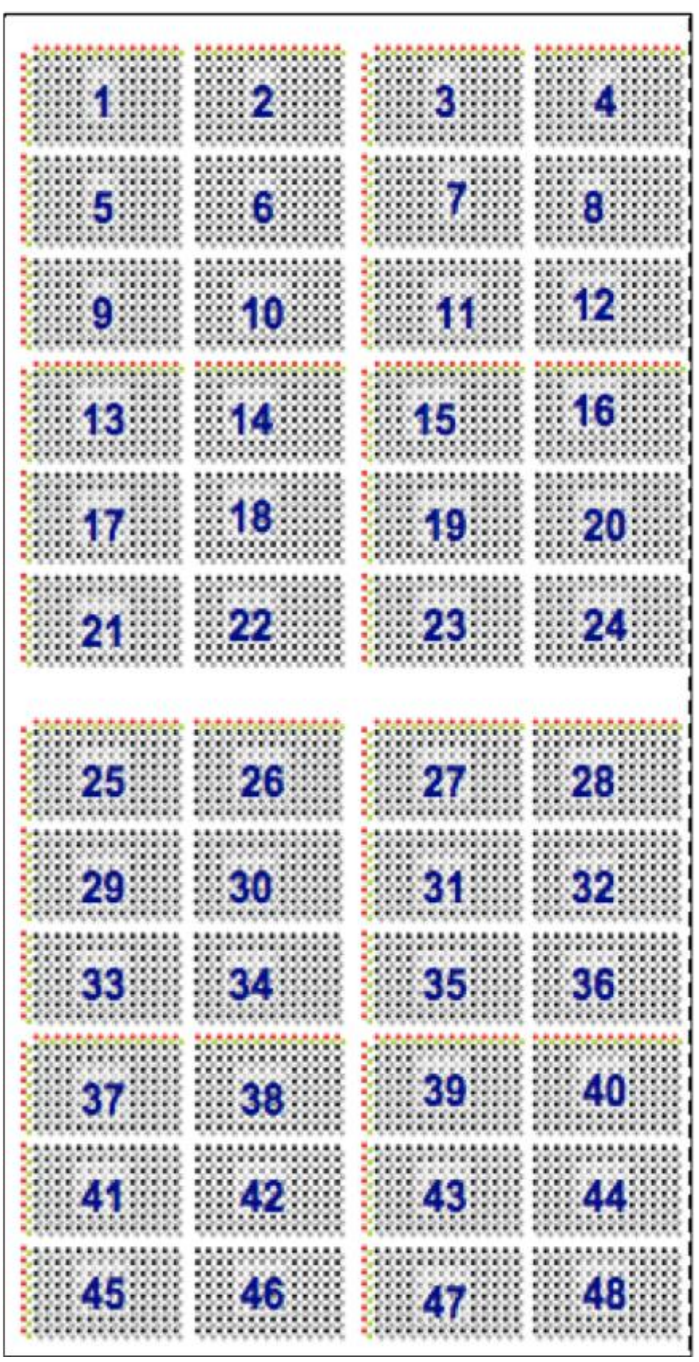

B

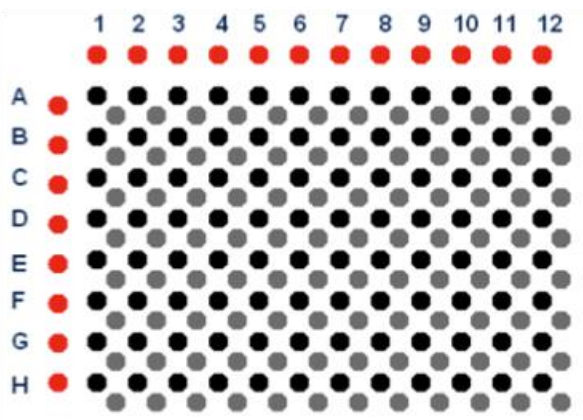

$\mathbf{C}$

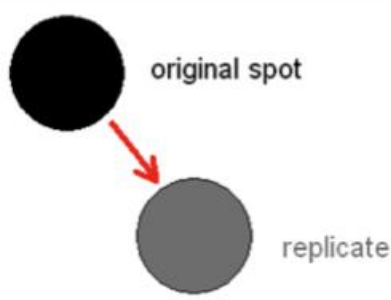

D

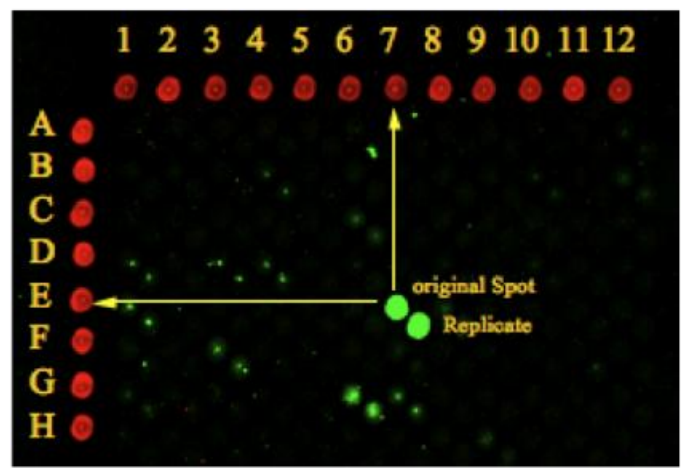

Figure 7: Layout of the 4608_RPL. (A) The 4608_RPL microarray chip contains 48 quadrants. (B) Layout of one quadrant; red, biotin positive-control; black, 15-mere random peptides; grey, peptide replicate. (C) Position of spot and its replicate. (D) Localization of positive-reacting peptide within a quadrant (Ulrike Beutling, personal communication). 


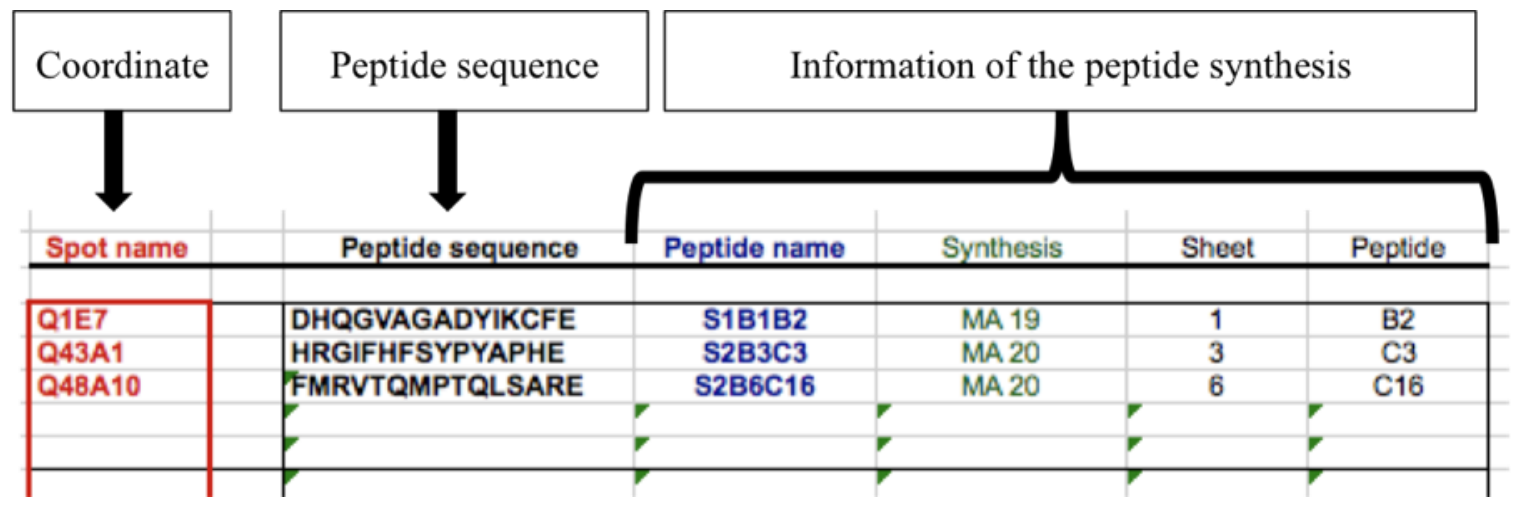

Figure 8: Structure of the Seek-Peptide program. To identify the sequence of a spot, a coordinate is entered into the red left hand column and the enter button is pressed on the PC keyboard. The program then provides the peptide sequence and synthesis information.

\subsubsection{Equipment}

The following equipment was used:

Agilent microarray scanner

Balance TE612

DFL shaker

HeraFreeze

Laminar flow Hera Safe

Magnetic Stirrer MR3000

Multifluge $3_{\mathrm{L}-\mathrm{K}}$

$\mathrm{pH}-$ Meter

Pipetus ${ }^{\circledR}$

Rotilabo ${ }^{\circledR}$ Desiccator

Thermomixer Compact

Varioklav, Autoclave

Vortex Genie 2 ${ }^{\mathrm{TM}}$

Water bath SW22
Agilent Technologies, Inc., USA

Sartorius, Göttingen

Schuett24GmbH, Göttingen

Thermo scientific, Langenselbold

Thermo scientific, Langenselbold

Heidolph GmbH, Schwabach

Thermo scientific, Langenselbold

Schütt Labortechnik, Göttingen

Hirschmann Laborgeräte GmbH, Eberstadt

CARL ROTH GmBH, Karlsruhe

Eppendorf Ag, Hamburg

Thermo scientific, Langenselbold

Bender \& Hobein AG, Zurich, Switzerland

Julabo GmbH, Seelbach 


\subsubsection{Software}

Software obtained from:

Agilent Feature Extraction

Endnote

MEME

Microsoft ${ }^{\circledR}$ Office Excel

Microsoft ${ }^{\circledR}$ Office Word

Muscle

Swiss-Pdb Viewer

Seek-Peptide
Version 7.5, Agilent Technologies, Inc., USA

Version X3, Thomson ISI Research Soft, Carlsbad, CA

Motif-based sequence analysis tools, http://meme.nbcr.net/meme4_5_0

Version 2008 for Mac, Microsoft Corporation

Version 2008 for Mac, Microsoft Corporation

Service of European Bioinformatics Institute (EBI), www.ebi.ac.uk/Tools/msa/muscle/

The Swiss Institute of Bioinformatics, Version 4.0, http://spdbv.vital-it.ch/

Ulrike Beutling (Department of Chemical Biology, HZI, Braunschweig

\subsubsection{Database}

The NCBI-Databank provided protein, nucleotide, and genomic sequences (http://www.ncbi.nlm.nih.gov/). To search for epitopes, the Immune Epitope Database (http://www.immuneepitope.org/) was used. HIV sequences were identified via the HIV database (http: //www.hiv.lanl.gov/).

\subsection{Methods}

\subsubsection{Microarray chip screening}

\subsubsection{General screening procedures}

The microarray chip was washed with absolute ethanol for 3 min and then with TBS three times for $3 \mathrm{~min}$. After incubation with blocking buffer for one hour, the chip was washed with T-TBS for 3 min. Thereafter, the primary antibody diluted 1/100 in blocking 
buffer was added onto the chip. The chip was incubated in a humidified chamber at room temperature for 3.5 hours. The chip was then washed 3 times for 5 min with T-TBS. To visualize the binding of the primary antibody, solution containing Cy3-conjugated streptavidin and Cy5-conjugated goat anti-species IgG (Jackson Immunoresearch Laboratories) was added onto the chip. The chip was kept in a humidified chamber at room temperature for 1.5 hours. Subsequently; the chip was washed twice for $5 \mathrm{~min}$ with T-TBS, 3 times with distilled water for $5 \mathrm{~min}$, and dried before screening with an Agilent DNA microarray scanner.

\subsubsection{Precautions during chip screening}

To obtain optimum scanning results, the following instructions are critical:

- Blocking buffer must be freshly prepared.

- Volume of antibody solution added on the slide must not exceed $60 \mu \mathrm{l}$.

- To obtain equal antibody distribution and avoid air bubble formation, the primary antibodies as well as the secondary antibodies must be added at one end of the glass slide as one droplet. A cover slip held by a pair of forceps must be placed on the droplet at a $45^{\circ}$ angle to the glass slide (figure $9 \mathrm{~A}$ ). The angle is then reduced gradually until the glass slide is completely covered (figure 9B).

- The cover slip must be cleaned. A washing step to clean the cover slip with $70 \%$ alcohol is necessary.

A

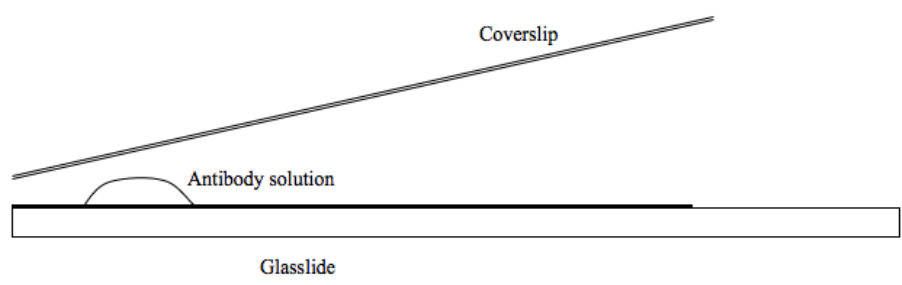

B
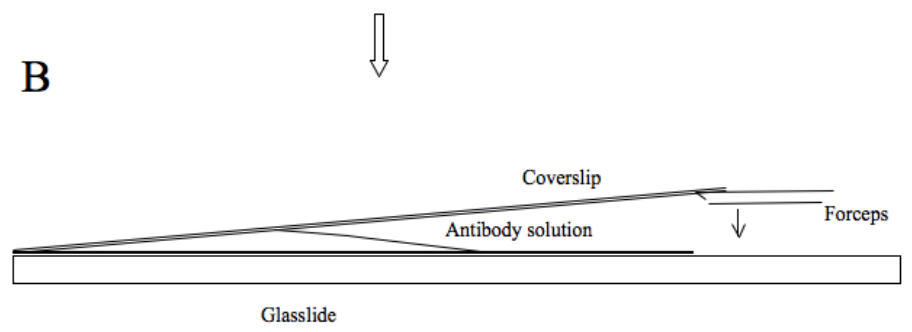

Figure 9: Applying of a cover slip to a microarray slide (Ulrike Beutling, personal communication). 
- If the cover slip cannot be easily removed after incubation, the glass slide should be immersed in T-TBS for $2 \mathrm{~min}$. Thus scratching off peptides from the slide surface is avoided.

- The slides must be incubated in a humidified chamber (figure 10) to avoid dust on the bottom surface of the slide.

- To avoid carrying over antibodies, use one pair of forceps per slide.

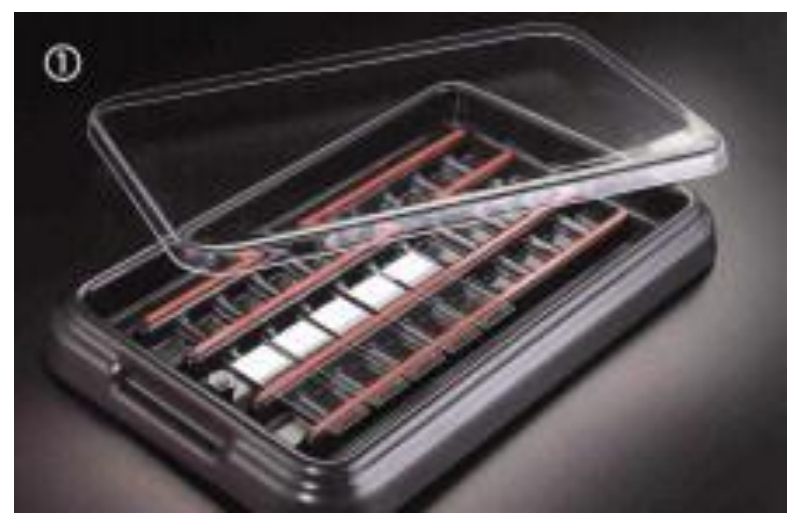

Figure 10: Incubation chamber for the microarray chip (Rotilabo ${ }^{\circledR}$-Färbekammern, CARL ROTH $\mathrm{GmBH}$, Karlsruhe).

\subsubsection{Scanning the chip with an Agilent microarray scanner}

The Agilent microarray scanner is turned on and allowed to warm up. The chip is deposited on the chip holder (figure 11). The active surface of the chip faces the cover. The chip is inserted into the carousel of the scanner. Before scanning, the Agilent Scan Control program in the attached PC must be started and adjusted to the scanning parameters (figure 12). The number of chips to be scanned is entered on the end slot field (upper right corner on figure 12). Thereafter, the scanning program is initiated by clicking on the Scan Slot field by the Scan Control program (lower right in figure 12). 


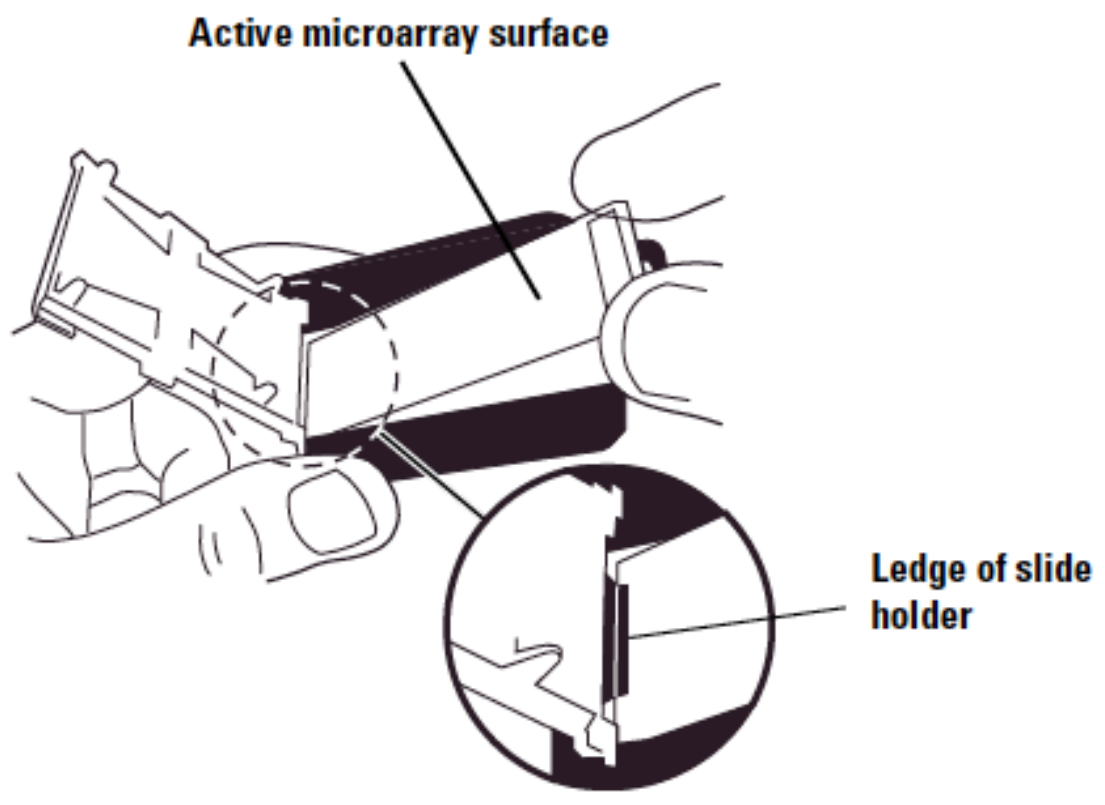

Figure 11: Placement of a microarray chip in the microarray slide holder (Agilent Technologies, Inc., USA).

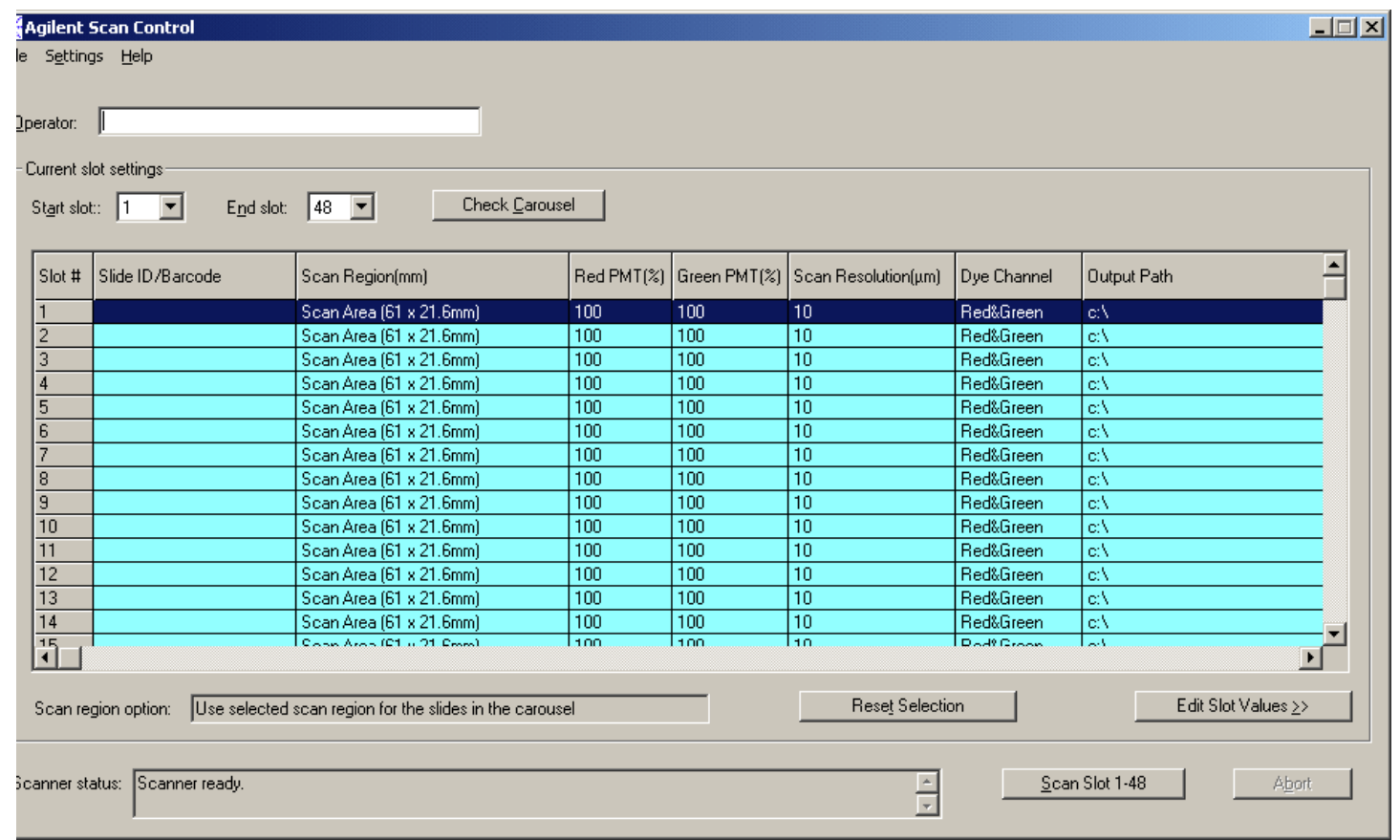

Figure 12: Agilent Scan Control program main window (Agilent Technologies, Inc., USA). 


\subsubsection{Filter membrane screening procedure}

The filter membrane was washed with TBS 3 times each for $10 \mathrm{~min}$, and then incubated with MBS at room temperature overnight. After washing with T-TBS for 10 min, the membrane was incubated with the primary antibody ( $40 \mu \mathrm{l}$ primary antibody +8 $\mathrm{ml}$ MBS) for 3.5 hours. The membrane was washed 3 times with T-TBS each for $10 \mathrm{~min}$. Then the membrane was incubated with the secondary antibody ( $4 \mu$ goat anti-mouse IgG labeled with alkaline phosphatase $+8 \mathrm{ml}$ MBS) for 1.5 hours. The membrane was washed twice with T-TBS for $10 \mathrm{~min}$, and then twice with CBS for $10 \mathrm{~min}$. Thereafter, the membrane was incubated with CDS until the signals were visible. The membrane was washed with PBS for $30 \mathrm{sec}$, then for $10 \mathrm{~min}$. Incubation and washing took place at room temperature and on a horizontal shaker.

\subsubsection{Sera from monkeys immunized with HIV/SIV}

The following three immunization experiments were conducted in the Infection Models Unit, German Primate Center (DPZ) under supervision of Dr. Christiane StahlHennig. Serum samples were kindly provided.

\subsubsection{Sera from monkeys immunized with DNA and modified vaccinia Ankara (MVA) as vector}

\subsection{SIV DNA and recombinant MVA vaccine constructs}

Two types of immunogen were used in this experiment. First the simian immunodeficiency virus (SIV) DNA which was composed of two RNA- and codonoptimized DNA encoding the SIVmac239 (SIVMM239; GenBank accession no. M33262) Pr55 ${ }^{\mathrm{Gag}}$, and the Pr160 ${ }^{\mathrm{Gag}-\mathrm{Pol}}$ polyprotein (SIV gag/pol), as well as the simianhuman immunodeficiency virus (SHIV) 89.6p (GenBank accession no. U89134) envelope derivatives gp160 and gp120. Synthetic genes were created by a stepwise PCR amplification of overlapping 60-mer oligonucleotides and subcloned into the unique restriction sites KpnI and $S a c \mathrm{I}$ of the pCRScript тм Amp SK(+) cloning vector (Stratagene, La Jolla, CA). In order to obtain high level, constitutive expression in mammalian cells, the Gag-Pol as well as the gp120/160 coding regions were placed into the KpnI and XhoI restriction sites of the pcDNA3.1(+) expression vector (Invitrogen, Carlsbad, CA) under the transcriptional control of the immediate-early promoter enhancer 
of cytomegalovirus (CMV), which yielded the final plasmids (1) SIV gag/pol, (2) HIV-1 89.6 env120, and (3) HIV-1 89.6 env160, respectively (Stolte-Leeb, Bieler et al. 2008).

The second immunogen was the modified vaccinia Ankara (MVAgpenv) recombinants expressing the Gag-Pol protein of SIVmac239, and the HIV-1 Env protein of SHIV89.6P (KB9), under control of the modified H5 VV promoter (Stolte-Leeb, Bieler et al. 2008).

\subsection{The regime of immunizing monkeys with DNA and MVA vector}

Fourteen purpose-bred monkeys (Macaca mulatta) were allocated to 4 groups. The first group of monkeys (S) was immunized with SIV DNA intramuscularly (IM) and intradermally (ID) at weeks 0,8, and 16, and boosted IM and ID with an MVAgpenv at week 24 and 32. The second group of monkeys (S/M) received the same immunization as group 1 until week 24, after which they were immunized orally with MVAgpenv at week 32. The third group of monkeys received empty DNA and MVA constructs as vector controls (VC). Two animals as naïve controls (NC) remained untreated. All animals were challenged intra-rectally with the SHIV89.6P swarm virus at week 40 (table 3). From each $\mathrm{S}$ and $\mathrm{S} / \mathrm{M}$ monkey one pre-immunization serum, 3 post-immunization sera, and one after-challenge serum were screened with the HIVenv chip. Of the VC animals, one sample was obtained at the time of challenge and two samples were tested thereafter. Two sera were tested from $\mathrm{NC}$ animals. 
Table 3: Immunization schedule of the SIV DNA and recombinant MVA vaccination experiment (Stolte-Leeb, Bieler et al. 2008).

\begin{tabular}{|c|c|c|c|c|}
\hline \multirow[b]{2}{*}{ No. of animals } & \multirow[b]{2}{*}{ Group } & \multicolumn{3}{|c|}{ Weeks } \\
\hline & & $0,8,16$ & 24 & 32 \\
\hline 4 & $\begin{array}{c}\mathrm{A} \\
\text { vaccinees }\end{array}$ & $\begin{array}{c}\text { SIV DNA } \\
\text { SIV syngag-pol }(0.5 \mathrm{mg}) \\
\text { 89.6P synenv gp120 }(0.25 \mathrm{mg}) \\
89.6 \mathrm{P} \text { synenv gp160 }(0.25 \mathrm{mg}) \\
0.5 \mathrm{mg}(\mathrm{IM}) / 0.5 \mathrm{mg}(\mathrm{ID})\end{array}$ & $\begin{array}{l}\text { MVAgpenv } \\
1 \times 10^{8} \text { (IM) } \\
1 \times 10^{8} \text { (ID) }\end{array}$ & $\begin{array}{l}\text { MVAgpenv } \\
1 \times 10^{8}(\mathrm{IM}) \\
1 \times 10^{8} \text { (ID) }\end{array}$ \\
\hline 4 & $\begin{array}{c}\text { B } \\
\text { vaccinees }\end{array}$ & $\begin{array}{c}\text { SIV DNA } \\
\text { SIV syngag-pol }(0.5 \mathrm{mg}) \\
89.6 \mathrm{P} \text { synenv gp120 }(0.25 \mathrm{mg}) \\
89.6 \mathrm{P} \text { synenv gp160 }(0.25 \mathrm{mg}) \\
0.5 \mathrm{mg}(\mathrm{IM}) / 5 \times 0.1 \mathrm{mg}(\mathrm{ID})\end{array}$ & $\begin{array}{c}\text { MVAgpenv } \\
2 \times 5 \times 10^{7} \text { (IM) } \\
5 \times 2 \times 10^{7} \text { (ID) }\end{array}$ & $\begin{array}{c}\text { MVAgpenv } \\
2 \times 10^{8} \text { (oral) }\end{array}$ \\
\hline 2 & $\begin{array}{c}\mathrm{C} \\
\text { vector } \\
\text { controls }\end{array}$ & $\begin{array}{c}\text { Empty DNA } \\
0.5 \mathrm{mg} \text { (IM)/0.5 mg (ID) }\end{array}$ & $\begin{array}{c}\text { MVA } \\
1 \times 10^{8}(\mathrm{IM}) \\
1 \times 10^{8} \text { (ID) }\end{array}$ & $\begin{array}{c}\text { MVA } \\
1 \times 10^{8}(\mathrm{IM}) \\
1 \times 10^{8}(\mathrm{ID})\end{array}$ \\
\hline 2 & & $\begin{array}{c}\text { Empty DNA } \\
0.5 \mathrm{mg} \text { (IM)/0.5 mg (ID) }\end{array}$ & $\begin{array}{c}\text { MVA } \\
1 \times 10^{8}(\mathrm{IM}) \\
1 \times 10^{8}(\mathrm{ID})\end{array}$ & $\begin{array}{c}\text { MVA } \\
2 \times 10^{8} \text { (oral) }\end{array}$ \\
\hline 2 & $\begin{array}{c}\text { D } \\
\text { naïve } \\
\text { controls }\end{array}$ & Not immunized & Not immunized & Not immunized \\
\hline
\end{tabular}

Abbreviations: MVAgpenv, modified vaccinia Ankara expressing SIV gag/pol and HIV-1 89.6env; IM, intramuscularly; ID, intradermally.

\subsubsection{Sera from monkeys immunized with DNA and adenovirus serotype 5 (Ad5)} as vector

\subsection{DNA and recombinant Ad5 vaccine constructs}

The DNA vaccine comprised pGX10-Gag- Env, pGX10-sPol, pGX10-sVif-Nef, and pGX10-sTat-Vpx (figure 13). To construct the recombinant Ad5 expressing SIV, HIV-1 and adjuvant genes (figure 13), each gene was cloned into the pShuttle- CMV (Qbiogene, CA, USA) and then inserted by homologous recombination into pAdEasy-1 [E1/E3- deleted human Ad5 viral DNA (Qbiogene)] (Stahl-Hennig, Suh et al. 2007). 


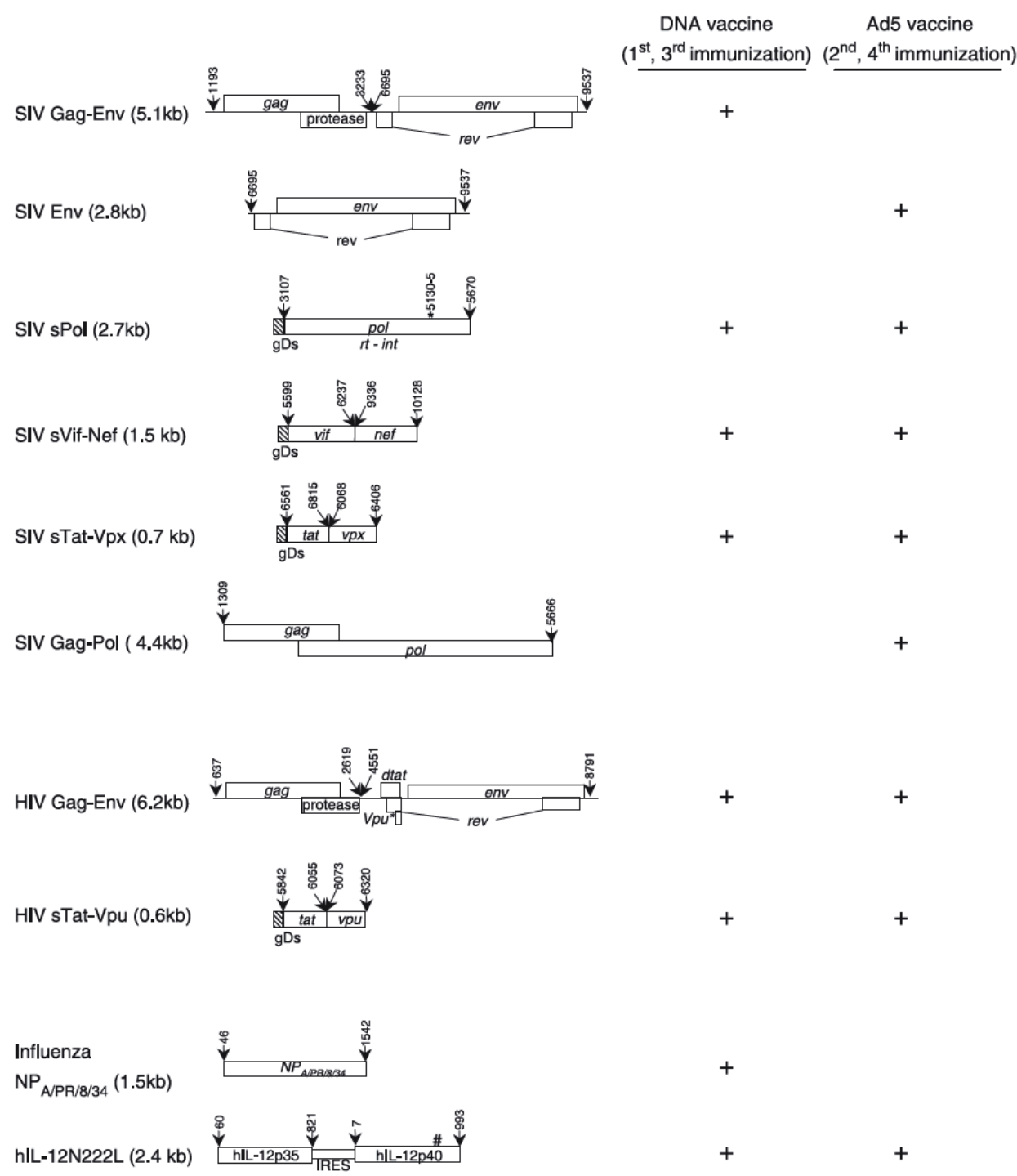

Figure 13: Schematic diagram of SIV, HIV-1 and adjuvant genes of the DNA and Ad5 vaccines. Gene sizes are indicated in parentheses (Stahl-Hennig, Suh et al. 2007).

\subsection{The regime of immunizing monkeys with DNA and recombinant Ad5 vaccine}

Two groups of six monkeys each were immunized. Group one monkeys received a DNA vaccine at week 0 and 16 and recombinant Ad5 vaccine at week 8 and 24. As controls Group two monkeys received DNA buffer and adenovirus dilution buffer. All monkeys were challenged with SHIV89.6P virus at week 40 and re-challenged with SIVmac239 at week 64. From each of the vaccinees, one pre-immunization, 5 postimmunization, and 3 post-challenge sera were screened with the HIVenv chips. Of the 
control monkeys, one serum at the time of challenge and three post-challenge sera were examined.

\subsubsection{Immunization of monkeys with single-cycle immunodeficiency virus vaccine (SCIV) and adenovirus recombinant vaccine}

Four rhesus macaques were immunized intravenously (IV) at week 0 with SCIV. The SCIVs were produced by transient transfection of an SIV genome that was made replication deficient by mutations in the primer binding site and a deletion of vif. To allow a single round of replication, the primer binding site mutations were complemented in trans by a matched tRNA expression plasmid in vif-independent 293 producer cells. After administration to the vaccinees, the SCIVs can undergo only a single round of replication, leading to the production of noninfectious virus-like particles in vivo. At week 8, the four macaques were immunized IM with recombinant adenovirus expressing the SIV envelope. Then, the macaques were challenged at week 20 with SIVmac239 by the tonsillar route (Stahl-Hennig, Kuate et al. 2007). Only sera obtained directly before challenge were screened with HIVenv chips. 


\section{Results and discussion}

\subsection{Method Development}

\subsubsection{Blocking buffer}

Pretreatment of the microarray chip with a blocking buffer (BB) is an important step, since it will minimize non-specific binding and increase the signal-to-noise ratio (S/N) (Collett, Cho et al. 2005). Three blocking buffers were compared on three HBV miniarrays: 4\% skimmed milk (SM) in T-TBS, 3\% BSA in PBS, and Whatman protein microarray blocking buffer (WMB). The blocked miniarrays were then tested with the same human serum from an HBV-vaccinated individual. This serum reacted with spot numbers 96, 97, 98, and 99 (figure 14). The SM produced the lowest background and the highest $\mathrm{S} / \mathrm{N}$ ratio. The reactivity was lost when $\mathrm{WMB}$ was used. SM was used as the BB for most of the work presented here. Later it was replaced with MBS containing casein, and saccharose in T-TBS. Its blocking activity was equivalent to SM.

A

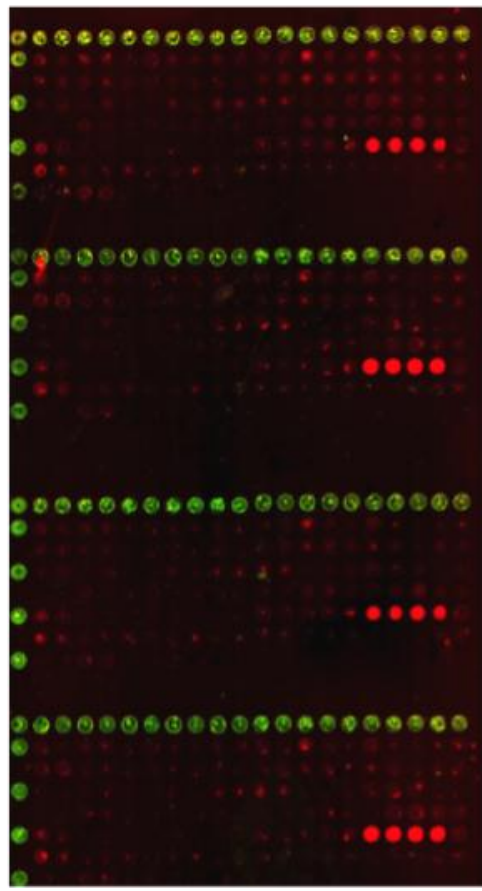

B

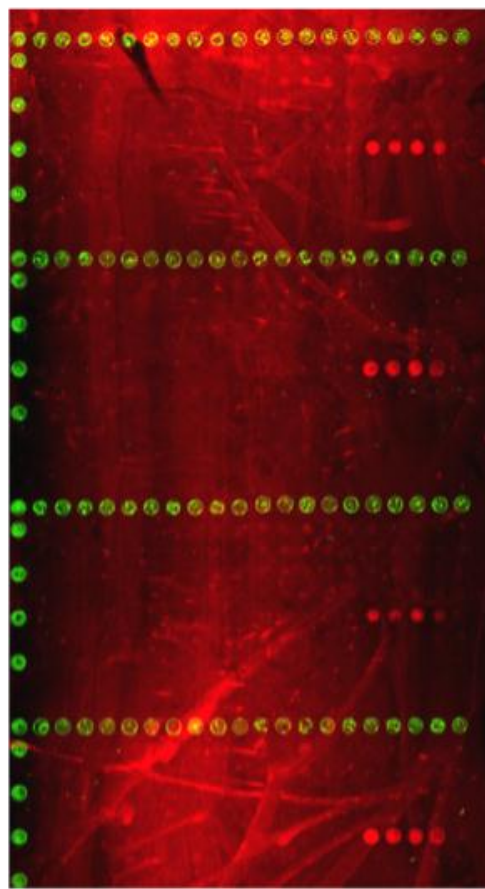

C

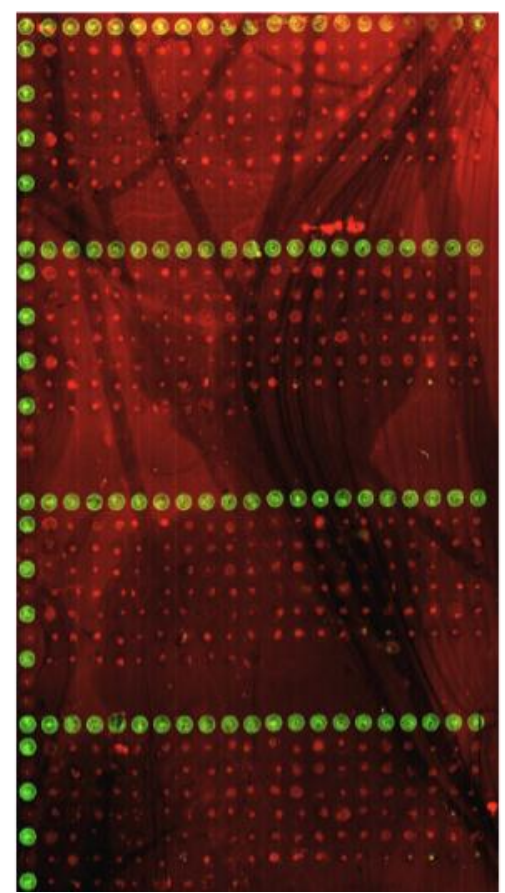

Figure 14: Comparison of blocking buffers. (A) SM, (B) BSA, and (C) WMB. 


\subsubsection{Peptide-cellulose conjugate (PCC) stock solution}

The peptides printed onto the microarray chip were synthesized by SPOT technology allowing for direct synthesis of peptides onto a cellulose membrane (Frank 1992). The peptide-containing cellulose spots were then punched out into a deep-well microtiter plate. The cellulose disc was dissolved in a trifluoroacetic acid (TFA) cocktail. This treatment solubilized the cellulose fibers while the peptide was still attached to small cellulose fragments. The PCC was precipitated with ether to remove the TFA however incompletely. PCC precipitate was dissolved in dimethyl sulphoxide (DMSO). To produce a microarray chip, PCC solution was printed onto glass microscope slides (Dikmans, Beutling et al. 2006). PCC stock solutions were kept at $-20^{\circ} \mathrm{C}$ for later printing of additional chips.

Over a year, HBV chips from different batches were used to screen mAbs and human sera. It was noticed that the stock solutions kept at $-20^{\circ} \mathrm{C}$ underwent an aging process, i.e. there was a reduced sensitivity of chips printed later. To examine this process, the reactivity of peptides printed directly after synthesis was compared to those kept at $-20^{\circ} \mathrm{C}$ and printed after one year. For this comparison, peptides reacting with two mAbs (MA18/7 and HB1) were selected. Chips were printed with freshly synthesized peptides and those kept for one year (figure 15). After reaction with the respective two mAbs, marked differences were seen between peptides printed directly after synthesis and those printed after one year. Thus printing directly after synthesis of peptides produces an optimum S/N ratio. Furthermore, only high concentrations of the stored peptides led to positive signals. A reduction in peptide reactivity might be explained by reactivation of a remnant of TFA upon thawing, which could reduce the ability of the PCC to stick to the glass surface. 

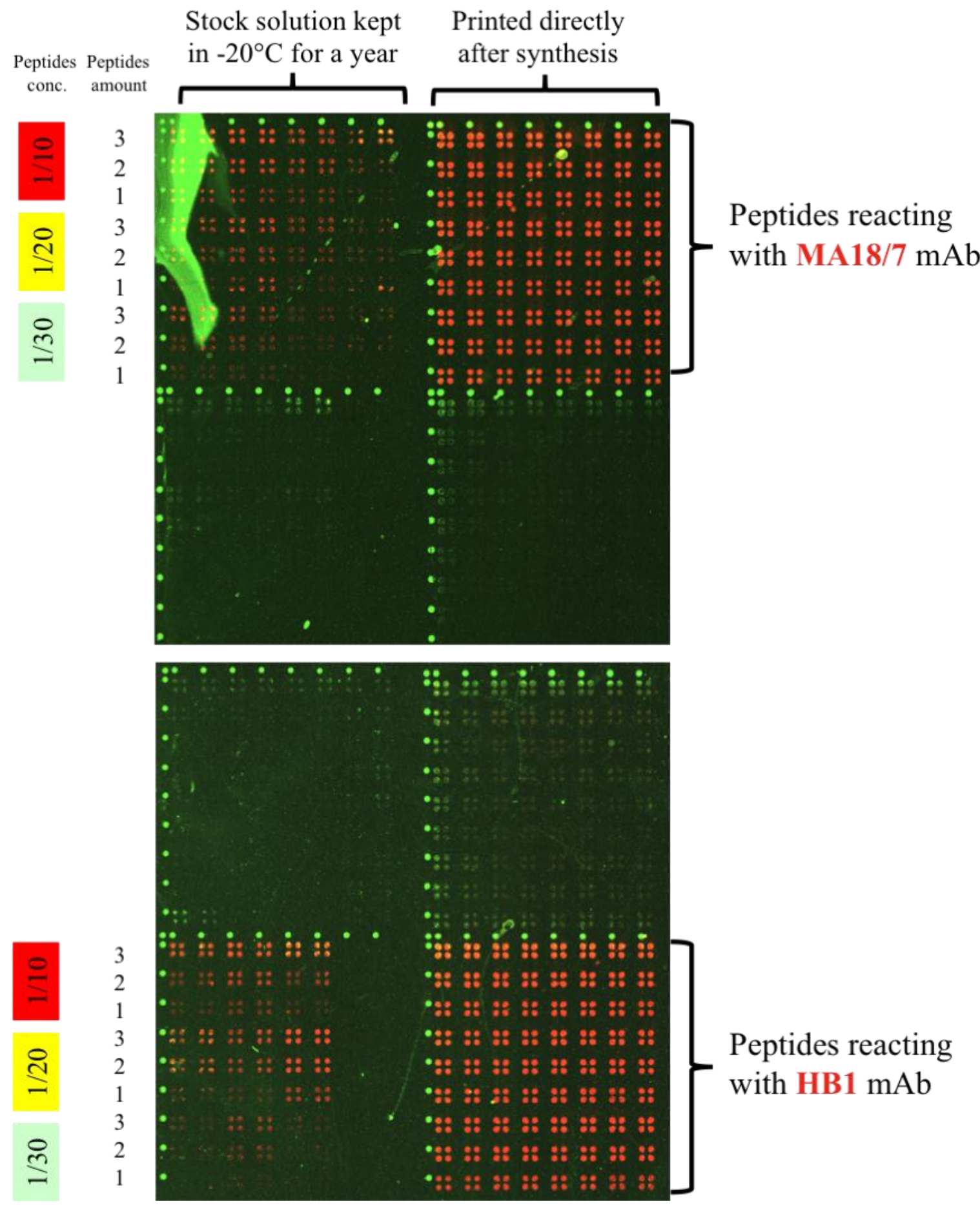

Figure 15: Comparison between the reactivity of peptides printed directly after synthesis and those after kept in $\mathbf{- 2 0}^{\circ} \mathrm{C}$ for a year. As indicated on the left hand side, three different concentrations and amounts were applied. 


\subsubsection{Storage conditions for printed slides}

These experiments were performed by Ulrike Beutling, Department of Chemical Biology, HZI, Braunschweig, Germany. Forty-seven slides were spotted with biotin and a peptide (sequence: NYGKYE) reacting with the ID3 mAb. Slides were stored at different conditions shown in table 4. After 195 days, two slides from each group were incubated with the ID3 mAb. Binding was visualized with secondary antibodies (Cy5-goat-antimouse antibody, and Cy3-Streptavidin) (table 5). 
Table 4: Different storage conditions of the slides.

\begin{tabular}{|c|c|c|c|c|c|c|}
\hline $\begin{array}{c}\text { Storage } \\
\text { conditions }\end{array}$ & Slides numbers & $\begin{array}{c}\text { Storage } \\
\text { temp. }\end{array}$ & $\operatorname{Gas}^{2}$ & $\begin{array}{l}\text { Drying bag } \\
\text { used/number }\end{array}$ & $\begin{array}{l}\text { Sealed in } \\
\text { plastic } \\
\text { bag }\end{array}$ & $\begin{array}{l}\text { Preserva- } \\
\text { tion of } \\
\text { reactivity }\end{array}$ \\
\hline $\begin{array}{l}\text { At room } \\
\text { temperature }\end{array}$ & $21,22,35,45,55,65$ & $20^{\circ} \mathrm{C}$ & --- & --- & $\begin{array}{c}1 \mathrm{x} \\
\text { sealed }\end{array}$ & Low \\
\hline $\begin{array}{l}\text { At room } \\
\text { temperature }+ \\
\text { drying bags }\end{array}$ & 42,43 & $20^{\circ} \mathrm{C}$ & --- & $\begin{array}{c}\text { yes } \\
2 \text { pieces }\end{array}$ & --- & Low \\
\hline $\begin{array}{l}\text { Refrigerator + } \\
\text { drying bags }\end{array}$ & $\begin{array}{l}23,24,36,46,56 \\
66,44\end{array}$ & $4^{\circ} \mathrm{C}$ & --- & $\begin{array}{c}\text { yes } \\
2 \text { pieces }\end{array}$ & $\begin{array}{c}1 \mathrm{x} \\
\text { sealed }\end{array}$ & Medium \\
\hline $\begin{array}{l}\text { Deep freezer } \\
\left(-20^{\circ} \mathrm{C}\right)+ \\
\text { drying bags }\end{array}$ & $25,26,37,47,57,67$ & $-20^{\circ} \mathrm{C}$ & --- & $\begin{array}{c}\text { yes } \\
2 \text { pieces }\end{array}$ & $\begin{array}{c}1 \mathrm{x} \\
\text { sealed }\end{array}$ & High \\
\hline $\begin{array}{l}\text { Refrigerator } \\
+ \text { drying bags } \\
+ \text { argon }\end{array}$ & $27,28,40,50,60,61$ & $4^{\circ} \mathrm{C}$ & Argon & $\begin{array}{c}\text { yes } \\
2 \text { pieces }\end{array}$ & $\begin{array}{c}2 \mathrm{x} \\
\text { sealed }\end{array}$ & High \\
\hline $\begin{array}{l}\text { Drying oven }{ }^{3} \\
+ \text { drying bags }\end{array}$ & $29,30,38,48,58,68$ & $50^{\circ} \mathrm{C}$ & -- & $\begin{array}{c}\text { yes } \\
2 \text { pieces }\end{array}$ & --- & Low \\
\hline $\begin{array}{l}\text { At room } \\
\text { temperature } \\
+ \text { drying bags } \\
+ \text { argon }\end{array}$ & $\begin{array}{l}33,34,41,51,62,63 \\
52,54\end{array}$ & $20^{\circ} \mathrm{C}$ & Argon & $\begin{array}{c}\text { yes } \\
2 \text { pieces }\end{array}$ & $\begin{array}{c}2 \mathrm{x} \\
\text { sealed }\end{array}$ & Medium \\
\hline $\begin{array}{l}\text { Desiccators } \\
+ \text { drying bags } \\
+ \text { argon }\end{array}$ & $31,32,39,49,59,64$ & $20^{\circ} \mathrm{C}$ & Argon & $\begin{array}{c}\text { yes } \\
2 \text { pieces }\end{array}$ & -- & Medium \\
\hline
\end{tabular}

${ }^{1}$ The drying bags were separated from the printed slides by an unprinted microscope to avoid dust coming into contact with the printed slides surfaces.

${ }^{2}$ When argon was used, the slide boxes were filled with the argon and closed (not sealed). They were then put in a plastic bag, which was also filled with argon and sealed with a bag sealer. Again, slides contained in the box and the bag were put into a second bag filled with the argon.

${ }^{3}$ The boxes in the desiccators and in the drying oven were not sealed with plastic bags.

Conclusions on the storage conditions experiment are shown in table 5:

The poorest results were from slides stored in the drying oven and at room temperature (regardless of with or without drying bag). The best results were from ones were stored in the refrigerator with drying bags and under argon or in the deep freezer with drying bags. Both showed similar spot intensities after storage. Generally the peptide spots seemed to be more sensitive to storage conditions than the biotin spots (on the poorest slides, the peptide spots disappeared earlier than the biotin spots). 
Table 5: Influence of different storage conditions on the signal intensities.

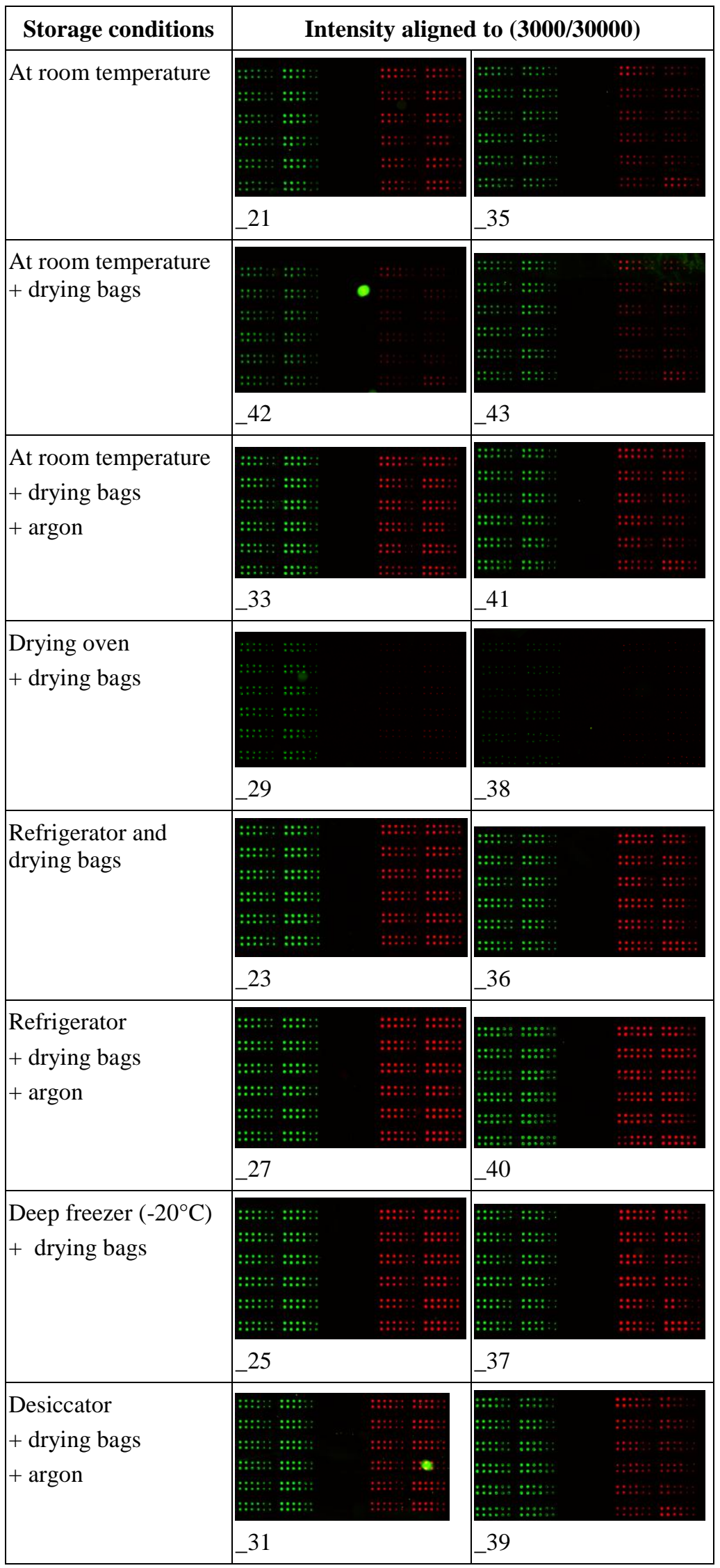




\subsection{Monoclonal antibodies}

\subsubsection{General remarks}

As descried in the Material section, the HIVenv chip is composed of 16 identical arrays, the HBV chip contains 12 identical arrays, and the HBV miniarray comprises four identical arrays. The only difference between the arrays within the same chip is the amount of peptide per spot. The HIVenv chip was stained with EVA3047 mAb (figure 16). All arrays displayed the same result except for arrays $7,8,15$, and 16 . The weak signal there was to be expected since these spots contain the lowest amount of peptides. Figure 17 shows only one of the 16 arrays. All further results will be represented in the same way and aa sequences of the reacting peptides are shown and the shared aa sequences colored red.

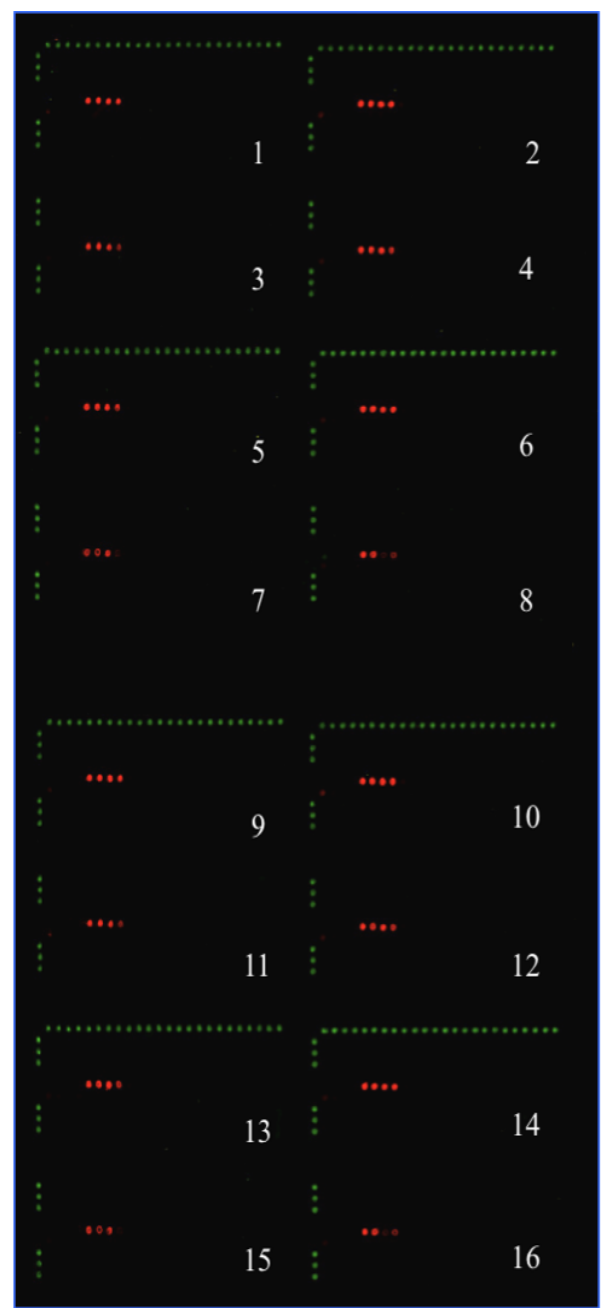

Figure 16: Testing the HIVenv chip with EVA3047. The arrays are numbered 1-16. 

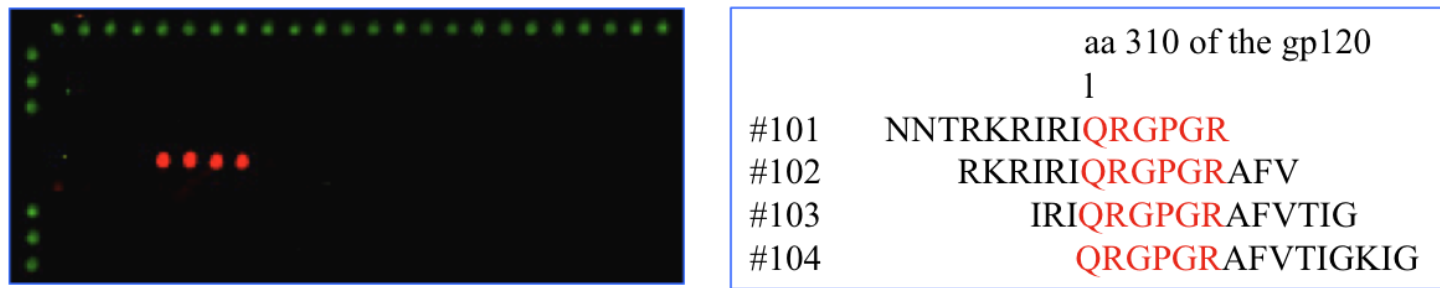

Figure 17: EVA3047-reactive peptides on the HIVenv chip. Left, array one of HIVenv chip (figure 16). Right, corresponding aa sequences of the reacting spots. The target sequence is shown in red comprising the aa $310-315$ of the gp160 sequences.

\subsubsection{Reactivity of monoclonal antibodies with HIVenv and HBV chips}

\subsubsection{Reactivity of the mAbs (EVA3012, EVA329, EVA3063 and EVA328) with the HIVenv chip}

The four HIVenv mAbs, EVA3012, EVA329, EVA3063 and EVA328 from Dr. A von Brunn, Dr. H Katinger, Dr. C Thiriart and Dr. C Bruck were provided by the EVA Program, Center of AIDS Reagent attached to the NIBSC, UK. The available information about these mAbs and their targets is listed in table 6. These mAbs were screened using the HIVenv chip to reproduce the results obtained by others.

EVA3012 reacted with the four peptides (102-105) of the HIVenv chip (figure 18A). The target of EVA3012 defined as the shared sequence of the four peptides is the PGRAFV (aa 313-318 of gp120). Earlier, the target of this mAb was identified with competitive ELISA to comprise the 15 aa RIQRGPGRAFVTIGK (table 6) (von Brunn, Brand et al. 1993). Likewise, using the scanning chip, the target sequence of EVA329 mAb was reduced from 21 to 6 aa (table $6 \&$ figure 18B) (Thiriart, Francotte et al. 1989).

The target sequence of mAb EVA3063 obtained with the HIVenv chip with EVA3063 was LELDKW (aa 661-666 of gp120) (figure 18C). In earlier work, using a peptide ELISA, a similar sequence was identified with shifted one aa to N-terminus (table 6) (Buchacher, Predl et al. 1994). The differences of the aa sequences described as targets is explained by the fact that our HIVen chip contained 15-mere with 12 aa overlapped with the neighboring. 
Table 6: Known information on the HIVen mAbs and reactivity with the HIVenv chip.

\begin{tabular}{|c|c|c|c|c|c|}
\hline $\begin{array}{l}\text { Designa- } \\
\text { tion }\end{array}$ & Isotype & Immunogen & Specificity* & Reference & $\begin{array}{l}\text { Target } \\
\text { sequences }^{+}\end{array}$ \\
\hline $\begin{array}{l}\text { EVA3012 } \\
(4 \mathrm{G} 10)\end{array}$ & $\begin{array}{l}\text { Mouse } \\
(\mathrm{BALB} / \mathrm{c}) / \\
\mathrm{Ag} 8653 \\
\text { IgG1 }\end{array}$ & $\begin{array}{l}\text { HIV-1 gp120 } \\
\text { (aa 308-322) } \\
\text { fused ro } \\
\text { HBcAG } \\
\text { particles }\end{array}$ & $\begin{array}{l}\text { Reacts in ELISA with } \\
\text { V3 loop, peptide } \\
\text { ARP734 } \\
\text { RIQRGPGRAFVTIGK, } \\
\text { and with purified } \\
\text { gp160. }\end{array}$ & $\begin{array}{l}\text { (von Brunn, } \\
\text { Brand et al. } \\
1993 \text { ) }\end{array}$ & $\begin{array}{lr}\text { aa } & 313-318 \\
\text { of } & \text { gp120 } \\
\text { (PGRAFV) }\end{array}$ \\
\hline $\begin{array}{l}\text { EVA329 } \\
(136.1)\end{array}$ & $\begin{array}{l}\text { Mouse } \\
(\text { BALB/c) / } \\
\text { Sp2 / } \\
\text { IgG2ak }\end{array}$ & $\begin{array}{l}\text { Recombinant } \\
\text { HIV-1 gp160 } \\
\text { produced in } \\
\text { yeast cells }\end{array}$ & $\begin{array}{l}\text { HIV-1 gp160/gp120 by } \\
\text { RIPA / Immunoblot / } \\
\text { ELISA. Target } \\
\text { sequence described aa } \\
\text { 362- } \\
\text { 381FKQSSGGDPEIVT } \\
\text { HSFNCGGE }\end{array}$ & $\begin{array}{l}\text { (Thiriart, } \\
\text { Francotte et } \\
\text { al. 1989) }\end{array}$ & $\begin{array}{lr}\text { aa } & 376-381 \\
\text { of } & \text { gp120 } \\
\text { (FNCGGE) }\end{array}$ \\
\hline $\begin{array}{l}\text { EVA3063 } \\
(2 F 5)\end{array}$ & $\begin{array}{l}\text { HIV-1 } \\
\text { infected } \\
\text { human } \\
\text { CB-F7 } \\
\text { IgG1k }\end{array}$ & $\begin{array}{l}\text { Recombinant } \\
\text { human Mab } \\
\text { produced in } \\
\text { CHO } \\
\text { cells }\end{array}$ & $\begin{array}{l}\text { HIV-1 gp41, Target } \\
\text { sequence described aa } \\
662-667 \text { ELDKWA }\end{array}$ & $\begin{array}{l}\text { (Buchacher, } \\
\text { Predl et al. } \\
1994)\end{array}$ & $\begin{array}{l}\text { aa } \quad 661-666 \\
\text { of gp } 41 \\
(\mathrm{LELDKW})\end{array}$ \\
\hline $\begin{array}{l}\text { EVA328 } \\
(60.1 .1)\end{array}$ & $\begin{array}{l}\text { Mouse } \\
(\text { BALB/c) / } \\
\text { Sp2 / } \\
\text { IgG2ak }\end{array}$ & $\begin{array}{l}\text { Recombinant } \\
\text { HIV-1 gp160 } \\
\text { produced in } \\
\text { yeast }\end{array}$ & $\begin{array}{l}\text { HIV-1 gp160/gp41 by } \\
\text { RIPA, Immunoblot., } \\
\text { Target } \\
\text { described aa } 362-381 \\
\text { FKQSSGGDPEIVTHS } \\
\text { FNCGGE) }\end{array}$ & $\begin{array}{l}\text { (Thiriart, } \\
\text { Francotte et } \\
\text { al. 1989) }\end{array}$ & $\begin{array}{l}\text { aa } 733-735 \\
\text { of gp } 41 \\
(E G G)\end{array}$ \\
\hline
\end{tabular}

*The target sequences of mAbs detected by other authors are colored blue. ${ }^{+}$The target sequences of mAbs obtained by the HIVenv scanning are colored red.

The result obtained with fourth mAb EVA328 was surprising. Its target sequence on our HIVenv chip was EGG (aa 733-735 of gp 41) (figure 18D). However the EVA catalogue gave the target sequence as FKQSSGGDPEIVTHSFNCGGE (aa 362-381 of gp120) (table 6). The EVA Program was informed about our discrepant result. They contacted Dr. Thiriart and found out that the target sequence that had been given by this mAb was an error.

The intensity and clarity of staining spots obtained with these four mAbs was quite different. This can be explained by the fact that mAbs EVA3012 (figure 18A), EVA329 (figure 18B) and EVA328 (figure 18D) were contained in tissue culture supernatant, while EVA3063 (figure 18C) was provided as highly purified IgG. 

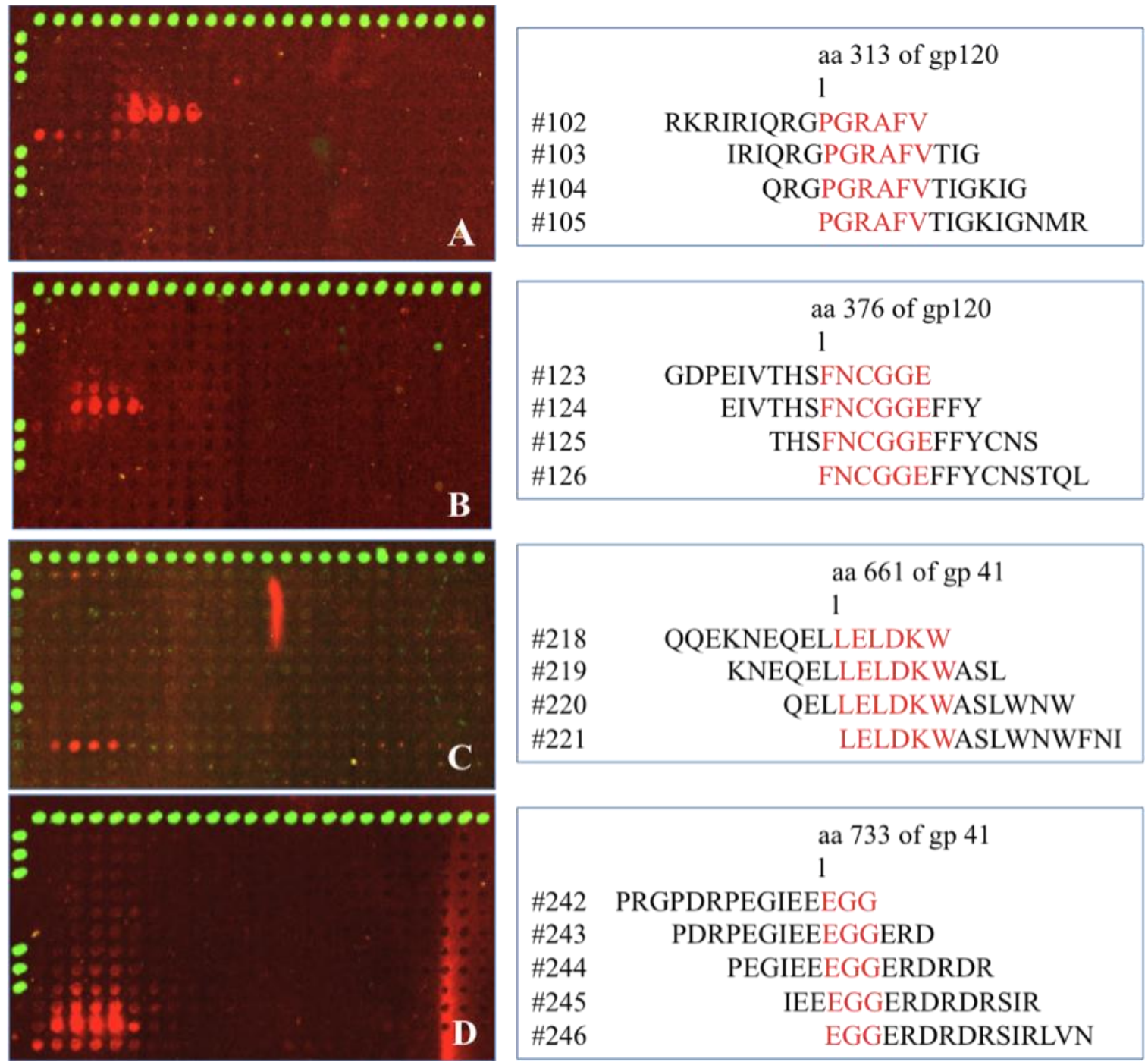

Figure 18: Results obtained with four mAbs on HIVenv chip. (A) EVA3012 mAb, (B) EVA329 mAb, (C) EVA3063 mAb, and (D) EVA328 mAb. Left is the one array field of the inspected HIVenv chip. Right are reactive overlapping peptides and the target sequence is shown in red.

\subsubsection{Discrimination of HBV genotypes and serotypes with mAbs}

According to their genome sequences, $\mathrm{HBV}$ isolates are classified into 8 genotypes (A-H). Each genotypes has a specific geographical distribution, e.g. in Europe mainly A and D. The most antigenic part of the HBV small-surface antigen (SHBsAg) is the antigenic loop (AGL). Variability in the AGL determines the nine HBsAg serotypes (Weber 2005; McMahon 2009; Kurbanov, Tanaka et al. 2010). The cross reactivity of the HB antibodies determines the broadness of the neutralization capacity. Our HBV chip contains the sequences of two genotypes found in Europe (A and D) and the nine HBV serotypes (Schaefer 2007). The targets sequences of these mAbs (2-11B1, HB1, HB3, and HB7) on different HBV genotypes or serotypes were determined. 


\subsection{Reactivity of 2-11B1 mAb}

The 2-11B1 mAb was prepared by immunizing mice with $\mathrm{HBsAg}$ from $\mathrm{HBV}$ carriers provided by Prof. Dr. Wolfram Gerlich, Institute of Medical Virology, University of Giessen. 2-11B1 mAb was screened with HBV scanning chips. As shown in figure 19, this mAb reacted with three peptides (202-204) leading to target sequence MQWNSTTFH (aa 1-9) of preS2 region of HBV genotype D. It did not react with genotype A. The only difference between both genotypes is at aa 7 where $T$ found in genotype $\mathrm{D}$ is replaced by $\mathrm{A}$ in genotype $\mathrm{A}$. This results target sequence was also found earlier by others with competitive ELISA using peptides containing either $\mathrm{T}$ or $\mathrm{A}$ (Sobotta, Sominskaya et al. 2000; Sominskaya, Paulij et al. 2002).
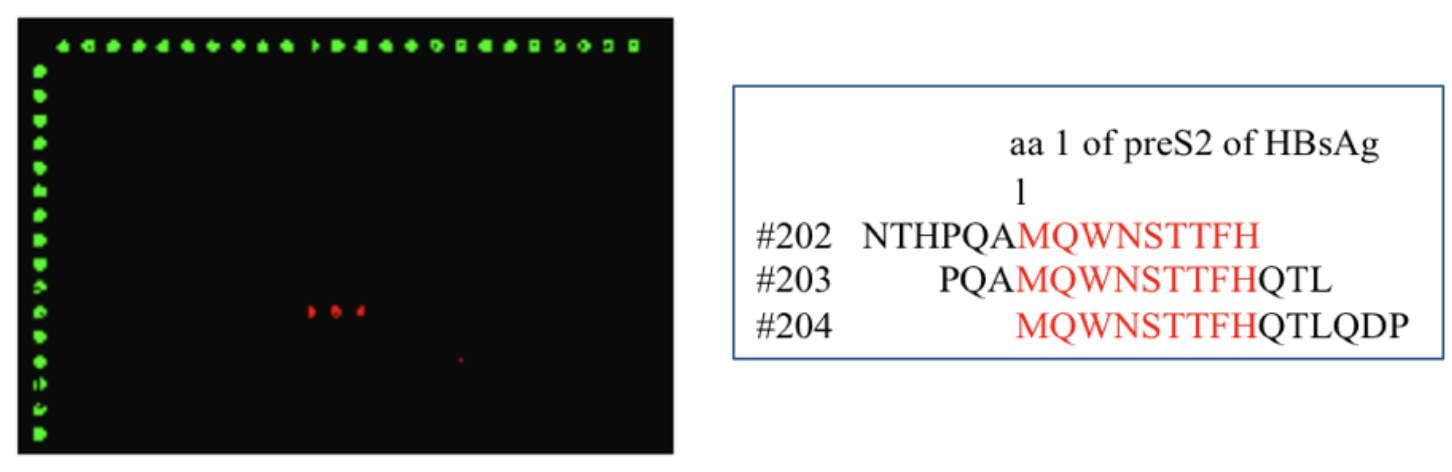

Figure 19: 2-11B1 reacting peptide on HBV microarray. Left, HBV scanning chip incubated with 211B1 mAb. Right is the recognition sequence.

\subsection{Reactivity of $\mathrm{HB} \mathrm{mAbs}$}

HB mAs (HB1, HB3, and HB7) were generated by immunizing mice with recombinant small hepatitis B surface antigen ( $\mathrm{SHBs}$, genotype D) produced in yeast. They were a gift from Prof. Dr. Wolfram Gerlich, Institute of Medical Virology, University of Giessen. These three mAbs were screened with the HBV chip. All of them detected 19 peptides on the HBV chip (figure 20 and table 7). The target sequence of this monoclonal was $\mathrm{C}(\mathrm{K} / \mathrm{R}) \mathrm{TCT}(\mathrm{T} / \mathrm{I})$ (aa 121-126 of SHBsAg). The second position of the recognition sequence can be either $\mathrm{L}$ or $\mathrm{R}$ and the last position either $\mathrm{T}$ or $\mathrm{I}$. These $\mathrm{mAbs}$ react with all known HBV serotypes except serotype ayw3. This serotype contains $\mathrm{M}$ at aa position 125 (spot numbers 149-151 in table 7). These results exemplify the superiority of our chip technology, which detects antibodies against various genotypes or serotype in one step. 


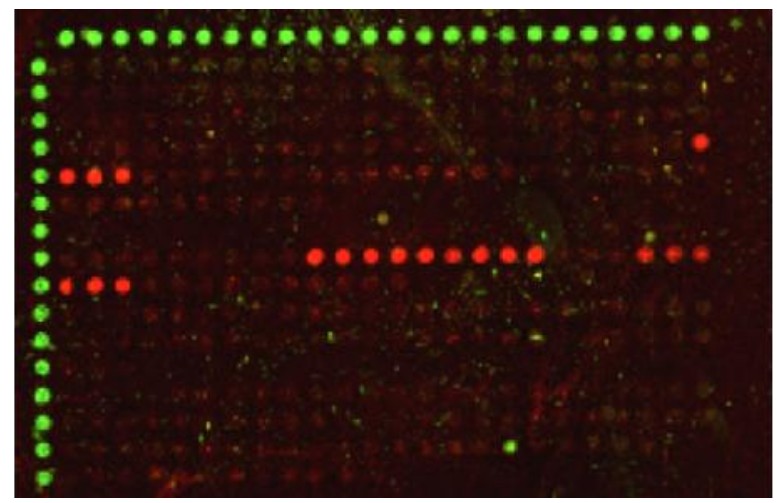

Figure 20: Screening HB1 mAb on HBVchip.

Table 7: HBV serotype-specific peptides and reactivity of their mAbs.

\begin{tabular}{|c|c|c|c|}
\hline $\begin{array}{c}\text { Spot } \\
\text { number }\end{array}$ & $\begin{array}{l}\text { aa sequence }(121-126) \text { of } \\
\text { HBsAg of all serotypes }\end{array}$ & Serotype & Reactive mAbs \\
\hline \#096 & GTTTTSTGPCKTCTT & \multirow[t]{4}{*}{$a d w 2$} & \multirow{4}{*}{$\begin{array}{l}\text { All HB mAbs react } \\
\text { with these spots }\end{array}$} \\
\hline \#097 & TTSTGPCKTCTTPAQ & & \\
\hline \#098 & TGPCKTCTTPAQGNS & & \\
\hline \#099 & CKTCTTPAQGNSMFP & & \\
\hline$\# 140$ & TSTGPCRTCTTPAQG & \multirow{3}{*}{$\begin{array}{c}\text { ayr } \\
\text { ayw1 } \\
\text { ayw2 }\end{array}$} & \multirow{9}{*}{$\begin{array}{l}\text { All HB mAbs reac } \\
\text { with these spots }\end{array}$} \\
\hline$\# 141$ & TTSTGPCRTCTTPAQ & & \\
\hline$\# 142$ & TGPCRTCTTPAQGNS & & \\
\hline \#143 & TSTGPCRTCTTIAQG & \multirow[t]{3}{*}{ ayw4 } & \\
\hline \#144 & TTSTGPCRTCTTIAQ & & \\
\hline$\# 145$ & TGPCRTCTTIAQGNS & & \\
\hline \#146 & TSTGPCKTCTIPAQG & \multirow{3}{*}{$\begin{array}{l}a d r \\
a d r q\end{array}$} & \\
\hline$\# 147$ & TTSTGPCKTCTIPAQ & & \\
\hline \#148 & TGPCKTCTIPAQGNS & & \\
\hline \#149 & TSTGPCRTCMTTAQG & \multirow[t]{3}{*}{ ayw3 } & \multirow{3}{*}{$\begin{array}{l}\text { No antibodies react } \\
\text { with these spots }\end{array}$} \\
\hline$\# 150$ & TTSTGPCRTCMTTAQ & & \\
\hline$\# 151$ & TGPCRTCMTTAQGNS & & \\
\hline$\# 152$ & TSTGPCRTCTTLAQG & \multirow[t]{3}{*}{ ayw 4} & \multirow{6}{*}{$\begin{array}{l}\text { All HB mAbs reac } \\
\text { with these spots }\end{array}$} \\
\hline$\# 153$ & TTSTGPCRTCTTLAQ & & \\
\hline$\# 154$ & TGPCRTCTTLAQGNS & & \\
\hline$\# 155$ & TSTGPCKTCTTLAQG & \multirow[t]{3}{*}{$a d w 4$} & \\
\hline$\# 156$ & TTSTGPCKTCTTLAQ & & \\
\hline$\# 157$ & TGPCKTCTTLAQGNS & & \\
\hline
\end{tabular}


The $\mathrm{C}(\mathrm{K} / \mathrm{R}) \mathrm{TC}$ motif is highly conserved among subtypes and mutants of HBsAg isolates (Qiu, Schroeder et al. 1996). The H166 is an mAb reactive with the C(K/R)TC motif. Diversity of aa surrounding the tetramer did not interfere with the reactivity with $\mathrm{H} 166 \mathrm{mAb}$. In addition, the reactivity of $\mathrm{H} 166 \mathrm{mAb}$ was preserved upon alkylation of the synthetic peptide containing such a motif, however, was completely destroyed upon reductive alkylation of the peptide (Chen, Delbrook et al. 1996). These results suggest that $\mathrm{H} 166 \mathrm{mAb}$ detected the $\mathrm{C}(\mathrm{K} / \mathrm{R}) \mathrm{TC}$ motif in its loop format with a disulfide bond holding the two cysteines together. In the case of HB mAbs, they detected with the linear form of $\mathrm{C}(\mathrm{K} / \mathrm{R}) \mathrm{TC}$ motif because the $\mathrm{SH}$ group of the cysteine of peptides prepared by SPOT technology were protected by trityl (Fields and Noble 1990; Frank 1992). The difference in reactivity between these mAbs might be due to the fact that the $\mathrm{H} 166 \mathrm{mAb}$ was prepared with mice immunized with HBsAg particles from human plasma, while with $\mathrm{HB}$ mAbs, the immunogen was from recombinant SHBs particles produced in yeast. Thus the yeast expresses the SHBs in another format than the natural antigen.

\subsubsection{Results obtained with mAbs (MA18/7 and EVA3047 mAbs) on scanning chips are reproduced and expanded with a random peptide library}

4608_RPL is a library containing 4608 random 15-mere peptides. Here it was used to identify target sequences of mAbs. MAbs (MA18/7 against HBsAg and EVA 3047 against HIV gp120) with known target sequences were screened with HBV miniarray and HIVenv chips and thereafter with 4608_RPL. The aa sequences of peptides reactive on 4608_RPL were aligned to derive the binding motif of these mAbs. The importance of each aa within the binding motif could be analyzed by comparison of the respective peptide sequences.

\subsubsection{Reactivity of MA18/7 mAb}

MA18/7 was generated by immunizing mice with purified HBV particles (Heermann, Goldmann et al. 1984). It was reported to recognize DPAF (aa 31-34 of preS1 in genotype A) (Germaschewski and Murray 1995). This MA18/7 was screened with the HBV miniarray where it recognized DPAFGA (aa 31-36 of preS1 in genotype A) (figure 21). The additional two aa at the C-terminus are not part of the binding site of the $\mathrm{mAb}$ but rather belong to the three aa shift of each overlapping peptide on our HBV miniarray. 

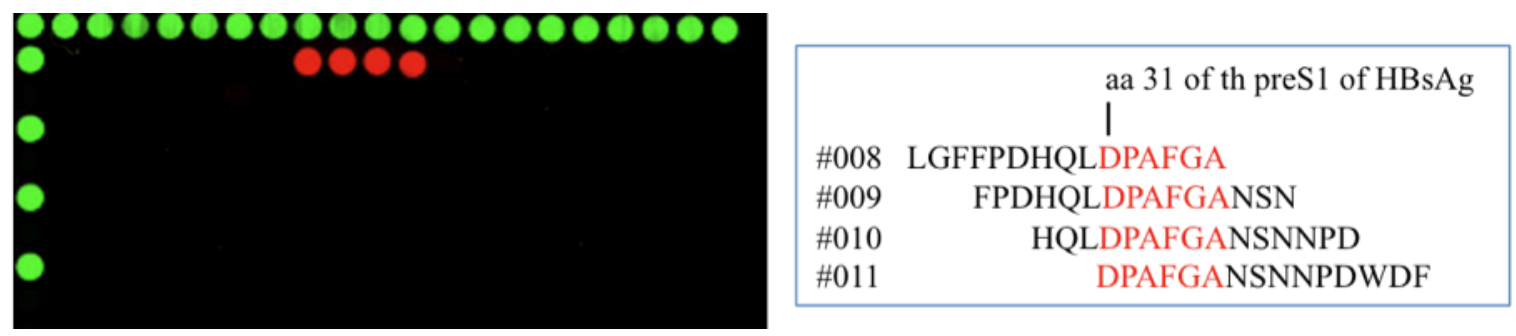

Figure 21: MA18/7 reacting peptide on HBV miniarray. Left is the screening of HBV miniarray with MA18/7. Right are reactive overlapping peptides and the target sequence is shown in red.

The MA18/7 was also screened with 4608_RPL (figure 22). It recognized 17 peptides, 11 strongly and 6 weakly (table 8). Alignment of the 11 strong responders revealed DPAF as the consensus sequence. The D at the first position was present in $7 / 11$ strong responders. In the remaining 4 strong responders, D was exchanged with $\mathrm{E}$ (three times) or $\mathrm{H}$. The Pro at the second position was found 3/11 strong responders and was replaced either by A, K, R, Q, or W (table 9). The A in the third position was found 6/11 and could be replaced either by G or C. In the fourth position, F detected 9/11, and could either be exchanged by W or Y. Germaschewski and Murray, as well as D'Mello and his colleagues, used a phage display library of $2 * 10^{8}$ or $2 * 10^{9}$ clones, respectively (Germaschewski and Murray 1995; D'Mello, Partidos et al. 1997). In an experimental by Germaschewski and Murray experiment, 30 peptides were identified; 6 of which did not align with DPAF (table 9). In the other 24 peptides, D and P were only allowed in both the first and the second positions respectively, while in the third position A was identified 13 times, G 9 times, and S, and V once. In the fourth position, F was present 22 times and Y twice. D’Mello and colleagues identified 20 reactive peptides. Only D and F were allowed in both the first and fourth positions, while the second and third were promiscuous (table 9). As described above, our experiment with the 4608_RPL and the results of the groups using the phage library derived the DPAF as a target sequence of the MA18/7 mAb. 


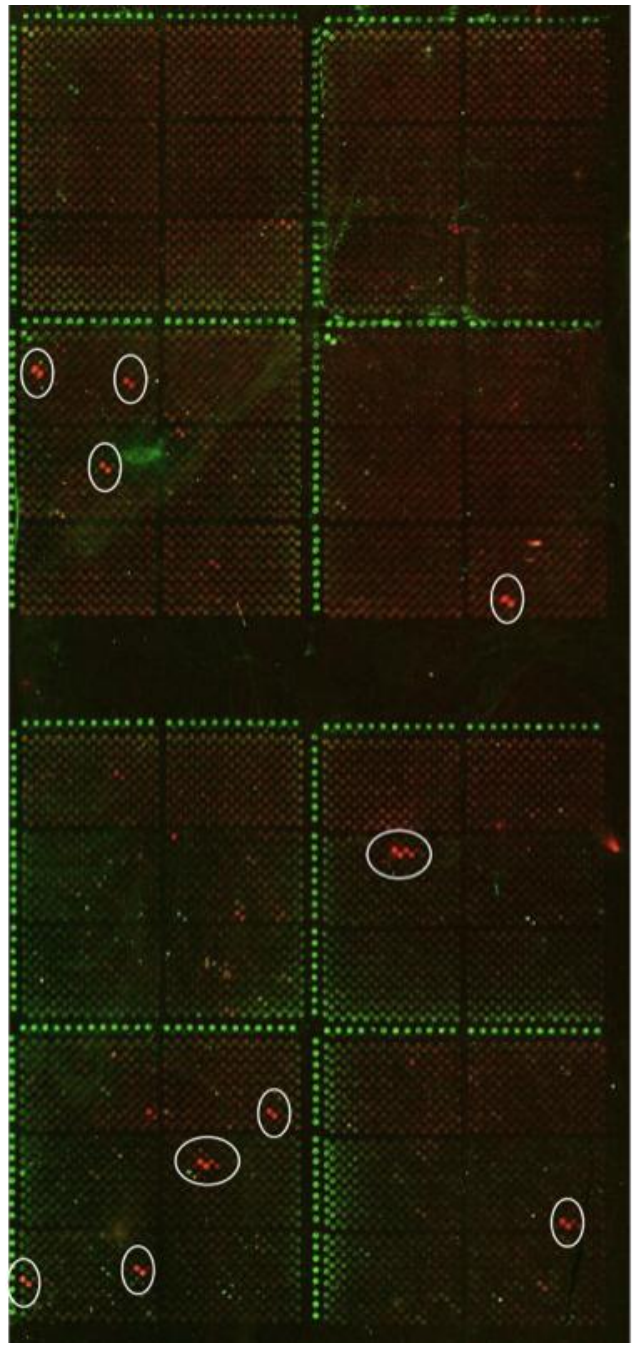

Table 9: The peptides reactive with the MA18/7 mAb. The detected motif is colored in red.

\begin{tabular}{|l|l|l|l|}
\hline Nr. & $\begin{array}{l}\text { Spot } \\
\text { number }\end{array}$ & Sequence & Class \\
\hline 1 & Q13D2 & GRVALYTEPGFRVQY & S \\
\hline 2 & Q13E10 & SIQCHQHHKAFQSRY & S \\
\hline 3 & Q17D8 & VDQAFKTFQAERKHT & S \\
\hline 4 & Q38G10 & TYWDRGFQGWYGMIN & S \\
\hline 5 & Q42C4 & MASEFTQALDAAFFK & S \\
\hline 6 & Q45D11 & VMPYPETEPAFLDKC & S \\
\hline 7 & Q45E1 & SAYQIFMEMWSDKAF & S \\
\hline 8 & Q24G4 & TMQHDKCWQYWFLCS & S \\
\hline 9 & Q31B7 & CWFNCMKMDPGFKTI & S \\
\hline 10 & Q31B8 & LQLQGYMMHRVEWCY & S \\
\hline 11 & Q44H9 & SNFPDAAFNNQEGID & S \\
\hline 12 & Q44H10 & FGVACFNFIHWGEMD & W \\
\hline 13 & Q48E7 & QMWYVYCMDAGYRYR & W \\
\hline 14 & Q10A11 & DFPFNTYGKWNHSTI & W \\
\hline 15 & Q22D5 & MDEHNWVDQWMTQYM & W \\
\hline 16 & Q11A12 & DCFTIWPAFIKSGDQ & W \\
\hline 17 & Q42C5 & NRVRIAWRDRINAQN & W \\
\hline
\end{tabular}

$\mathrm{S}$ is strong responder and $\mathrm{W}$ is weak responder

Figure 22: EVA3047 mAb screened with 4608_RPL. The strong responders are circled in white.

Table 9: DPAF was identified as the target sequence of MA18/7 from the peptide profiles obtained in three independent experiments.

4608 RPL

\begin{tabular}{|l|l|l|l|}
\hline D (7) & P(3) & A (6) & F (9) \\
\hline E (3) & K (3) & G (3) & Y \\
\hline H & A (2) & C (2) & W \\
\hline & R & & \\
\hline & Q & & \\
\hline & W & & \\
\hline
\end{tabular}

Germaschewski and Murray 1995

\begin{tabular}{|l|l|l|l|}
\hline $\begin{array}{l}\mathrm{D} \\
(24)\end{array}$ & $\begin{array}{l}\mathrm{P} \\
(24)\end{array}$ & $\begin{array}{l}\mathrm{A} \\
(13)\end{array}$ & $\begin{array}{l}\mathrm{F} \\
(22)\end{array}$ \\
\hline & & $\mathrm{G}(9)$ & $\mathrm{Y}(2)$ \\
\hline & & $\mathrm{S}$ & \\
\hline & & $\mathrm{V}$ & \\
\hline
\end{tabular}

D'Mello, et al. 1997

\begin{tabular}{|l|l|l|l|}
\hline $\begin{array}{l}\mathrm{D} \\
(20)\end{array}$ & $\begin{array}{l}\mathrm{P} \\
(12)\end{array}$ & $\begin{array}{l}\mathrm{A} \\
(10)\end{array}$ & $\begin{array}{l}\mathrm{F} \\
(20)\end{array}$ \\
\hline & $\mathrm{R}(6)$ & $\mathrm{V}(5)$ & \\
\hline & $\mathrm{S}$ & $\mathrm{G}(4)$ & \\
\hline & L & S & \\
\hline & & & \\
\hline
\end{tabular}


An important technical issue is the target sequence of an mAb, which can be identified with 4608_RPL in around 6 hours, whereas preparation and screening of phage display libraries may take a month to perform. In addition, in phage display libraries, some DNA inserts are over-represented and other immunologically important ones may be missing. Therefore, the 4608_RPL is a simple and powerful tool to identify targets of mAbs.

To further consolidate these results, MA18/7 was reacted with 120 15-mere peptides in which each of the 4 aa of the binding motif is exchange by either of the 20 aa (figure 23). Only one aa substitution per peptide was allowed. As a result, D at the first position can only be replaced by $\mathrm{E}$ or $\mathrm{H}$. The second position $\mathrm{P}$ is more promiscuous and less significant for the MA18/7 recognition. The third position can either be A, G or V and the forth F or L. A very similar result was obtained with 4608_RPL except for the third and fourth positions (table 9). D'Mello's results resemble ours for the second and third positions, while Germaschewski and Murray's for the third position only. Thus the results obtained in three independent experiments are similar but not identical. This might be due to the fact that in the single residue substitution assay only one aa of the binding sequence was exchanged, while peptides of the 4608_RPL or the phage display libraries recognized by MA18/7 contained multiple aa exchanges. 


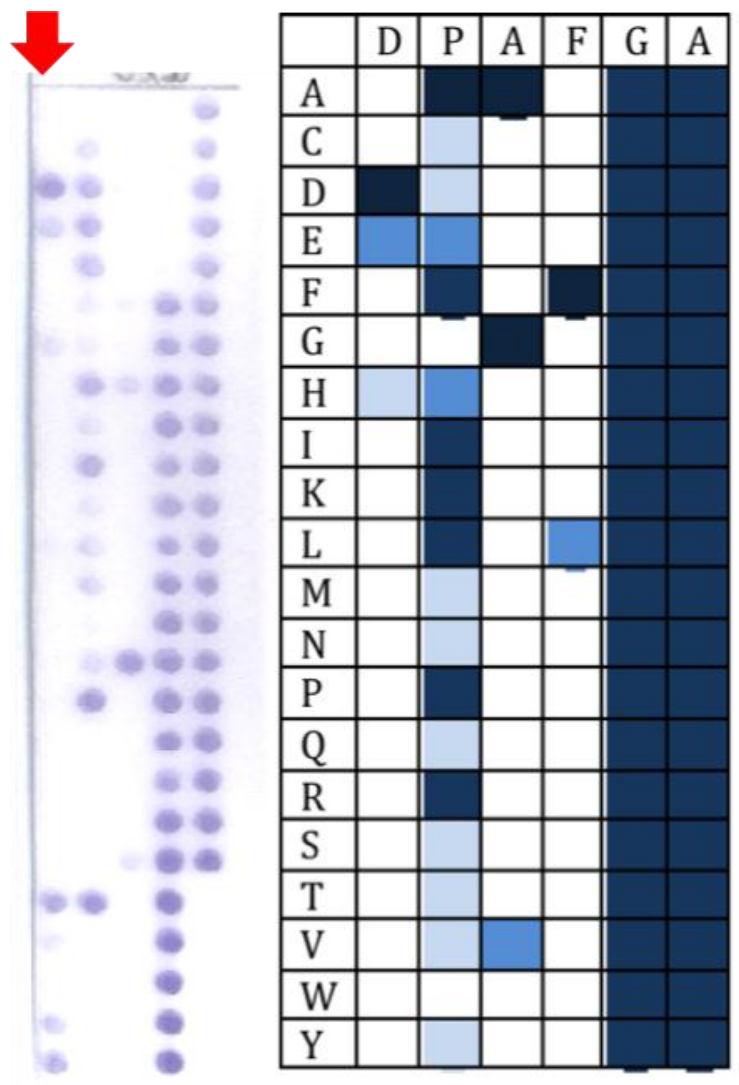

Figure 23: Single aa residue substitution assay identified the MA18/7 binding motif. Left, reactivity with the 15-mere spotted on a nitrocellulose sheet. The first position of the binding motif is indicated by a red arrow. Right, signal strength in quartiles (Dark blue strong reactivity and white no reactivity).

\subsubsection{Reactivity of EVA3047 mAb}

The EVA 3047 mAb from Dr J Laman was provided by the EU Programme EVA Center of AIDS Reagent, attached to NIBSC, UK. It was generated by immunizing mice with the gp120 HIV-1 peptide (IRIQRGPGRAFVTIGC). The reactive sequence of EVA3047 was found to be QRGP (aa 310-313 of HIV gp120) (Laman, Schellekens et al. 1992). It was screened with the HIVenv chip. The target sequence was identified as QRGPGR (aa 310-315 of HIVgp120) (figures 16 \& 17). The additional two aa at the Cterminus in our sequence were explained above.

The EVA3047 was also screened with the 4608_RPL. Twenty-four binding peptides were identified, five as strong responders (figure 24 and table 10). Aligning the five strong responders revealed the QxGP as the target sequence of EVA3047. X was M, $\mathrm{R}$, or $\mathrm{V}$. 


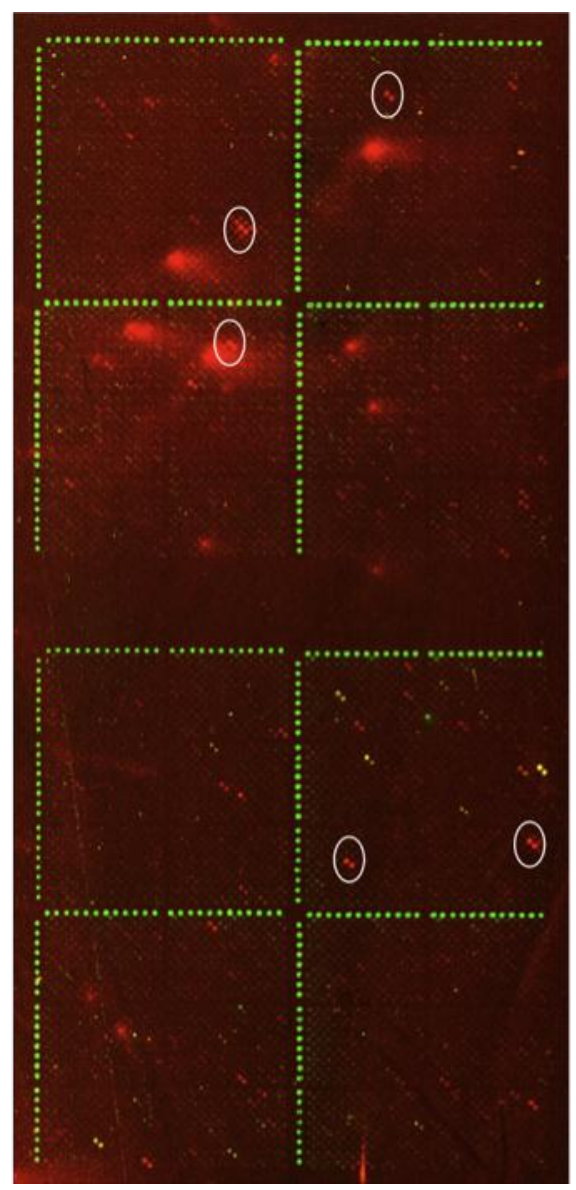

Table 10: The peptides reactive with the EVA3047 mAb. The detected motif is colored in red.

\begin{tabular}{|c|c|c|c|}
\hline Nr. & $\begin{array}{c}\text { Spot } \\
\text { number }\end{array}$ & Sequence & Class \\
\hline 1 & Q10B8 & KSPPMWYQMGPRMQE & $\mathrm{S}$ \\
\hline 2 & Q3E9 & LHQYEYMREQFKGWT & $\mathrm{S}$ \\
\hline 3 & Q14D7 & QDSWVQMQQSIWRLR & $\mathrm{S}$ \\
\hline 4 & Q36B11 & CLYNYLCWVDRQVGP & $\mathrm{S}$ \\
\hline 5 & Q35D5 & WGWMYPLEQDQRGPR & $\mathrm{S}$ \\
\hline 6 & Q1F6 & FNRQSWRQEQRKANY & W \\
\hline 7 & Q48B11 & EYTFPFRHQMVVFRW & W \\
\hline 8 & Q1F11 & NPQMHNKLVYNMHQY & W \\
\hline 9 & Q4D9 & FMVESHQFLYSHRRR & W \\
\hline 10 & Q14H3 & DRGQGRFKQMTYNIW & W \\
\hline 11 & Q24H8 & CECGQRILIRGQRQI & W \\
\hline 12 & Q21A3 & QQQFQLWFNMSACIR & W \\
\hline 13 & Q24B10 & FRGFATRMYYPSRAM & W \\
\hline 14 & Q24C10 & QMDQCRRRFTCQIWF & W \\
\hline 15 & Q26H12 & FTTWCQPGWGRFRHQ & W \\
\hline 16 & Q30E6 & GFHPRLMQQVGIMRS & W \\
\hline 17 & Q27G6 & RRKRHIFRRNRKKTC & W \\
\hline 18 & Q27A11 & QRIWNFSLSNFHQFE & $\mathrm{W}$ \\
\hline 19 & Q27D11 & LQLKHQFNMHTLQWS & $\mathrm{W}$ \\
\hline 20 & Q28G4 & RQFMDQGNWLGQQFQ & W \\
\hline 21 & Q32C10 & RSERESSVNYKTQTP & $\mathrm{W}$ \\
\hline 22 & Q38A5 & QHCPPDVPLDHQFVK & W \\
\hline 23 & Q45H11 & IEWFNHGPGMTLELA & $\mathrm{W}$ \\
\hline 24 & Q42H8 & FLPDLFPLHFHQFRH & W \\
\hline
\end{tabular}

$\mathrm{S}$ is strong responder and $\mathrm{W}$ is weak responder

Figure 24: EVA3047 mAb screened with

4608_RPL. The strong responders are circled in white.

As described above with the MA18/7 mAb, a peptide substitution assay was performed for QRGPGR sequence to define the relevance of each aa for the EVA3047 binding. $\mathrm{R}$ in the second, $\mathrm{G}$ in the third and fifth, and $\mathrm{R}$ in the last position are promiscuous and can be substituted with any of the other 19 aa (figure 25). Again the 4608_RPL was useful for identify the targets of four aa in length. 

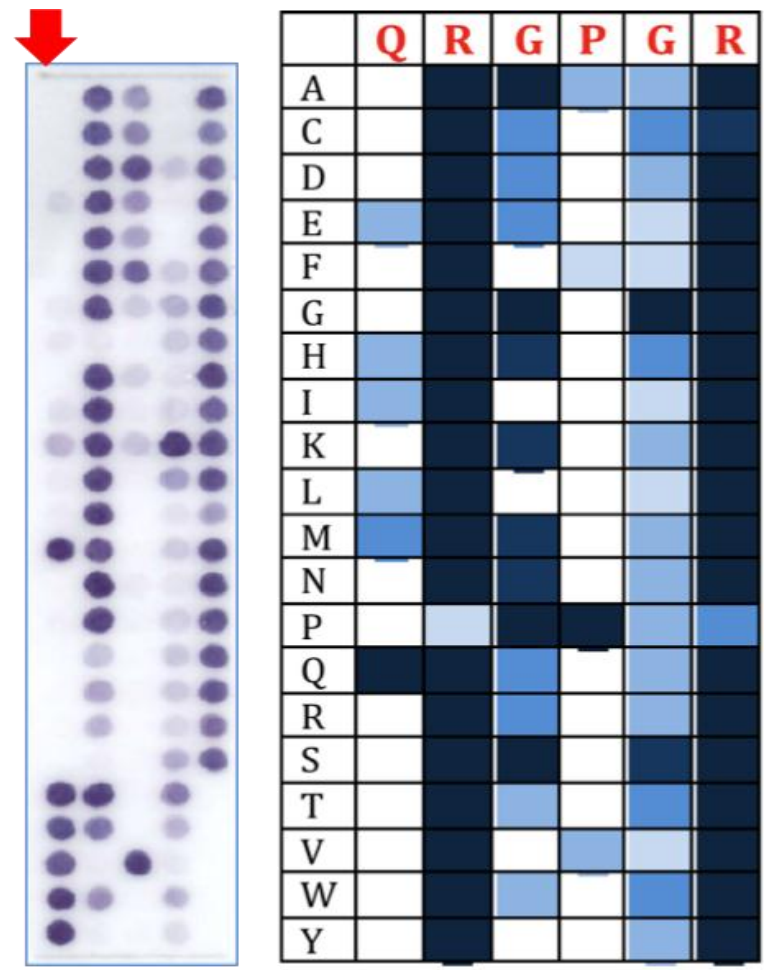

Figure 25: Single aa residue substitution assay identified the EVA 3047 binding motif. Left, reactivity with the 15-mere spotted on a nitrocellulose sheet. The first position of the binding motif is indicated by a red arrow. Right, signal strength in quartiles (Dark blue strong reactivity and white no reactivity).

\subsubsection{No reactive peptide found on the scanning chips with HBV and HIV mAbs except for 4608_RPL}

The paratopes on an antibody binds to the epitope of an antigen. Depending on the tertiary structure of an antigen, an epitope can either be continuous (linear) or discontinuous (conformational) (figure 26). A continuous epitope comprises a group of consecutive aa representing the primary sequence at a specific site. The mAbs MA18/7 and EVA3047 tested on 4608_RPL in figure 22 and 24 recognize continuous epitopes. Continuous epitopes withstand denaturation of the antigen. A discontinuous epitope comprises two or more groups of residues located close to each other in the tertiary structure. Denaturation destroys the reactivity of the discontinuous epitopes (Reineke 2004). Epitopes may also contain modified residues (e.g. glycosylation, phosphorylation) (Lisowska 2002). Here are attempts to identify targets of three mAbs C20/02, and EVA332 recognize discontinuous epitopes while Q19/10 recognizes modified residues. 


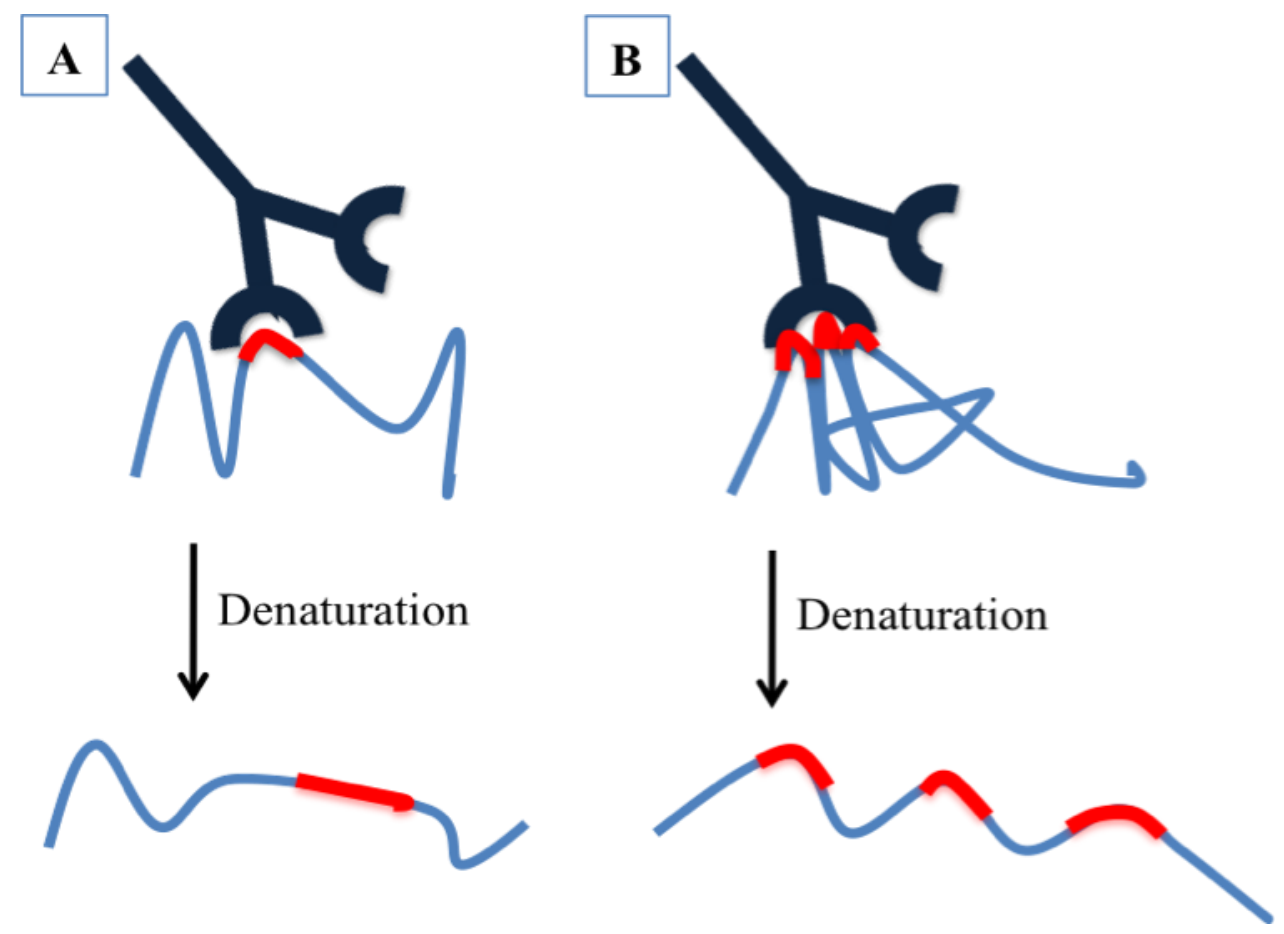

Figure 26: Antigen antibody interaction. (A) Continuous epitope. (B) Discontinuous epitope.

\subsubsection{Reactivity of $\mathrm{C20} / 02 \mathrm{mAb}$}

C20/02 mAb (provided by Prof. Dr. Wolfram Gerlich, Institute of Medical Virology, University of Giessen) was generated by immunizing mice with subviral particles from HBV derived from a chronic carrier. It reacted neither with western blot (Wolfram Gerlich, personal communication) nor with the HBV scanning chip. Thus it might recognize a discontinuous epitope or epitope of modified residues. C20/02 recognized 72 peptides on 4608_RPL. Fifteen were strong responders (table 11 and figure 27) while 57 reacted weakly (table 12). The alignment of the 15 strong responder sequences using the MUSCLE program available from EBI revealed $\mathrm{YKP}+\mathrm{F}+\mathrm{G}++\mathrm{GWG}+\mathrm{N}-\mathrm{M}$ (Figure 28A) as a consensus sequence. This consensus sequence was compared with aa 100-180 of SHBsAg genotype D. The consensus sequence aligned with three parts of the SHBsAg: aa 100, aa 141-145, and aa 165 (figure 28B). 


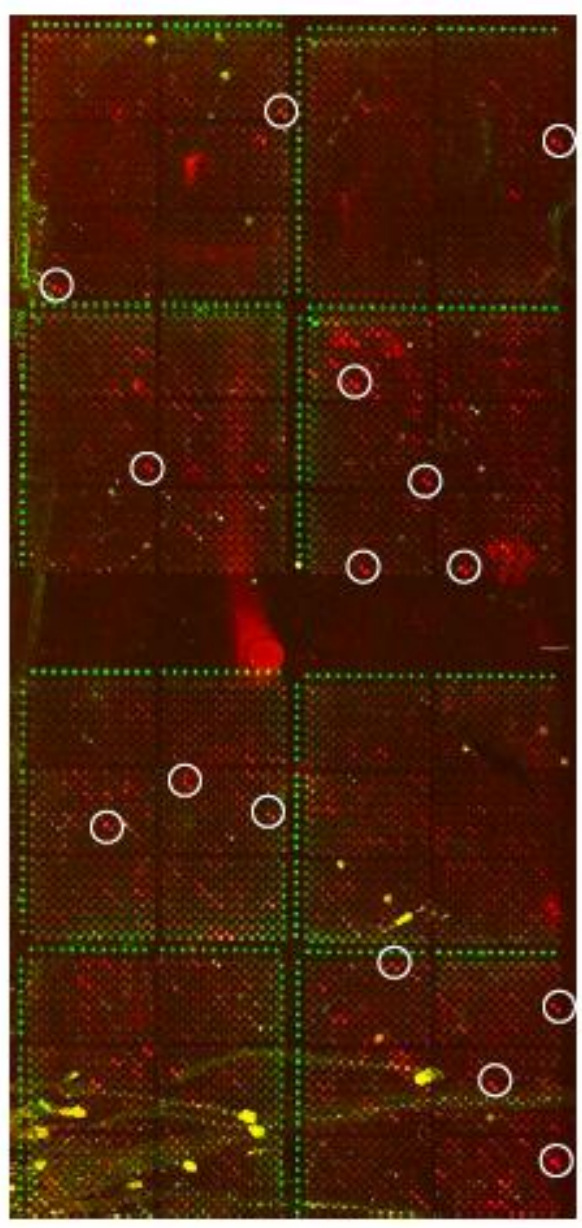

Figure 27: C20/02 mAb screened with 4608_RPL. The strong responders are circled in white.

Table 11: The peptides strongly reactive with $\mathrm{C20/02} \mathrm{mAb}$.

\begin{tabular}{||c|l||}
\hline Spot number & \multicolumn{1}{|c|}{ Sequence } \\
\hline Q9H3 & GPDQCVGWMGGMQPW \\
\hline Q2H12 & PKAITGEDFWDATRM \\
\hline Q17G12 & ARGEGWMIPLKFRFI \\
\hline Q29F8 & NYDRLYRREPGTGGN \\
\hline Q30B3 & NWKFRFCYMACLFRI \\
\hline Q30E11 & GFKPCYYFRDMAEFD \\
\hline Q8B12 & ALTCAGNIPNKLFNM \\
\hline Q15G5 & FFKSVCNGPMAVGWA \\
\hline Q19H12 & INPPKFFQRNEWMWH \\
\hline Q23H6 & YAPMCVGIRGITPKV \\
\hline Q24H3 & GGIFRGKPVYQEYHM \\
\hline Q39A9 & SQTIVDKFRGYMRNF \\
\hline Q40E12 & AEPMVNPFAFHAFRP \\
\hline Q44D6 & FYAPPLIGAQDWYYN \\
\hline Q48C12 & GYVLPLFYGKQHMGP \\
\hline
\end{tabular}


Table 12: The peptides weakly reactive with $\mathrm{C20/02} \mathrm{mAb}$.

\begin{tabular}{|c|c|c|c|}
\hline Spot number & Sequence & Spot number & Sequence \\
\hline Q6B10 & MTPWNCWCIFNWLQF & Q12F4 & HCVPRAFWNATMYWN \\
\hline Q13D11 & FISRKVMNNVGWYIN & Q15B7 & WNRRHKPQYAFFQGL \\
\hline Q13H9 & KFPVGEYVLWSFRVK & Q15C5 & YEHNFWCFRTYFPNV \\
\hline Q18B4 & IPDKWKAGMKWRDKK & Q15F1 & FCFADTLFRKHRQAN \\
\hline Q18G10 & FLEFCWCMAFRWANV & Q15F6 & THGLVFNRGEWSIWD \\
\hline Q22D3 & GRSISLMFPFWMQMI & Q15H7 & DENFFKPWKRIVFKR \\
\hline Q26H9 & QFKGFPGRADDFLFF & Q15H11 & SMRWPVHTYKPTMFT \\
\hline Q33D11 & VRNSRFPRCKFRSPA & Q16E7 & NQMVLNSCPSYYPCG \\
\hline Q33F3 & WWRRCRFNNHLGMVF & Q20A8 & VKGCIWQFTKPMFFL \\
\hline Q34E11 & FMMAYQWPFFNFRAD & Q23A12 & RWWTGAWAKFNPRIS \\
\hline Q34E6 & GSVEPKFREQEKLCW & Q27G2 & RAPWMFFSPYLGITN \\
\hline Q34C4 & MKCMYRKALDYPGYM & Q27G5 & KVHTICAMLFRLRPW \\
\hline Q37E6 & GSHIKFFFRGYGHWP & Q27G8 & SIGNGRIPINFGIDW \\
\hline Q38A4 & YLVTKTYFWRKYRTF & Q31D3 & PCCPCFWLQMFMSPP \\
\hline Q38B11 & TWQFRIAREWFMPCG & Q39B11 & SQFTFCAKIREGGFF \\
\hline Q38C9 & WMKVVNQEFRIFNMN & Q39C2 & NKMLWYGFMNQPARQ \\
\hline Q41A12 & LNEYARMWFNAQPGY & Q39F4 & RPYRSYHRRFMGWMD \\
\hline Q41B9 & SAMCWNSAVRTIWRA & Q43A10 & TNICVFRKTKKFMTA \\
\hline Q41D7 & YMGTPWFFAAPFMRR & Q43C10 & MSGNTWSPKNHMFNI \\
\hline $\mathrm{Q} 42 \mathrm{C} 2$ & EALKNLYFNLSAKMS & Q43D2 & HSHTRSLYDPFSDGY \\
\hline Q42F4 & YVEHVAYVELNRRYL & Q43D12 & ELQCMWRVSHGMQWF \\
\hline Q45E3 & RNIFRCRYRQILWGF & Q43F7 & YAQCVGYMYVFRWCT \\
\hline Q45G2 & IMACILPNFYYSGRF & Q43F11 & FFRAGSLMEWLNEFI \\
\hline $\mathrm{Q} 46 \mathrm{~A} 2$ & YSITGFEEQTVHTNW & Q43G9 & TNDENPYIFWSVFRR \\
\hline Q46G3 & LVVRFCINKVIRFIT & Q48D1 & PFGWWMMGYLYDATP \\
\hline Q3G6 & PQPFIHVNMLFRYRV & Q48E7 & QMWYVYCMDAGYRYR \\
\hline Q4E6 & TWPQGWKFKNLGNGE & Q48G6 & KFRYTIGNTYGNPCH \\
\hline Q4G5 & RWRDSSLGYKFRLAF & Q48G7 & HGGQCPYGALYGSCP \\
\hline Q8G8 & YGVWDCFSTPCVGGL & & \\
\hline
\end{tabular}

Several motifs could be extracted from the peptides reacting with C20/02. (1) $\mathrm{KxxxG} / \mathrm{R}$ motif was found in 3 of the strong responders and in 7 of the weak responders (violet in tables $11 \& 12$ ). This motif might represent aa 141-145 of SHBsAg. (2) 6/15 strong responders and 2/57 week responders contained PxxxG/R motif (red in tables 11 \& 12). (3) 9 peptides contained $\mathrm{WxF}$ motif (blue in tables $11 \& 12$ ). This motif might represent aa 156-158 of SHBsAg. (4) Spot number Q13H9 (orange in table 12) contained the motifs 1 and 3 of the consensus sequence KxxxGxxxxWxF. (5) A motif of 3 residues encompassing $\mathrm{G}$ at the first position, any of the 20 aa at the second position, and then a stitch of aliphatic aa was found in 10 reactive peptides (green in tables $11 \& 12$ ). This 
motif might represent aa 102-104 of SHBsAg. (6) The YR motif was found in 8 peptides, while the closely related WR motif was seen in 6 (brown in tables $11 \& 12$ ).
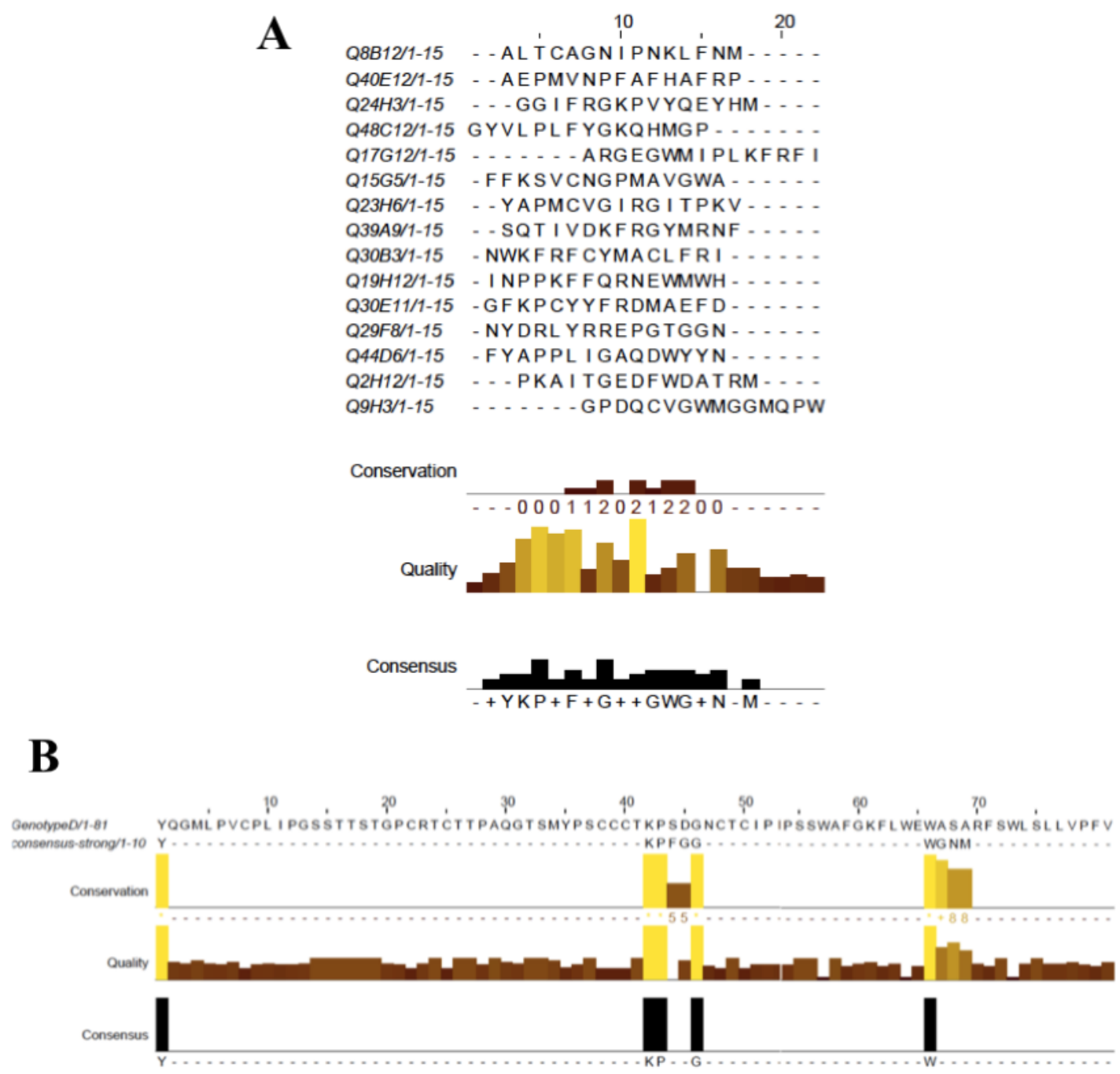

Figure 28: Alignment of the C20/02 strongly reactive peptides derived from 4608_RPL. (A) Alignment of the 15 strong responders. (B) Alignment of aa 100-180 of SHBsAg (upper row) with C20/02 strongresponders-consensus sequence (lower row). This alignment was done using the MUSCLE program. The numbers above the sequences in the first row represent the numbering in the MUSCLE program not the position within the SHBsAg. The program placed the consensus sequences in three parts within the SHBsAg (aa 100, aa 141-145, and aa 165 of SHBsAg).

In an independent experiment performed by Prof. Dr. Camille Sureau, Laboratoire de Virologie Moléculaire, Institut National de la Transfusion Sanguine, Paris, a panel of HBV subviral particles bearing the 3 envelope proteins L-, M- and SHBsAg (LMS) was constructed. Each LMS mutant bears an amino acid substitution at one position of HBV 
AGL (residues 101 to 172), S for $\mathrm{C}$ or A for non-C. A couple of substitutions (grey in the histograms, figure 29) could not be produced. For C20/02 epitope mapping the antibody was fixed to wells in a Maxisorp ELISA plate and reacted with LMS particles. Bound particles were detected by anti-preS2 antibodies.

The LMS binding profile of C20/2 is shown in figure 29. Binding of C20/02 was affected by many residues. Some substitutions seemed to improve recognition e.g. T118A, T123A, M125A, T127A, Y134A, S136A, and T149A. But substitutions of all C by $\mathrm{S}$ were detrimental. This was expected because disulfide bonds between $\mathrm{C}$ keep the HBsAg tertiary structure. Moreover, the C20/02 reactivity was lost with the following substitutions G119A, P120A, T140A, K141A, D144A, and G145A. In addition, LMS particles with substitutions in the $\mathrm{C}$ terminus of SHBsAg (some single aa substitutions and deletions between residues 172 and 226) had no effect on C20/02 binding (unpublished data).

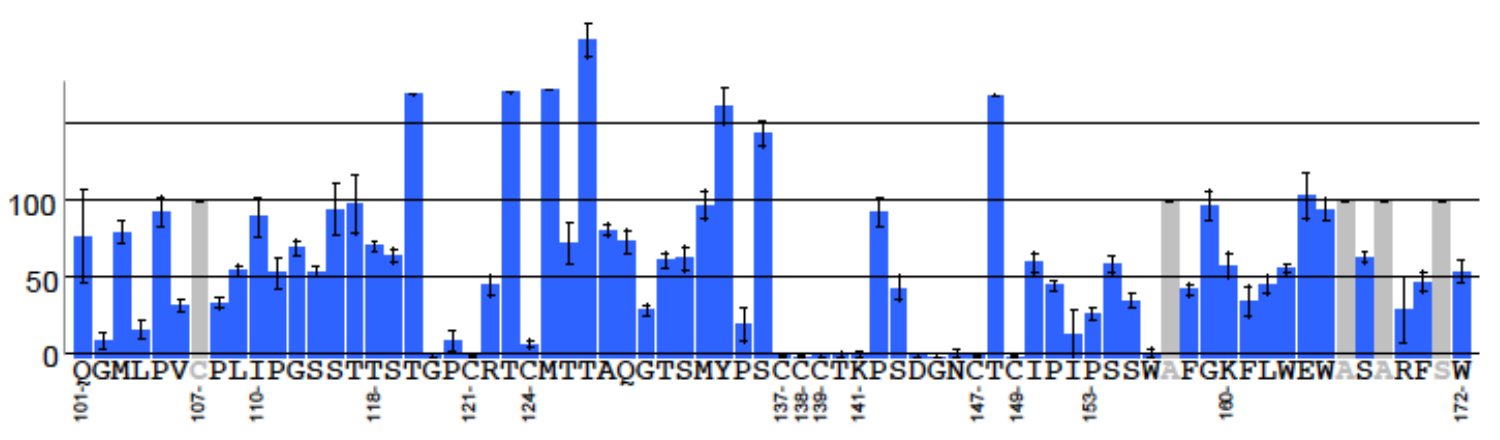

Figure 29: Reactivity of C20/02 with LMS. LMS are different HBV subviral-particles, each containing an amino acid substitution in the AGL. The gray columns indicate non-permissible mutant. The effect of each substitution on the recognition of C20/02 was tested in ELISA. C20/02 did not detect LMS having substitutions of cysteine with serine in addition, G119A, P120A, T140A, K141A, D144A, G145A, and N146A (unpublished data).

Thus both our 4608_RPL and Dr. Sureau's LMS experiments showed that the binding site of the C20/02 might include three parts within AGL, the N-terminal, in the middle part, and the C-terminal sequences. Since the HBsAg 3D structure has not been determined (Ren, Tsubota et al. 2006), our results could be of great help in constructing a 3D model of HBsAg. 


\subsubsection{Reactivity of Q19/10 mAb}

Q19/10 (provided by Prof. Dr. Wolfram Gerlich, Institute of Medical Virology, University of Giessen) was generated by immunizing mice with purified $\mathrm{HBsAg} / \mathrm{adw}$ subviral particles from a chronic HBV carrier. Q19/10 target sequence is the $\mathrm{N}$ terminus of the preS2 of the middle hepatitis B surface antigen (MHBsAg), i.e. the N-glycosylated aa 1-6 of preS2 (MQWNST) of MHBsAg (Heermann, Waldeck et al. 1988; Glebe, Aliakbari et al. 2003). When screened on an HBV chip. Q19/11 did not recognize peptides. This was expected because this antibody is glycan-dependent. Interestingly, it recognizes 20 peptides within the 4608_RL (figure 30 and table 13). One of these peptides (spot number: Q41B9) contains MCWNSA, which shared 4 residues with aa 1-6 of preS2 of MHBsAg (expectation value 0.019) (red in table 13).

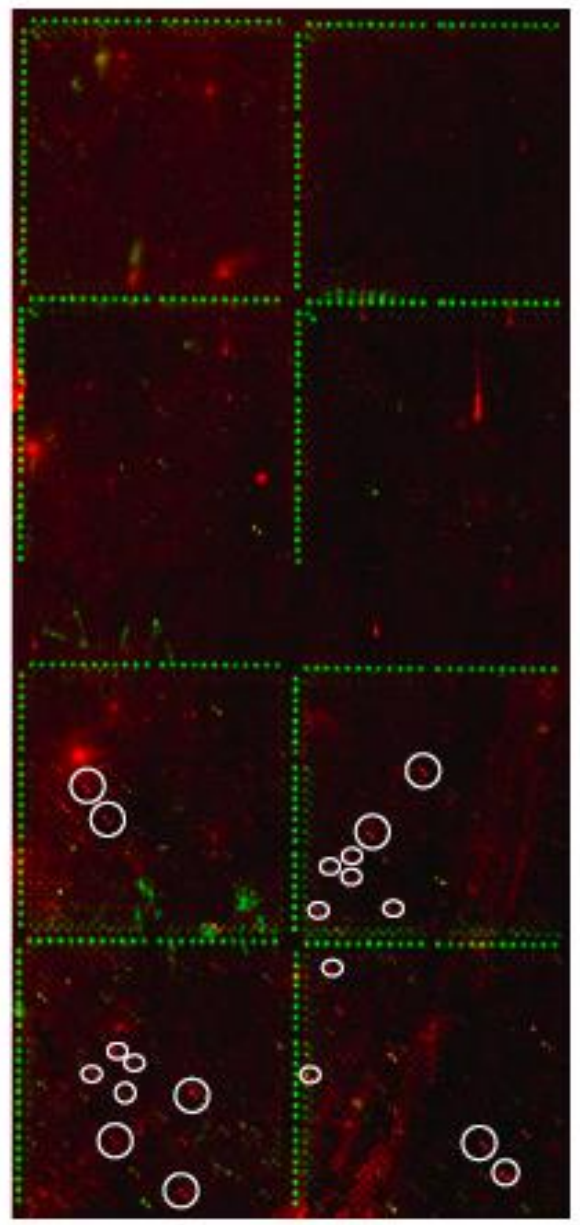

Table 13: The peptides reactive with the Q19/10 mAb.

\begin{tabular}{|c|l|l||}
\hline Nr. & \multicolumn{1}{|c|}{$\begin{array}{c}\text { Spot } \\
\text { number }\end{array}$} & \multicolumn{1}{|c|}{ Sequence } \\
\hline 1 & Q29C6 & ARAESPRNFWRRCCL \\
\hline 2 & Q29F8 & NYDRLYRREPGTGGN \\
\hline 3 & Q41B9 & SAMCWNSAVRTIWRA \\
\hline 4 & Q41C11 & RCRFPYGMMANKWGL \\
\hline 5 & Q41D7 & YMGTPWFFAAPFMRR \\
\hline 6 & Q41F10 & HRWYIPHIFGRFDGK \\
\hline 7 & Q45B9 & PWINCVVCKAFHHNP \\
\hline 8 & Q46G3 & LVVRFCINKVIRFIT \\
\hline 9 & Q42F4 & YVEHVAYVELNRRYL \\
\hline 10 & Q31A12 & RSWYRKQTINNMNIT \\
\hline 11 & Q31G7 & GRCGVWYGNKCYARW \\
\hline 12 & Q35A5 & CGVGFSRSTIMNYRG \\
\hline 13 & Q35B3 & RFRWIHPHRHMFHGN \\
\hline 14 & Q35C5 & CLNWYWMPSVIRQRW \\
\hline 15 & Q35F1 & DCTVTHGHGTLCYRF \\
\hline 16 & Q35F9 & YFGKITRCVNRHYQK \\
\hline 17 & Q39B3 & IHYSSCLICVIMKMA \\
\hline 18 & Q43D1 & ISPTTKGQYAEGQSV \\
\hline 19 & Q48B5 & CRYFQYYNNCLPPIM \\
\hline 20 & Q48E7 & QMWYVYCMDAGYRYR \\
\hline
\end{tabular}

Figure 30: Q19/10 mAb screened with 4608_RPL. The reactive peptides are circled in white. 
The reactivity of Q19/10 mAb with peptides of the 4608_RPL, which lack the glycans, might indicate that the Q19/10 did not detect the glycan itself. But the glycan rather helps to present the epitopes in a way compatible with binding and this structure effect can be mimicked by an appropriate aa sequence. Several studies showed N-linked glycosylation influences on the protein folding (figure 31). A study presented the importance of glycosylation in determining peptide antigen structure and function. Synthesized glycosylated and phosphorylated versions of the two peptides were compared with the native peptide using CD and FT-IR spectroscopy. The data showed that incorporation of glycan into peptides resulted, with a high probability, in a type I $\beta$-turn formation (Otvos, Thurin et al. 1991). Huang X and his colleagues prepared glycosylated analogues of the principal neutralizing determinant of HIV gp120 and studied their conformations by NMR and circular dichroism spectroscopies. Moreover, they studied the binding affinity of $0.5 \beta \mathrm{mAb}$ with these particles. The data showed that glycosylation of gp120 peptides could affect their conformations as well as their interactions with antibodies (Huang, Barchi et al. 1997).

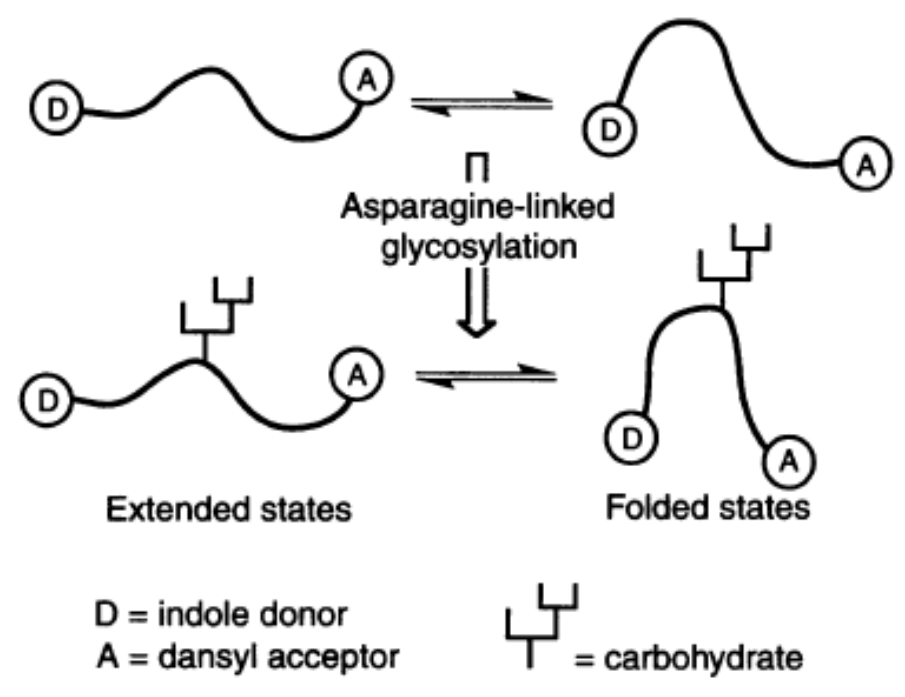

Figure 31: Influence of N-glycosylation on peptide folding (Imperiali and Rickert 1995).

Another observation made with the 20 positive peptides was that the YR motif presented 6 times (expectation value 0.7) (blue in table 13). Currently, there is no explanation for the reactivity of Q19/10 with such a motif. 


\subsubsection{Reactivity of EVA332 mAb}

The EVA 332 mAb from Drs. C. Thiriart and C. Bruck was provided by the EU Programme EVA Center of AIDS Reagent, attached to NIBSC, UK. EVA332 was generated by immunizing mice with recombinant HIV-1 gp160 from yeast. The reactive sequence of EVA332 was found to be aa 101-120 (VEQMHEDIISLWDQSLKPCV) (Thiriart, Francotte et al. 1989; Moore, Sattentau et al. 1994). It recognized no peptides when screened with the HIVenv chip.

Screening with the 4608_RPL revealed 178 reactive peptides (figure 32, table S5). Feeding their sequences into the motif recognition program "Meme" lead to $[\mathrm{VT}] \mathrm{E}[\mathrm{HQR}][\mathrm{MC}][\mathrm{QN}] \mathrm{C}[\mathrm{KG}] \mathrm{G}$ as a suggested target for EVA332. The first four positions of the motif contain aa $101-104$ of gp120 (VEQM). This sequence is equivalent to the first four positions of the targets identified earlier. The last four positions of the motif contain the string 377 - 380 of gp120 (NCGG). This might indicate that EVA332 recognizes a discontinuous epitope composed of the two strings VEQM and NCGG. The reactivity of the EVA332 in the competition assay of Thiriart et al., 1989 might be due to specific experimental conditions, e.g. concentrations of $\mathrm{mAb}$, and/or peptides sufficient for $\mathrm{mAb}$ binding with low affinity. 


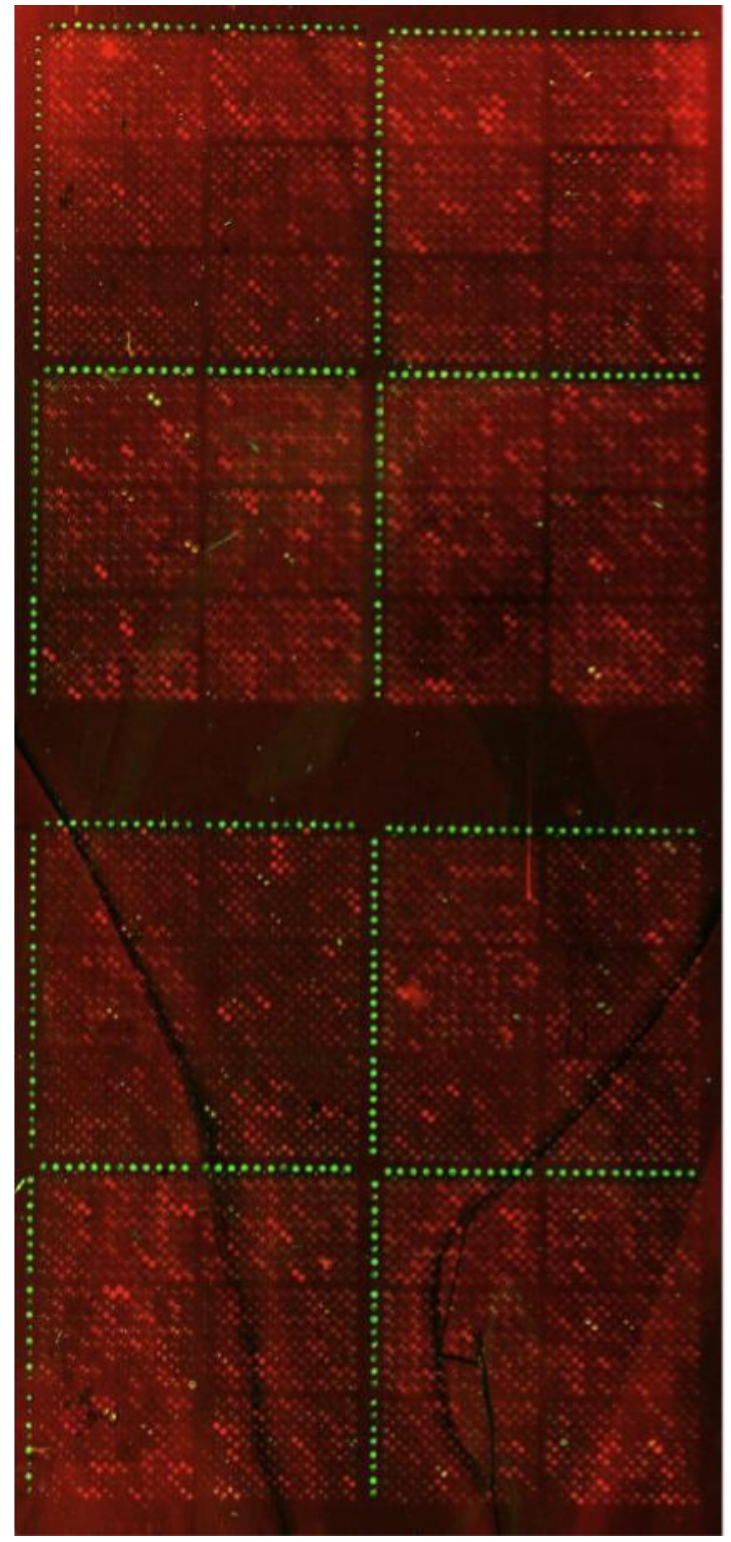

Figure 32: EVA332 mAb screened with 4608_RPL.

\subsubsection{No unambiguous results obtained with the random peptide library despite clear identification of target sequence on the scanning chip}

The target sequences of 6 mAbs (2.11B1, HB, ARP301, ARP3051, EVA3046, EVA3048) were identified using the scanning chips (table 14). Screening them with the 4608_RPL derived a number of reacting spots (table 14) but the targets could not be determined. However, the targets of mAbs MA18/7 and EVA3047 could be identified with the 4608_RPL. This might be explained by the short target size of 4 aa of MA18/7 and EVA3047, while targets of HB1 and EVA3048 comprised six residues, of 2.11B1, ARP301, and ARP3051 nine, and of EVA3046 twelve residues. Moreover, our random 
library contains 4608 15-mere peptides. To detect motifs of 6, 9, or 12 aa, a larger random peptide library might be needed.

Table 14: Target sequence and the recognized peptide of six mAbs.

\begin{tabular}{|c|c|c|}
\hline Mab & Target sequence & Recognized peptides on \\
\hline HB1 & $\begin{array}{l}\text { aa 121-126 of SHBsAg } \\
\text { (CKTCTT) }\end{array}$ & $\begin{array}{c}45 \\
\text { (figure } \mathbf{S} 1 \text { \& table } \mathbf{S 6} \text { ) }\end{array}$ \\
\hline $\begin{array}{l}\text { EVA3048 (IIIB- } \\
\text { V3-21) }\end{array}$ & $\begin{array}{l}\text { aa 295-300 of HIV gp120 } \\
\text { (NCTRPN) }\end{array}$ & $\begin{array}{c}12 \text { strong responders only } \\
\text { (figure } \mathbf{S} 2 \& \text { table } \mathbf{S} 7 \text { ) }\end{array}$ \\
\hline 2-11B1 & $\begin{array}{l}\text { aa } 1-11 \text { of preS2 of } \mathrm{HBsAg} \\
\text { (MQWNSTTFH) }\end{array}$ & $\begin{array}{c}31 \\
\text { (figure } \mathbf{S} 3 \& \text { table } \mathbf{S} 8 \text { ) }\end{array}$ \\
\hline ARP301(221) & $\begin{array}{l}\text { aa } 475-482 \text { of HIV gp120 } \\
\text { (MRDNWRSEL) }\end{array}$ & $\begin{array}{c}62 \\
\text { (figure } \mathbf{S} 4 \& \text { table } \mathbf{S} 9 \text { ) }\end{array}$ \\
\hline $\begin{array}{l}\text { ARP3051 } \\
(4 \mathrm{D} 7 / 4))\end{array}$ & $\begin{array}{l}\text { aa } 370-378 \text { of HIV gp120 } \\
\text { (EIVTHSFNC) }\end{array}$ & $\begin{array}{l}23 \text { strong responder only } \\
\text { (figure } \mathbf{S} 5 \text { \& table } \mathbf{S} 10 \text { ) }\end{array}$ \\
\hline $\begin{array}{l}\text { EVA3046 (IIIB- } \\
\text { V3-01) }\end{array}$ & $\begin{array}{l}\text { aa } 319-330 \text { of HIV gp120 } \\
\text { (TIGKIGNMRQAH) }\end{array}$ & $\begin{array}{c}7 \\
\text { (figure } \mathbf{S} 6 \text { \& table } \mathbf{S} 11 \text { ) }\end{array}$ \\
\hline
\end{tabular}

\subsubsection{Synopsis and general conclusions}

Use of the scanning chips (HIVenv and HBV) is a simple, rapid (6 hours) and reliable method to detect linear targets of mAbs. Targets of all mAbs used in this study focusing on linear sequence were identified using the scanning chips. The 4608_RPL contained targets of antibodies recognizing different types of epitopes; continuous 4 aa in length, discontinuous, and those with modified residues. However, the 4608_RPL could not identify sequences of mAbs detecting continuous epitopes of 6, 9, or 12 aa. Nevertheless, mimics of targets of these mAbs were detected. The 4608_RPL is the starting point towards developing a larger library that could serve as a universal tool to identify antibody targets (one chip serves all). There are several programs available online to identify mAbs targets. Some of them were successful with one mAb but not with others. Consequently, a special program that extracts the target-motifs from 4608_RPLbinding peptides is needed. 


\subsection{Reactivity of human sera to the HBV chips}

HBV epiopes recognized by sera from HBV-vaccinated or -infected humans were identified with HBV microarray and miniarray.

\subsubsection{Sera from HBV-vaccinated individuals}

Two types of HBV vaccine are currently on the market. (1) Engerix-B (yeastderived vaccine), the most widely used HBV vaccine contains only the SHBsAg produced in Hansenula polymorpha. (2) Bio-Hep-B (mammalian-derived vaccine), less widely used, contains the complete HBsAg comprising preS1, preS2 and SHBsAg produced in Chinese hamster ovary cells (Shouval 2003; Zhou, Wu et al. 2009). Both vaccines protect against HBV infection.

\subsubsection{Epitopes detected by Engerix-B-vaccinated individuals}

Forty-eight serum samples (provided by Dr. Angela Uy, UMG, Göttingen, and Prof. Dr. Wolfram Gerlich, University of Giessen) from healthy individuals vaccinated with Engerix-B were screened with HBV miniarray. 23/48 sera detected the CKTCTT motif (121-126 of SHBsAg, Ep\#11 in table 17) on the HBV miniarray (figure 33A). Mouse sera (gift from Prof. Wolfram Gerlich, University of Giessen) obtained after vaccination with SHBs particles produced in yeast (like Engerix-B) also recognized the CKTCTT motif. Moreover, Folgori et.al., identified the same motif in a phage display library with two sera from immunized individuals (Folgori, Tafi et al. 1994). Since only about $50 \%$ of Engerix-B-vaccinated individuals had made antibodies against the CKTCTT motif, the high titers of all sera against HBsAg is best explained by additional antibodies reactive to discontinuous HBsAg epitopes. The presence of antibodies against glycosylated epitopes was excluded because the Engerix-B vaccine contains unglycosylated SHBsAg (Valenzuela, Medina et al. 1982).

Other studies detected reactivity of serum samples from individuals vaccinated with HBV-yeast-derived vaccine (like Engerix-B) to both the cyclic and linear forms of peptides corresponding to aa 139-147 of SHBsAg (Brown, Howard et al. 1984; Brown, Stanley et al. 1986; Emini, Ellis et al. 1986). The affinity of antibodies for the cyclical form of the peptide was higher than for the linear form. However, the linear of this peptide presented in the HBV microarray chip used in this study did not produce a signal 
from the 48 human sera examined. These conflicting results may be explained by a difference in the detection assays, while in the studies mentioned above, the peptides were presented to the antibodies in high concentrations and in liquid. The antigen is fixed onto glass slides in the microarray chip. Surprisingly, aa 139-147 of SHBsAg was a part of the discontinuous epitope recognized by the $\mathrm{C} 20 / 02 \mathrm{mAb}$ (section 3.2.4.1). It might be that sera from vaccinees are able to detect the same discontinuous epitope as the $\mathrm{C} 20 / 02 \mathrm{mAb}$.

A

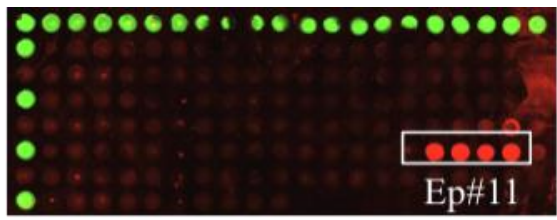

$\mathrm{B}$

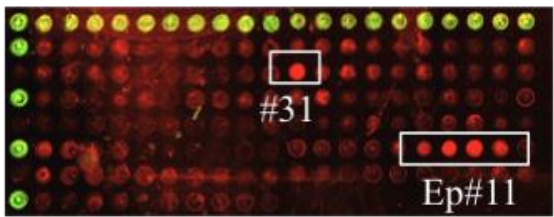

$\mathrm{C}$

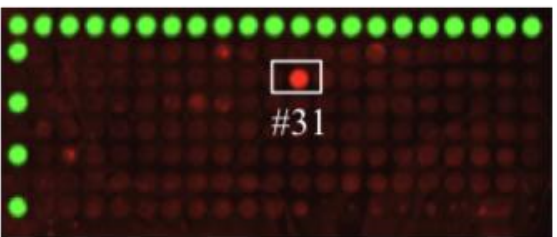

$\mathrm{D}$
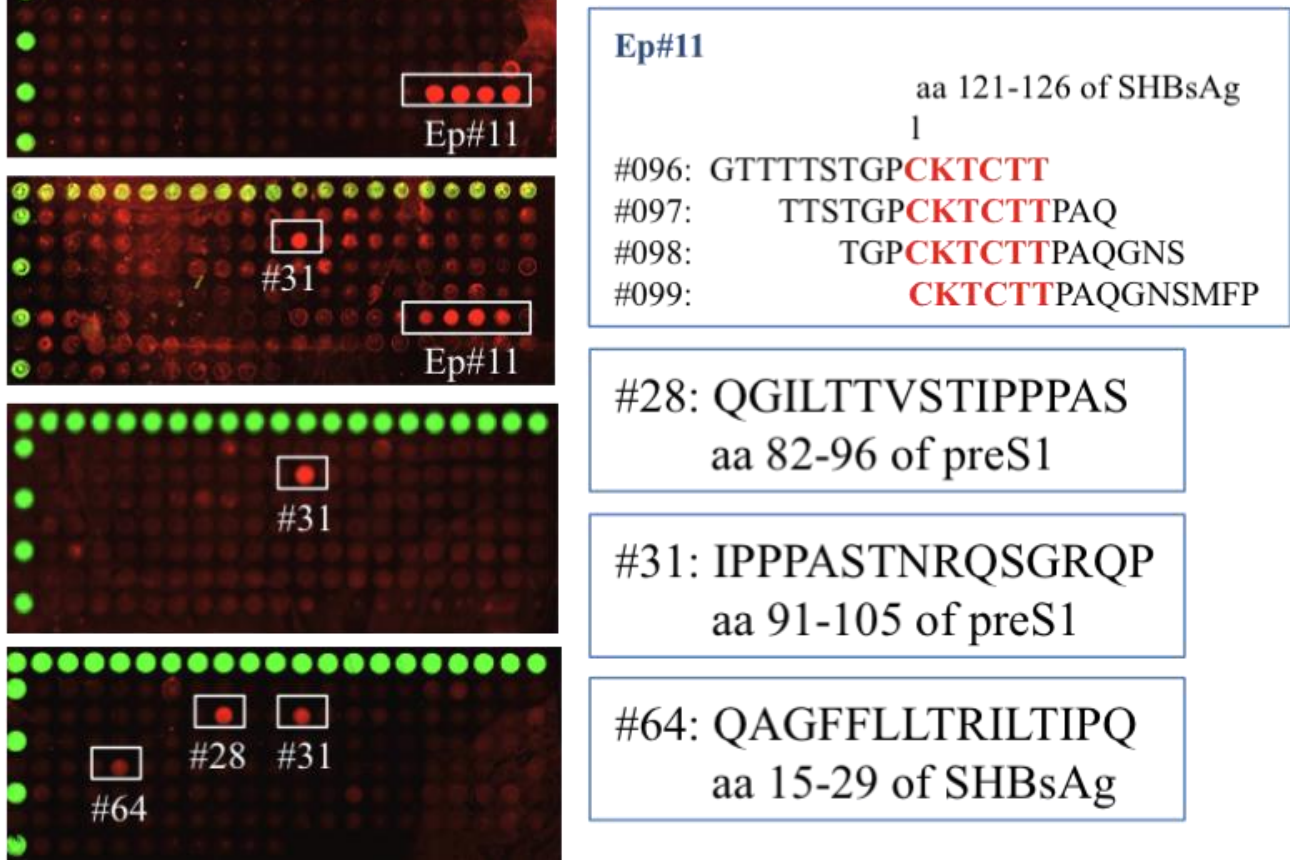

Figure 33: Serum reactivity on the HBV miniarray of 4 Engerix-B vaccinees.

3/48 sera recognized additional peptides: \#28, \#31, and \#64 (figure 33B, C \& D). Interestingly, peptides \#28 and \#31 are located in preS1 sequence. However, Engerix-B vaccine contains only the SHBsAg. Thus these individual were either infected with HBV or exposed to other pathogens with HBV-homologous sequences. Surprisingly, the sera reacted only with a single spot, while mAbs tested in this study reacted with at least 2 spots. 


\subsubsection{Epitopes detected by Bio-Hep-B-vaccinated individuals}

Serum samples from $6 \mathrm{HBV}$-infected patients vaccinated with the Bio-Hep-B vaccine (not yet approved in Germany) were provided by Prof. Dr. Michael Roggendorf, Institute of Virology, University Clinic Essen. From each patient, pre- and postvaccination sera were examined. The first individual recognized the same epitopes in both samples; individuals 2-5 did not detect any epitope, while patient number 6 had antibodies to one epitope prior to vaccination (table 15). Interestingly, this reactivity was lost after vaccination.

Table 15: Screening sera from Bio-Hep-B-vaccinated individuals with HBV chips.

\begin{tabular}{|c|c|c|}
\hline \multirow[t]{2}{*}{ Individual No. } & \multicolumn{2}{|c|}{ Recognized epitopes } \\
\hline & Pre-vaccination & Post-vaccination \\
\hline 1 & $\begin{array}{l}\text { 46-KVGAGAFGL-54 of preS1 } \\
\text { 26-SVRDLLDNASALYR-39 of } \\
\text { HBcAg }\end{array}$ & $\begin{array}{l}\text { 46-KVGAGAFGL-54 of preS1 } \\
\text { 26-SVRDLLDNASALYR-39 of } \\
\text { HBcAg }\end{array}$ \\
\hline 2 & -- & -- \\
\hline 3 & -- & -- \\
\hline 4 & -- & -- \\
\hline 5 & -- & -- \\
\hline 6 & $\begin{array}{l}\text { 184- VVRRRDRGRSPR-195 of } \\
\text { HBcAg }\end{array}$ & -- \\
\hline
\end{tabular}

Hellstrom et. al., examined the reactivity of 28 healthy newborns vaccinated with Bio-Hep-B vaccine with three synthetic peptides representing aa 21-32, aa 32-47 and aa 94-117 of the prS1. (Hellstrom, Madalinski et al. 2009). Fifty precent of the sera detected aa $21-32,54 \%$ aa $32-47$ and $43 \%$ aa $94-117$. Interestingly, with sera available for this study, these three epitopes were never detected, probably due to the fact that they were derived from $\mathrm{HBV}$-infected individuals producing an excess of $\mathrm{HB}$ subviral particles (Chai, Chang et al. 2008; Patient, Hourioux et al. 2009). Also the HBsAg discontinuous epitopes seemed to play an important role in protection (Chen, Delbrook et al. 1996; Germaschewski and Murray 1996). 


\subsubsection{Sera from $\mathrm{HBV}$-infected patients (inf-Pa) in the recovery phase}

72 inf-Pa sera (provided by Dr. Angela Uy, UMG, Göttingen) had antiHBs titer ranging from 175 to $>1000 \mathrm{iu} / \mathrm{ml}$ (AXSYM, Abbott). Independence from the antiHBs titer, 14/72 sera reacted with peptides on the HBV microarray (table 16). It could will be that the 58/72 non-reactive sera contained only antibodies to SHBsAg discontinuous epitope (Park, Cho et al. 2000).

Serum number HBV_\#01 in table 11 detected 3 epitopes (Ep\#10, Ep\#11, and Ep\#16); in addition, it reacts with all HBV serotypes (figure 34A). Serum HBV_\#14 also reacted with Ep\#11 but not all HBV serotypes (figure 34B). These two HBV-infected patients were vaccinated with the HBV-yeast-derived vaccine (Engerix-B) as a therapeutic trial. Ep\#11 was also identified with sera from individuals vaccinated with the same vaccine as a preventive measure (see section 3.3.1.1). With the limited number of serum samples employed in this study, Ep\#11 was only detected with sera from individuals vaccinated with Engerix-B but not with sera from infected but unvaccinated individuals. However the number of samples was too low to draw further conclusions.
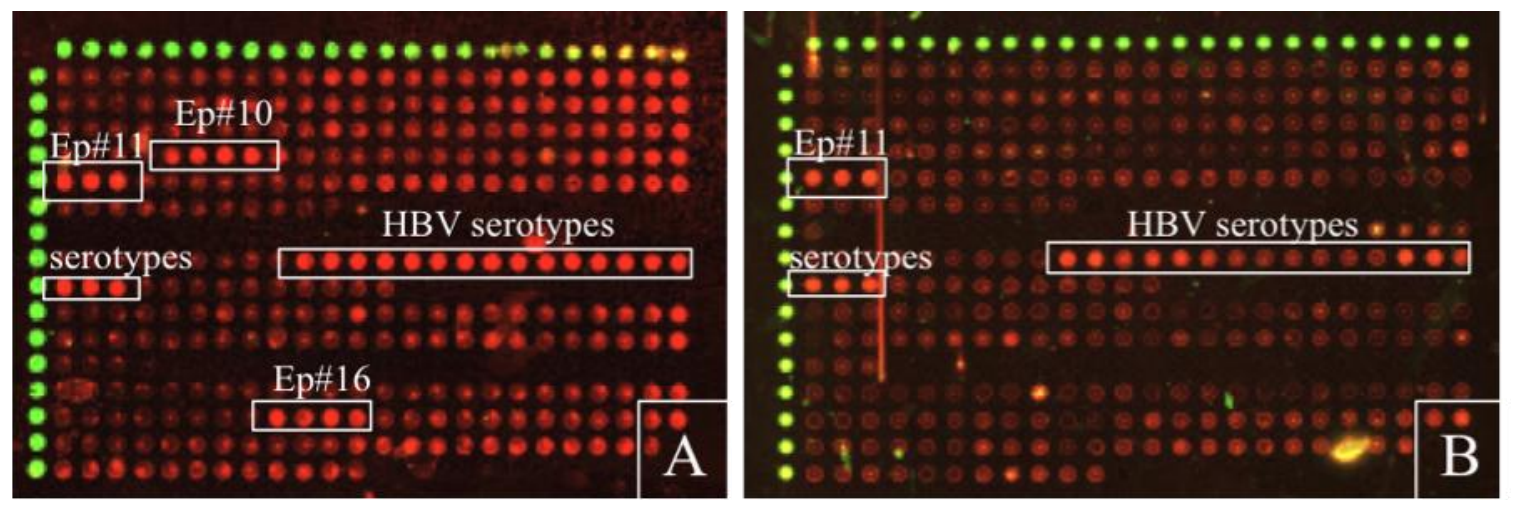

Figure 34: Reactivity of HBV_\#01 (A) and HBV_\#14 (B) on HBV chip. The epitope numbers are shown above the reacting peptides.

Serum HBV_\#02 recognized 4 other epitopes (Ep\#02, Ep\#07, Ep\#14, and Ep\#15) (figure 35). Many sera recognized epitopes of either genotypes A or D, e.g. Ep\#1 and Ep\#3 (table 17). Others detected epitopes from both genotypes, e.g. Ep\#02, and Ep\#04 (table 17). Overall, 14/72 reactive inf-Pa identified 17 epitopes (Table 17, and figure $34 \&$ 35). 10 epitopes (Ep\#1 through Ep\#9 plus Ep\#11) have been identified earlier (Alberti, Cavalletto et al. 1990; Folgori, Tafi et al. 1994; Germaschewski and Murray 1996; Park, 
Cho et al. 2000; Zhang, Wan et al. 2001). However, the remained 7 epitopes (Ep\#10, and Ep\#12- Ep\#17) identified with the HBV microarray chip were detected for the first time.

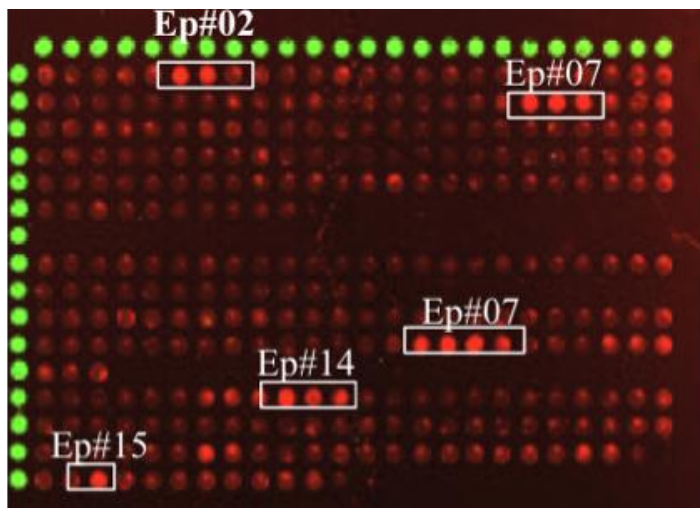

Figure 35: Reactivity of sample number HBV_\#02 on HBV chip. The epitope numbers are shown above the reacting peptides.

Table 16: HBsAg epitopes reactive with sera from HBV-infected patients in the recovery phase.

\begin{tabular}{|c|l|l|l|l|c|}
\hline \multicolumn{1}{|c|}{ No. } & \multicolumn{1}{|c|}{ Code } & $\begin{array}{c}\text { Anti- } \\
\text { HBs } \\
\text { titer } \\
\text { IU/ml }\end{array}$ & $\begin{array}{c}\text { Anti- } \\
\text { HBc }\end{array}$ & \multicolumn{1}{|c|}{ The identified epitope } & Figure \\
\hline HBV_\#01 & $7701 / 07$ & $>1000$ & + & Ep\#10, Ep\#11, Ep\#16 & $34 A$ \\
\hline HBV_\#02 & $10168 / 07$ & $>1000$ & + & Ep\#02, Ep\#07, Ep\#14, Ep\#15 & 35 \\
\hline HBV_\#03 & $10658 / 07$ & $>1000$ & + & Ep\#02, Ep\#04, Ep\#07 & S7 \\
\hline HBV_\#04 & $9912 / 07$ & 323 & + & Ep\#07, Ep\#14, Ep\#15 & S8 \\
\hline HBV_\#05 & $10748 / 07$ & 265 & + & Ep\#03, Ep\#09 & S9 \\
\hline HBV_\#06 & $9922 / 07$ & 175 & + & Ep\#09, Ep\#12 & S10 \\
\hline HBV_\#07 & $10282 / 07$ & $>1000$ & + & Ep\#07, Ep\#09 & S11 \\
\hline HBV_\#08 & $10248 / 07$ & $>1000$ & + & Ep\#02, Ep\#04, Ep\#07 & S12 \\
\hline HBV_\#09 & $10283 / 07$ & $>1000$ & + & Ep\#06, Ep\#13 & S13 \\
\hline HBV_\#10 & $8927 / 07$ & $>1000$ & + & Ep\#02 & S14 \\
\hline HBV_\#11 & $8698 / 07$ & 809 & + & Ep\#08, Ep\#09, Ep\#17 & S15 \\
\hline HBV_\#12 & $12071 / 07$ & 1004 & + & Ep\#01, Ep\#09 & S16 \\
\hline HBV_\#13 & $5097 / 07$ & 1472 & + & Ep\#02, Ep\#05 & S17 \\
\hline HBV_\#14 & $60 / 08$ & $>1000$ & + & Ep\#11 & $34 B$ \\
\hline
\end{tabular}


Table 17: Sequence and position of the epitopes recognized by sera of $\mathrm{HBV}$-infected patients in the recovery phase.

\begin{tabular}{|c|c|c|c|}
\hline $\begin{array}{l}\text { Epitope } \\
\text { Number }\end{array}$ & Sequence recognized & Position & $\begin{array}{c}\text { Number of sera } \\
\text { detecting the } \\
\text { epitope }\end{array}$ \\
\hline Ep\#01 & GTNLSV & aa 2-7 of preS1, genotype A & 1 \\
\hline Ep\#02 & $\begin{array}{l}\text { LGFFPD } \\
\text { PLGFFP }\end{array}$ & $\begin{array}{l}\text { aa } 11-16 \text { of preS1, genotype A } \\
\text { aa } 10-16 \text { of preS1, genotype D }\end{array}$ & 5 \\
\hline Ep\#03 & NSNNPD & aa 26-31 of preS1, genotype A & 1 \\
\hline Ep\#04 & $\begin{array}{l}\text { PHGGVLGWSPQA } \\
\text { PPHGGLLGW }\end{array}$ & $\begin{array}{l}\text { aa } 59-70 \text { of preS1, genotype A } \\
\text { aa 58-66 of preS1, genotype D }\end{array}$ & 2 \\
\hline Ep\#05 & PTPLSP & aa $94-99$ of preS1, genotype D & 1 \\
\hline Ep\#06 & PQAMQWNST & $\begin{array}{l}\text { aa } 106-108 \text { of preS1, genotype D + } \\
\text { aa } 1-6 \text { of preS2, genotype D }\end{array}$ & 1 \\
\hline Ep\#07 & $\begin{array}{l}\text { DPKVRGLYF } \\
\text { QDPRVRGLY }\end{array}$ & $\begin{array}{l}\text { aa } 13-21 \text { of preS2, genotype A } \\
\text { aa } 12-20 \text { of preS2, genotype D }\end{array}$ & 5 \\
\hline Ep\#08 & TVNPVP & aa $31-36$ of preS2, genotype D & 1 \\
\hline Ep\#09 & $\begin{array}{l}\text { PISSIFSRIGD } \\
\text { HISSIS } \\
\quad \text { ARTGDPVTNMEN }\end{array}$ & $\begin{array}{l}\text { aa } 39-49 \text { of preS2, genotype D } \\
\text { aa } 39-44 \text { of preS2, genotype A } \\
\text { aa } 45-53 \text { of preS2, genotype A + } \\
\text { aa 1-3 of SHBsAg, genotype A }\end{array}$ & 5 \\
\hline Ep\#10 & SCPPIC & aa $63-68$ of SHBsAg, genotype A & 1 \\
\hline Ep\#11 & CКTCTT & aa $121-126$ of SHBsAg genotype A & 2 \\
\hline Ep\#12 & SSWAFAKYL & aa $153-161$ of SHBsAg genotype A & 1 \\
\hline Ep\#13 & IVSPFIPLL & aa $207-215$ of SHBsAg genotype A & 1 \\
\hline Ep\#14 & PYKMDIDPY & aa $-3-6$ of $\mathrm{HBcAg}$, genotype A & 2 \\
\hline Ep\#15 & $\begin{array}{l}\text { SVRDLLDNASALYRE } \\
\text { PSVRDLLDTASALYR }\end{array}$ & $\begin{array}{l}\text { aa 26-40 of HBcAg,genotype D } \\
\text { aa 25-39 of } \mathrm{HBcAg} \text {, genotype A }\end{array}$ & 2 \\
\hline Ep\#16 & TWVGNN & aa $70-75$ of $\mathrm{HBcAg}$ genotype $\mathrm{A}$ & 1 \\
\hline Ep\#17 & PRRRRSP & aa $165-171$ of $\mathrm{HBcAg}$ genotype A & 1 \\
\hline
\end{tabular}


Interestingly, Ep\#02, Ep\#07, and Ep\#09 were detected with the highest frequency (tables 16 \& 17). In ongoing experiments with Prof. Dr. Stephan Urban, Department of Molecular Virology, University Clinic Heidelberg, IgG fractions will be isolated from human sera reacted with Ep\#02, Ep\#07, and Ep\#09 in order to examine the reactivity with 4608_RPL. This will answer the question of whether antibodies from different sera recognize a similar set of random peptides.

Ep\#2 recognized by five sera resides at the most $\mathrm{N}$-terminal end of the HBV preS1 region. This region is important for HBV infectivity (Gripon, Le Seyec et al. 1995; Bruss, Hagelstein et al. 1996). Studies are underway to examine whether antibodies to Ep\#2 neutralize HBV.

As seen in figures 33, 34, and 35, unfractionated sera created a background noise in the microarray, which is absent when purified mAbs are used (figures 16, 17, 19 and 20). As a negative control, sera from HBV-unvaccinated and HBV-negative individuals were screened with HBV microarray chips.

\subsubsection{Synopsis and general conclusions}

HBV contain three antigens, $\mathrm{HBsAg}, \mathrm{HBcAg}$ and $\mathrm{HBeAg}$, recognized by sera from HBV-infected individuals. The HBsAg comprises three antigenic regions: preS1, preS2 and SHBsAg. These three regions contain continuous epitopes (Alberti, Cavalletto et al. 1990; Folgori, Tafi et al. 1994; Germaschewski and Murray 1995; Germaschewski and Murray 1996; Park, Cho et al. 2000; Zhang, Wan et al. 2001; Hellstrom, Madalinski et al. 2009). These epitopes can be detected on the HBV microarray with sera from HBVinfected and/or -vaccinated individuals. Moreover, the microarrays detect continuous epitopes on the SHBsAg and HBcAg not identified earlier. The motif CKTCTT (aa 121126 of SHBsAg, Ep\#11) was only detected by sera from humans or mice inoculated with a yeast-derived HBV vaccine. The lack of reactivity of human sera with high HBs antibody titer on the HBV microarray is explained by the recognition of discontinuous epitopes. Screening the HBV serum samples from vaccinated individuals using the 4608_RPL failed due to both pre-immunized and post-immunized sera identifying the same pattern of peptides on the 4608_RPL. Affinity-purified antibodies from human sera are needed to identify motifs on 4608_RPL. 


\subsection{Reactivity of monkey sera to the HIVenv chips}

Mapping targets of antibodies produced following vaccination is of great value for monitoring vaccination efficacy since targets may be identified as responsible for viral load reduction and protection. Monkey sera from three different immunization experiments conducted in the DPZ were screened with HIVenv chips (Dr. Christiane Stahl Hennig, Infection Models Unit, DPZ, provided us with these sera). In the first experiment (E1) (figure 36), DNA prime/MVA expressing HIV and SIV antigens were used (Stolte-Leeb, Bieler et al. 2008) and in the second (E2) (figure 37) DNA prime/Ad5 expressing also HIV and SIV antigens (Stahl-Hennig, Suh et al. 2007) were used. In the third experiment (E3) another adenovirus/SIV construct was employed. Immunized monkeys were challenged with SHIV 89.6P in E1 and E2 and with SIV mac239 in E3 and as a secondary challenge in E2.

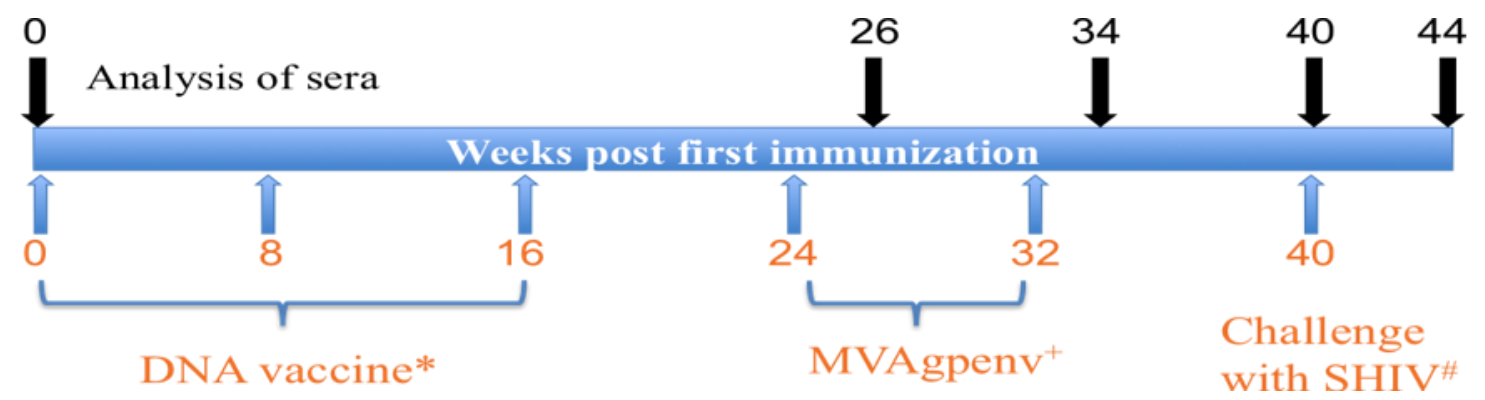

Figure 36: Vaccination regime and timing of sera collection in E1. * DNA vaccine: SIV gag/pol and HIV-1 env genes; ${ }^{+}$MVAgpenv: MVA expressing SIV gag/pol and HIV-1 89.6env; ${ }^{*}$ SHIV: simian-human immunodeficiency virus $89.6 \mathrm{P}$.

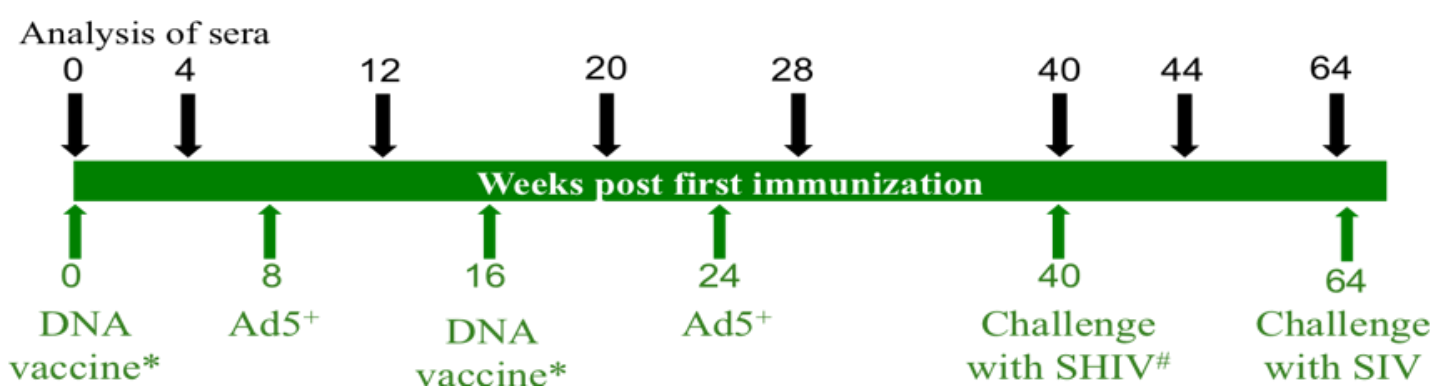

Figure 37: Vaccination regime and timing of sera collection in E2. * DNA vaccine: SIV Gag-Env, sPol, sVif-Nef and sTat-Vpx and HIV-1 Gag-Env and Tat-Vpu genes and other adjuvant gene; ${ }^{+}$Ad5: adenoviruses expressing SIV, HIV-1 and adjuvant genes (SIV Env, sPol, sVif-Nef and sTat-Vpx and HIV-1 Gag-Env and Tat-Vpu); ${ }^{\#}$ SHIV: simian-human immunodeficiency virus 89.6P. 
Overall monkey sera from E1 (tables $\mathbf{S} 13$ \& $\mathbf{S} 14)$ and E2 (table $\mathbf{S} 15)$ recognized 14 epitopes on the HIVenv chip (table 18 and figure 38). In these two experiments both HIV and SIV genes were included in the vaccine. Thus the question was whether the identified epitopes were specific for HIVenv and/or SIVenv. Monkeys of E3 were immunized only with adenovirus/SIV components. Monkey sera from E3 were screened with HIVenv chips. These sera did not recognise peptides on the HIVenv chip. Thus, epitopes identified with sera from E1 and E2 were due to HIV but not SIV immunization.

In E1, 11 epitopes were identified with a distribution between gp120 and gp41 of 8:3, while with E2 (8 epitopes), this ratio was 3:5 (table 18 and figure 38). These results show that the MVA used in E1 seems to facilitate preferentially the recognition of gp120 epitopes, while the adenovirus of E2 induces mainly antibodies to gp41 epitopes.

Five epitopes (HIV_Ep\# 05, 08, 10, 11 and 12) (table 18 and dark blue triangle in figure 38) were identified with sera from both E1 and E2 as well as control groups (tables $\mathbf{S} 12$ \& S16). Their presence was not correlated with reduced vial load.

Table 18: Epitopes mapped with monkey sera samples.

\begin{tabular}{|c|c|c|c|c|c|c|c|}
\hline \multirow{2}{*}{$\begin{array}{l}\text { Epitope } \\
\text { number }\end{array}$} & \multirow{2}{*}{$\begin{array}{c}\text { Spot } \\
\text { number }\end{array}$} & \multirow[t]{2}{*}{ Sequence } & \multirow[t]{2}{*}{ Site at HIVenv } & \multicolumn{4}{|c|}{ Frequency } \\
\hline & & & & E1 & $\mathbf{E 2}$ & $\mathbf{E 3}$ & control \\
\hline HIV_Ep\#01 & $23-26$ & PTDPNP & aa $76-81$ of gp120 & $03 / 08$ & - & - & - \\
\hline HIV_Ep\#02 & $34-36$ & EDIISLWDQ & aa106-114 of gp120 & 03/08 & - & - & - \\
\hline HIV_Ep\#02A & $52-54$ & NISTSIRGK & aa $160-168$ of gp120 & - & $01 / 06$ & - & - \\
\hline HIV_Ep\#03 & $68-70$ & VSFEPIPIH & aa $208-216$ of gp120 & $01 / 08$ & - & - & - \\
\hline HIV_Ep\#04 & $85-88$ & NGSLAE & aa $262-267$ of gp 120 & 03/08 & - & - & - \\
\hline HIV_Ep\#05 & $101-104$ & QRGPGR & aa $310-315$ of gp 120 & $04 / 08$ & 06/06 & - & $07 / 12$ \\
\hline HIV_Ep\#06 & $142-144$ & VGKAMYAPP & aa $450-458$ of gp120 & $02 / 08$ & - & - & - \\
\hline HIV_Ep\#07 & $154-156$ & EIFRPGGGD & aa $466-474$ of gp120 & $08 / 08$ & - & - & - \\
\hline HIV_Ep\#08 & $166-168$ & KRRVVQREK & aa $502-510$ of gp120 & 06/08 & $05 / 06$ & - & $08 / 12$ \\
\hline HIV_Ep\#09 & $178-180$ & TVQARQLLS & aa $538-546$ of gp41 & - & $01 / 06$ & - & - \\
\hline HIV_Ep\#10 & $198-201$ & KLICTT & aa $601-606$ of gp41 & 08/08 & $04 / 06$ & - & $11 / 12$ \\
\hline HIV_Ep\#11 & $\begin{array}{l}235-238 \\
238-240\end{array}$ & $\begin{array}{l}\text { YSPLSF } \\
\text { QTHLPTPRG }\end{array}$ & $\begin{array}{l}\text { aa } 712-717 \text { of gp41 } \\
\text { aa } 718-726 \text { of gp41 }\end{array}$ & 07/08 & $05 / 06$ & - & 08/12 \\
\hline HIV_Ep\#12 & $241-245$ & IEE & aa $733-735$ gp41 & 08/08 & $06 / 06$ & - & $08 / 12$ \\
\hline HIV_Ep\#13 & $280-282$ & HIPRRIRQGLE & aa $842-852$ of gp41 & - & $03 / 06$ & - & - \\
\hline
\end{tabular}




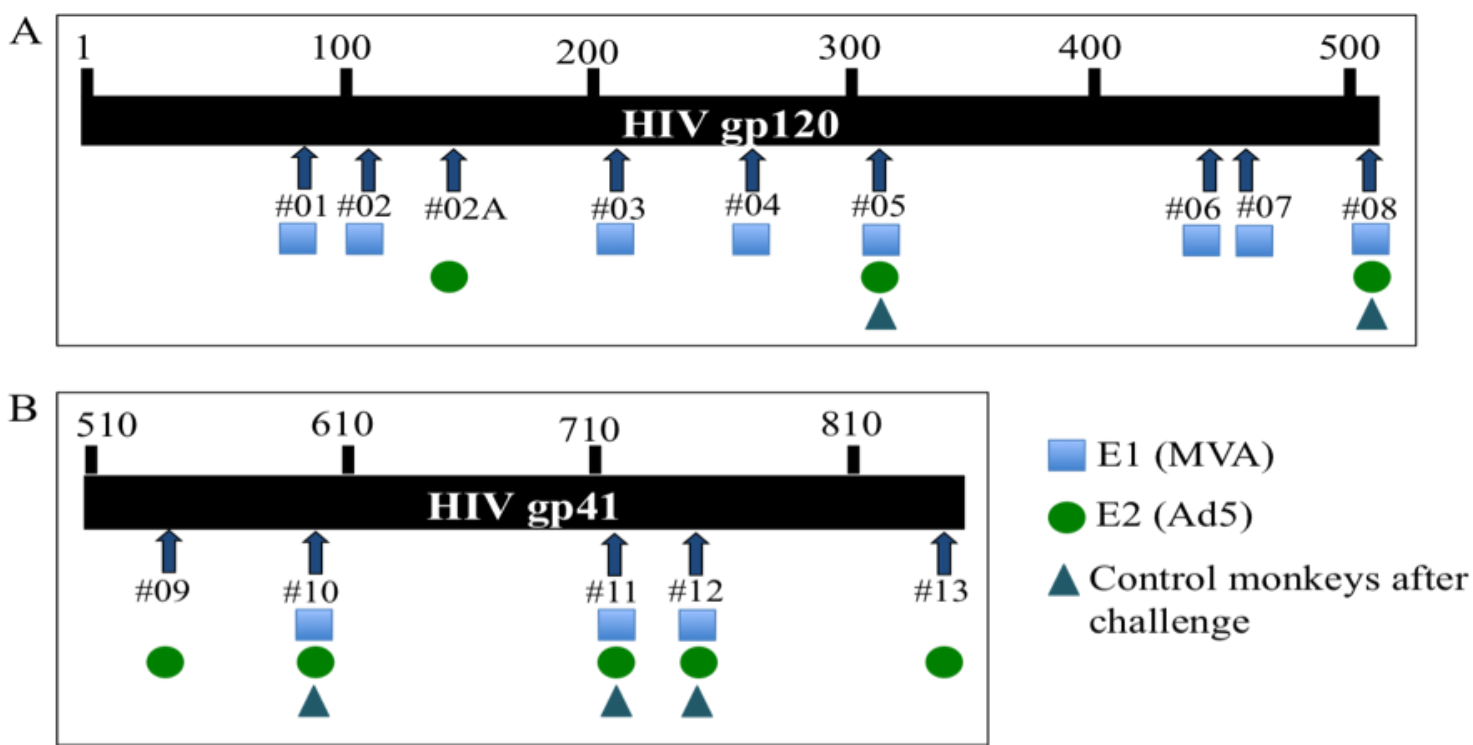

Figure 38: Locations of the 14 epitopes identified with monkey sera from E1, and E2 on gp120 (A) and gp41 (B).

Three monkeys in E2 recognized a unique epitope (HIV_Ep\# 13) (figure 39). Two out of three animals had, to some extent, a lower peak of viremia after challenge with SHIV 89.6P (monkeys ID 11985, and 11986 in figure 40). Perhaps recognition of this epitope mediates some protection. HIV_Ep\#13 is located at the C-terminal cytoplasmic tail of HIV gp41. This region has been identified earlier as a T-cell epitope (Frahm, Korber et al. 2004; Plana, Garcia et al. 2004). This is the first description of this B-cell epitope. Interestingly, the removal of this part of the HIV gp41 prevents the conformational change required for membrane fusion during viral entry (Costin, Rausch et al. 2007; Jiang and Aiken 2007).

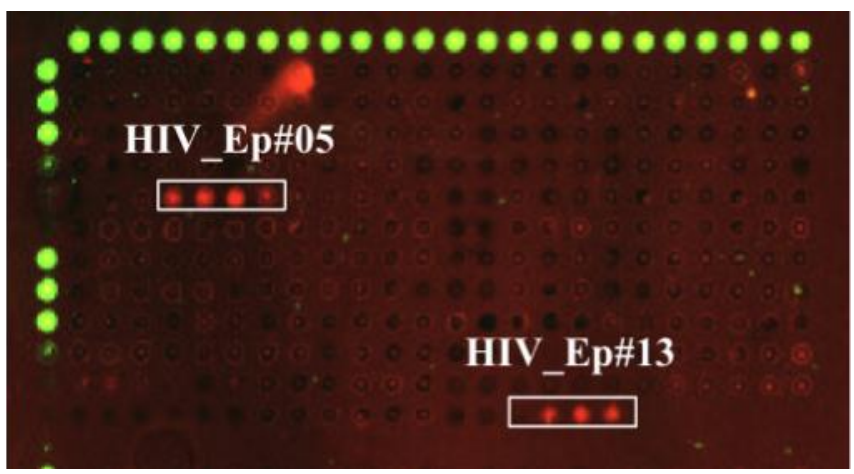

Figure 39: Reactive-peptides of one monkey serum from E2 on HIVenv chip. 


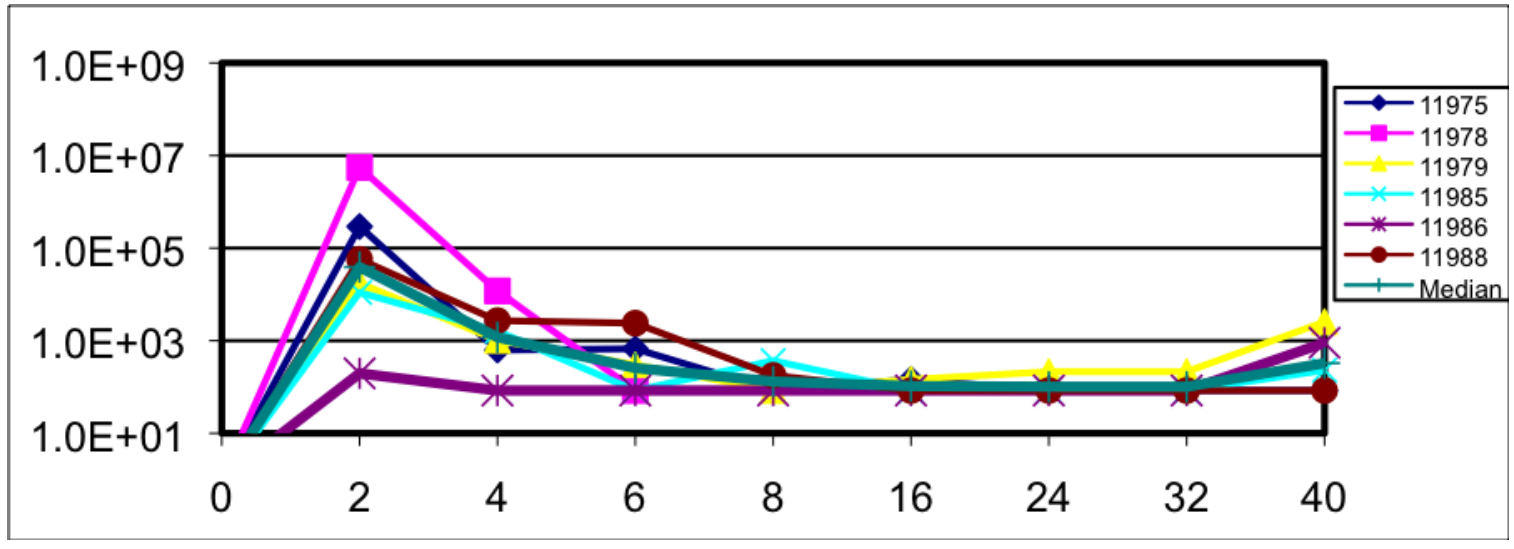

Figure 40: Viral loads in E2-vaccinated monkeys after rectal challenge with SHIV89.6P. RNA viral loads are expressed as RNA equivalents per milliliter of plasma of each animal for individual time points. The geometric mean of viral RNA copy numbers of each group at each time point is shown \pm SD (unpublished data, provided by Dr. Christiane Stahl Hennig, Infection Models Unit, DPZ).

In conclusion, 14 epitopes were mapped using monkey sera from two immunization experiments conducted in DPZ. 13/14 has been mapped before (http://www.hiv.lanl.gov/). In this study, HIV_Ep\#13 was identified for the first time as a B cell epitope. None of the immunized monkeys in these experiments is fully protected. Testing sera from fully protected vaccinees or individuals clear of the infection will give us more information about the correlation between antibody epitope and protection. Many researchers in the HIV vaccine field believed that an effective HIV vaccine must induce both broadly neutralizing antibodies and strong cell-mediated response (Baum 2010; Benmira, Bhattacharya et al. 2010). A recent study published in Science showed that a human mAb neutralizes over $90 \%$ of circulating HIV-1 isolates (Wu, Yang et al. 2010). Mapping targets of the broadly neutralizing antibody may help to design a vaccine able to produce such a response. 


\subsection{Cooperations}

\subsubsection{Neutralizing epitopes in the preS1 attachment site of hepatitis B virus are partially masked by $\mathrm{N}$-terminal myristoylation}

The preS1-domain of LHBsAg responsible for the attachment of HBV to the host cell via its N-terminal-myristoylated aa sequence 2-48 (Gripon, Le Seyec et al. 1995; Bruss, Hagelstein et al. 1996; Glebe, Urban et al. 2005; Glebe and Urban 2007). The neutralizing power of antibodies produced against this region is not known. To characterize this, the entire preS1 domains, C- and N-terminal preS1 stretches were inserted into the most immunogenic region of $\mathrm{HBcAg}$ to produce nine subviral particles (figure 41). BALB/c mice were immunized with these particles and the binding properties, and the neutralization potential of resulting antibodies were tested in vitro (figure 42) (Bremer, Sominskaya et al. 2010). The antibodies directed to the C-terminus of preS1 did not neutralize $\mathrm{HBV}$ infection in vitro, whereas, antibodies elicited to $\mathrm{N}$ terminal of preS1 (aa 2-48) strongly neutralized the infection. Interestingly, antibodies against the very $\mathrm{N}$-terminal part of preS1 (aa 1-21) were not able to neutralize although this sequence contains the most conserved part essential for HBV attachment to the cells.

To test whether the immunized mice produced antibodies against the inoculated construct, their sera were screened with the HBV microarray (figure 43). As expected, the sera identified the corresponding peptides (table 19). Sera against the preS1 N-terminus reacted mainly with peptides covering aa 1-33. Surprisingly, antibodies against preS1core constructs that contained the full aa 2-48 sequence of preS1 reacted also with peptide aa 33-48, indicating a different conformation for these constructs in comparison to those without the aminoterminal preS1 aa 2-8. However, there was a unexpected low reaction of the antibodies against preS1 (aa 20-48) in the first three spots that might be explained by sequence homologies between spots number 131-333 and 136-139 (TxNP). Interestingly, an antiserum to preS1 (aa 1-21) recognized spots 1-7, which include preS1 aa 1-33, showing again, that the nonmyristoylated $\mathrm{N}$-terminus of preS1 is very well recognized by the antibodies. Unfortunately, this antiserum did not prevent the HBV infection in vitro (figure 42). The $\mathrm{N}$-terminal myristic acid presumably masks the most conserved part of the preS1 essential for viral attachment, thereby protecting against neutralizing antibodies, whereas antibodies to neighbouring sequences neutralize very well. This was a joint work with Prof. Dr. Wolfram Gerlich, University of Giessen, and 
has been accepted for publication by the Journal of Hepatology (manuscript on the supplementary $\mathrm{CD}$ ).

A

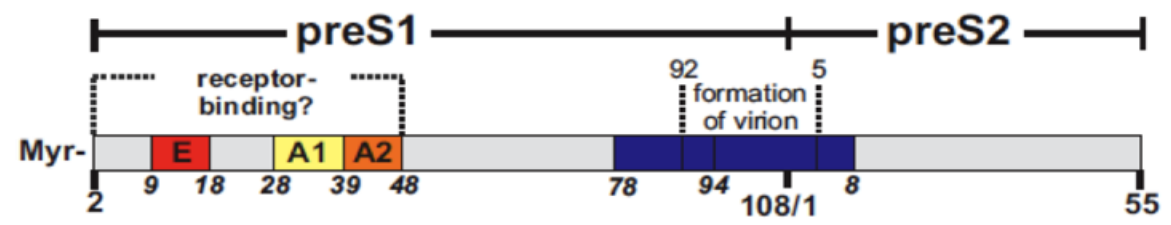

B

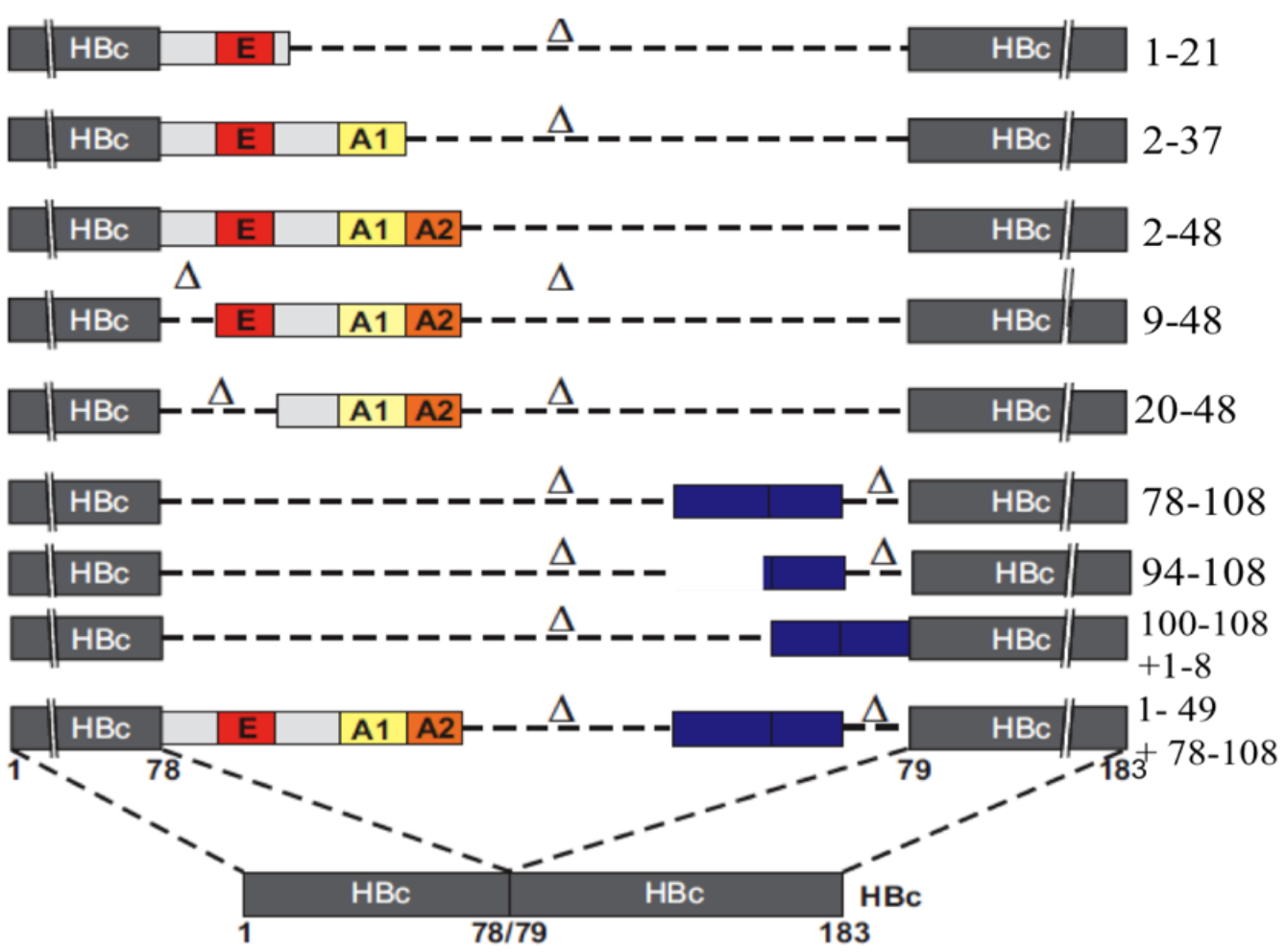

Figure 41: HBV preS-domain and peptide sequences inserted into HBc particles. (A) Structure of HB preS1 and preS2 domains. (B) PreS1 and preS2 short peptides inserted within the major immunogenic region of the HBcAg (Corinna M. Bremer, University of Giessen, personal communication). 


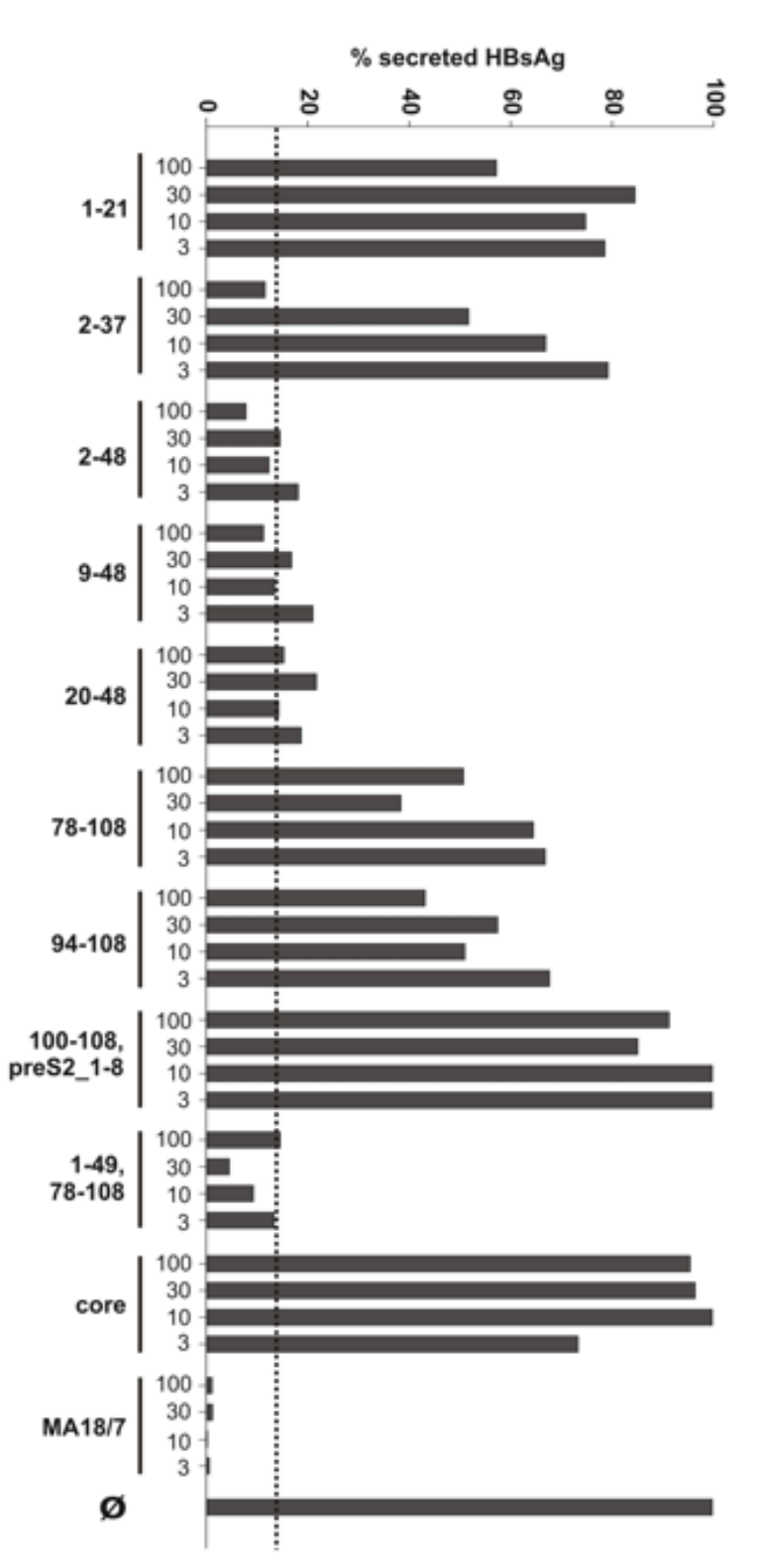

Figure 42: Neutralization of $\mathrm{HBV}$-infection with the murine sera against the subviral particles. Highly purified HBV from chronic carriers was preincubated with the sera. Then, the mixture was incubated with primary tupaia hepatocytes. The neutralization power of sera was determined by the amount of $\mathrm{HBs} \mathrm{Ag}$ produced. The dotted line indicates the detection limit for HBsAg (Bremer CM et. al., accepted Journal of Hepatology). 


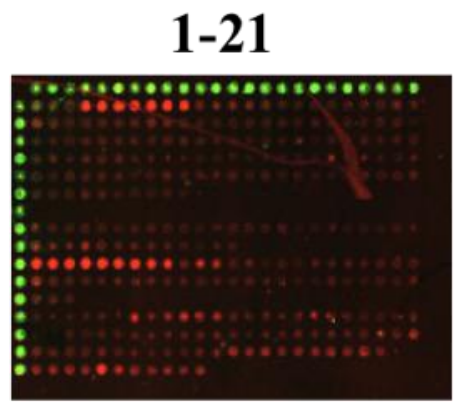

9-48

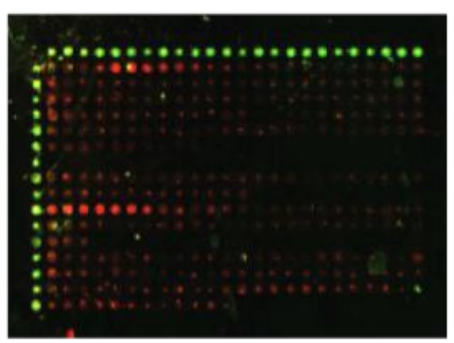

94-108

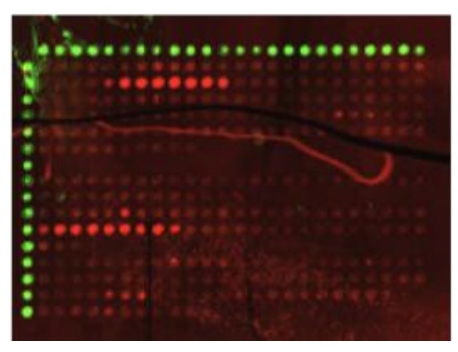

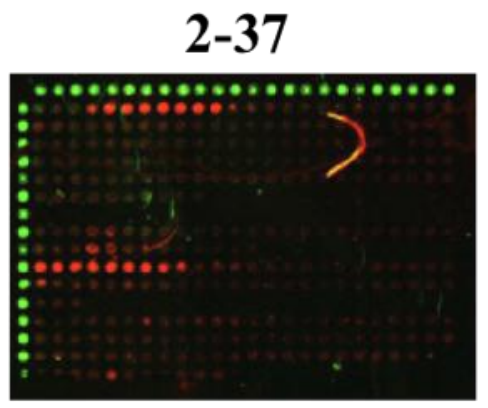

20-48

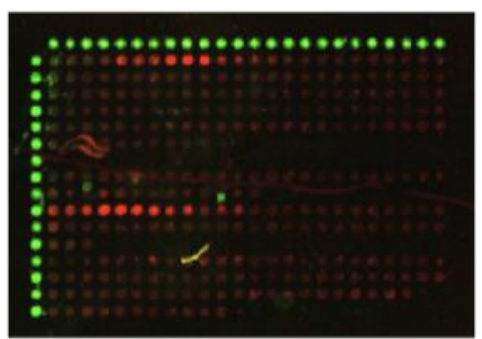

$$
100-108+1-8
$$

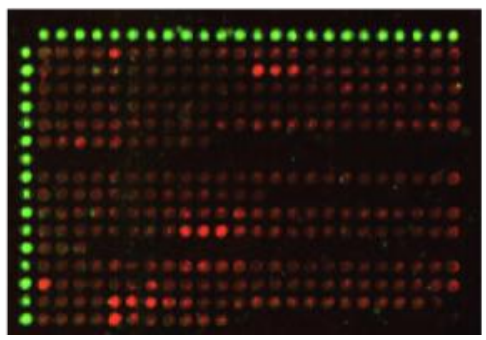

2-48

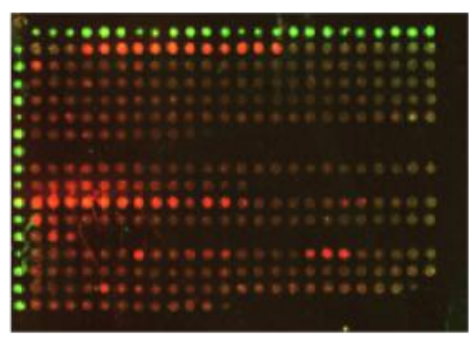

78-108

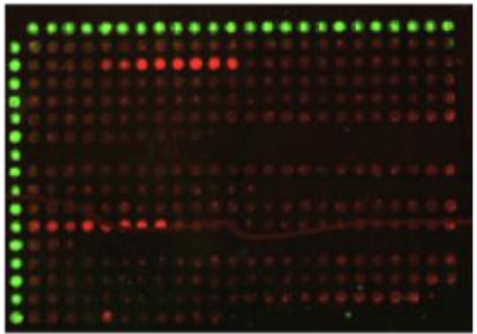

1- $49+78-108$

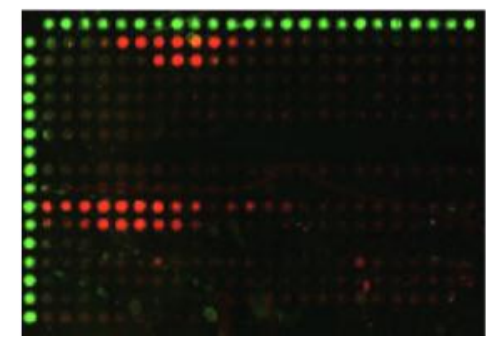

Figure 43: Reactivity of murine sera on the HBV microarray. The numbers of the reactive spots of each serum are given above each array. Sera identified sequence of both genotypes A and D. Many sera detected HBcAg sequences (1-21, 2-37, 2-48, 78-108, 94-108, 100-108+1-8, and 1-49+78-108). 
Table 19: Sequence and position of the epitopes recognized by murine sera. Only the reactivity against preS1 and preS2 of HBV genotype D is shown.

\begin{tabular}{|c|c|c|c|c|c|c|c|c|c|c|c|c|c|}
\hline Spot & Sequence & Pos & ion & $\stackrel{\vec{\Lambda}}{I}$ & $\hat{n}$ & $\stackrel{\infty}{\stackrel{\infty}{d}}$ & $\underset{\substack{+\alpha}}{\infty}$ & $\stackrel{\infty}{+}$ & $\frac{\infty}{\infty}$ & $\stackrel{\infty}{\stackrel{\infty}{q}}$ & 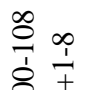 & $\begin{array}{l}\infty \\
+\infty \\
+\infty \\
\stackrel{\infty}{+}\end{array}$ & $\sum_{0}^{\infty}$ \\
\hline 168 & MGQNLSTSNPLGFFP & 1 & 15 & & & & & & & & & & \\
\hline 169 & NLSTSNPLGFFPDHQ & 4 & 18 & & & & & & & & & & \\
\hline 170 & TSNPLGFFPDHQLDP & 7 & 21 & & & & & & & & & & \\
\hline 171 & PLGFFPDHQLDPAFR & 10 & 24 & & & & & & & & & & \\
\hline 172 & FFPDHQLDPAFRANT & 13 & 27 & & & & & & & & & & \\
\hline 173 & DHQLDPAFRANTANP & 16 & 30 & & & & & & & & & & \\
\hline 174 & LDPAFRANTANPDWD & 19 & 33 & & & & & & & & & & \\
\hline 175 & AFRANTANPDWDFNP & 22 & 36 & & & & & & & & & & \\
\hline 176 & ANTANPDWDFNPNKD & 25 & 39 & & & & & & & & & & \\
\hline 177 & ANPDWDFNPNKDTWP & 28 & 42 & & & & & & & & & & \\
\hline 178 & DWDFNPNKDTWPDAN & 31 & 45 & & & & & & & & & & \\
\hline 179 & FNPNKDTWPDANKVG & 34 & 48 & & & & & & & & & & \\
\hline 192 & ILETLPANPPPASTN & 73 & 87 & & & & & & & & & & \\
\hline 193 & TLPANPPPASTNRQS & 76 & 90 & & & & & & & & & & \\
\hline 194 & ANPPPASTNRQSGRQ & 79 & 93 & & & & & & & & & & \\
\hline 195 & PPASTNRQSGRQPTP & 82 & 96 & & & & & & & & & & \\
\hline 196 & STNRQSGRQPTPLSP & 85 & 99 & & & & & & & & & & \\
\hline 197 & RQSGRQPTPLSPPLR & 88 & 102 & & & & & & & & & & \\
\hline 198 & GRQPTPLSPPLRNTH & 91 & 105 & & & & & & & & & & \\
\hline 199 & PTPLSPPLRNTHPQA & 94 & 108 & & & & & & & & & & \\
\hline 200 & LSPPLRNTHPQAMQW & 97 & 3 & & & & & & & & & & \\
\hline 201 & PLRNTHPQAMQWNST & 100 & 6 & & & & & & & & & & \\
\hline 202 & NTHPQAMQWNSTTFH & 103 & 9 & & & & & & & & & & \\
\hline
\end{tabular}

red, strong responders; yellow, weak responders; blue, preS1 sequence; green, preS2 sequence.

\subsubsection{Performance of polyclonal sera against preS1 and preS2 domains on the HBV microarray}

$\alpha-$ Myrcludex B (myristoylated aa 2-48 of HBV preS1 domain) and recombinant hexa-histidine-preS1+preS2 fusion protein produced in E.coli were used to immunize two rabbits, AMBA and H863A, respectively (this experiment was performed in Prof. Dr. Stephan Urban's laboratory). Both immunogens were derived from the genotype D sequence. Sera from AMBA and H863A were screened with HBV microarray. As expected, AMBA reacted with aa 2-48 as this antigen was used for immunization (figure 44, table 20). Interestingly, H863A identified all preS1 and preS2 sequences on the HBV microarray, except spots 186-189, 199-205, and 213-218 (table 20). Thus these latter regions are not immunogenic. Because of the sequence difference between genotype $\mathrm{A}$ and D, H863A reacted with more peptides of genotype D than of genotype A. The 
unexpected reactivity of $\mathrm{AMBA}$ and $\mathrm{H} 863 \mathrm{~A}$ sera with one peptide of $\mathrm{HBcAg}$ was detected. Perhaps these rabbits were exposed to other pathogens with HBV homologous sequences.

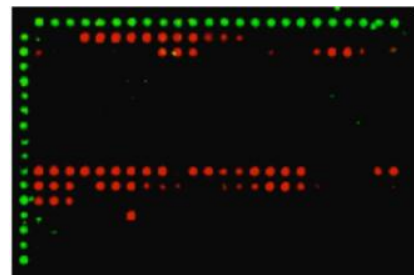

$\mathrm{H} 863$

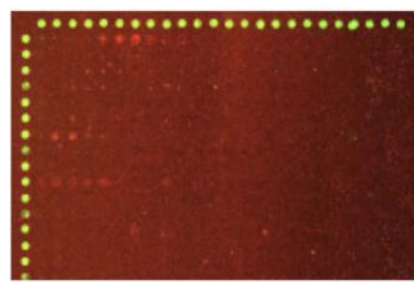

H863 preS/5-15

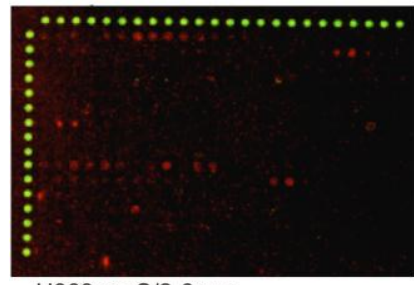

H863 preS/2-6myr

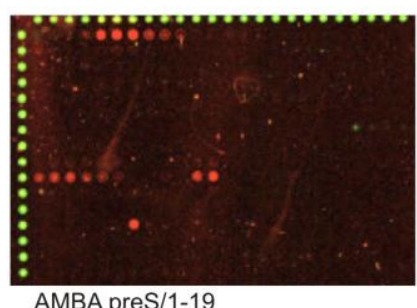

AMBA preS/1-19

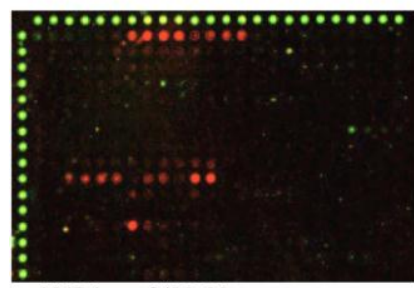

AMBA preS/20-29

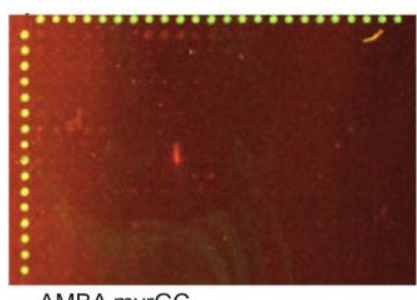

AMBA myrGC

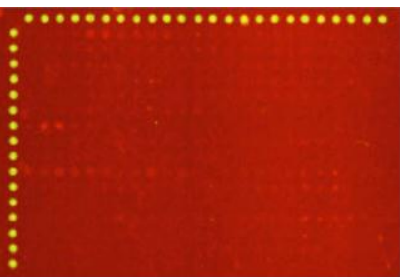

H863 preS/1-10

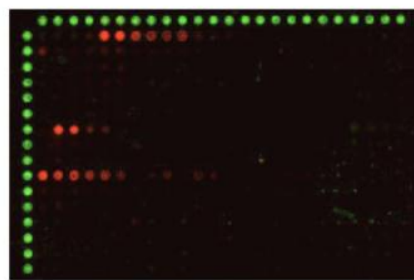

H863 preS/10-19

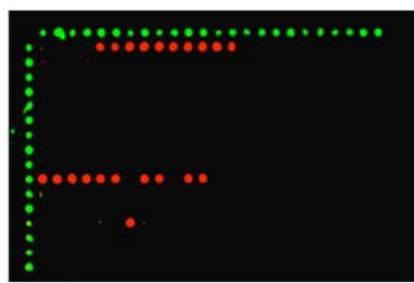

$\alpha-$ Myrcludex B

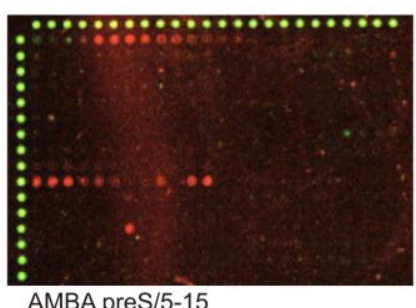

AMBA preS/5-15

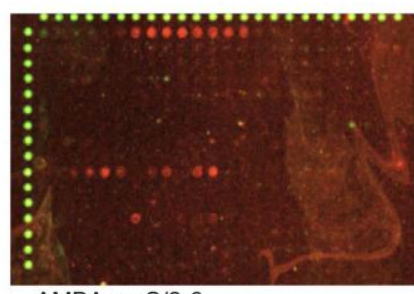

AMBA preS/2-6

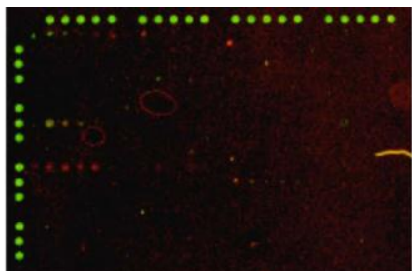

H863 preS/1-19

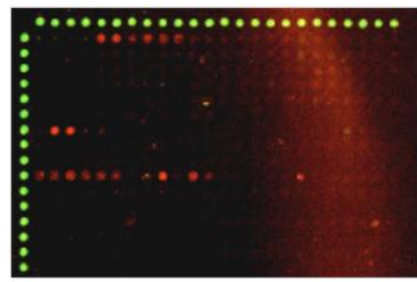

H863 preS/20-29

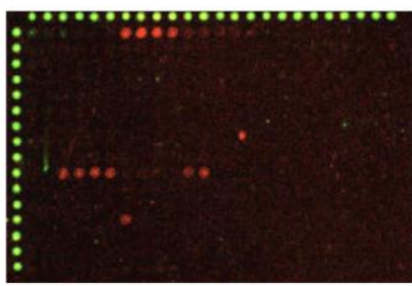

AMBA preS/1-10

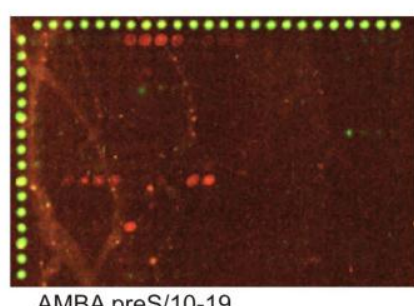

AMBA preS/10-19

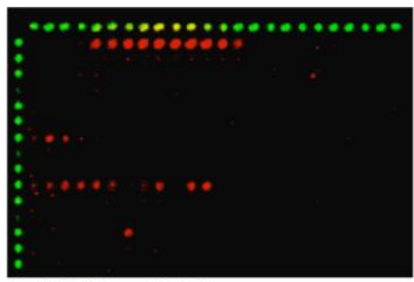

AMBA preS/2-48myr

Figure 44: Reactivity of rabbit sera AMBA and H863A with the HBV microarray. Under each array the antibody fractions eluted from affinity column loaded with the serum indicated are shown. 
Table 20: Sequence and position of the epitopes recognized by AMBA and H863A rabbit sera and their localization on the HBV microarray.

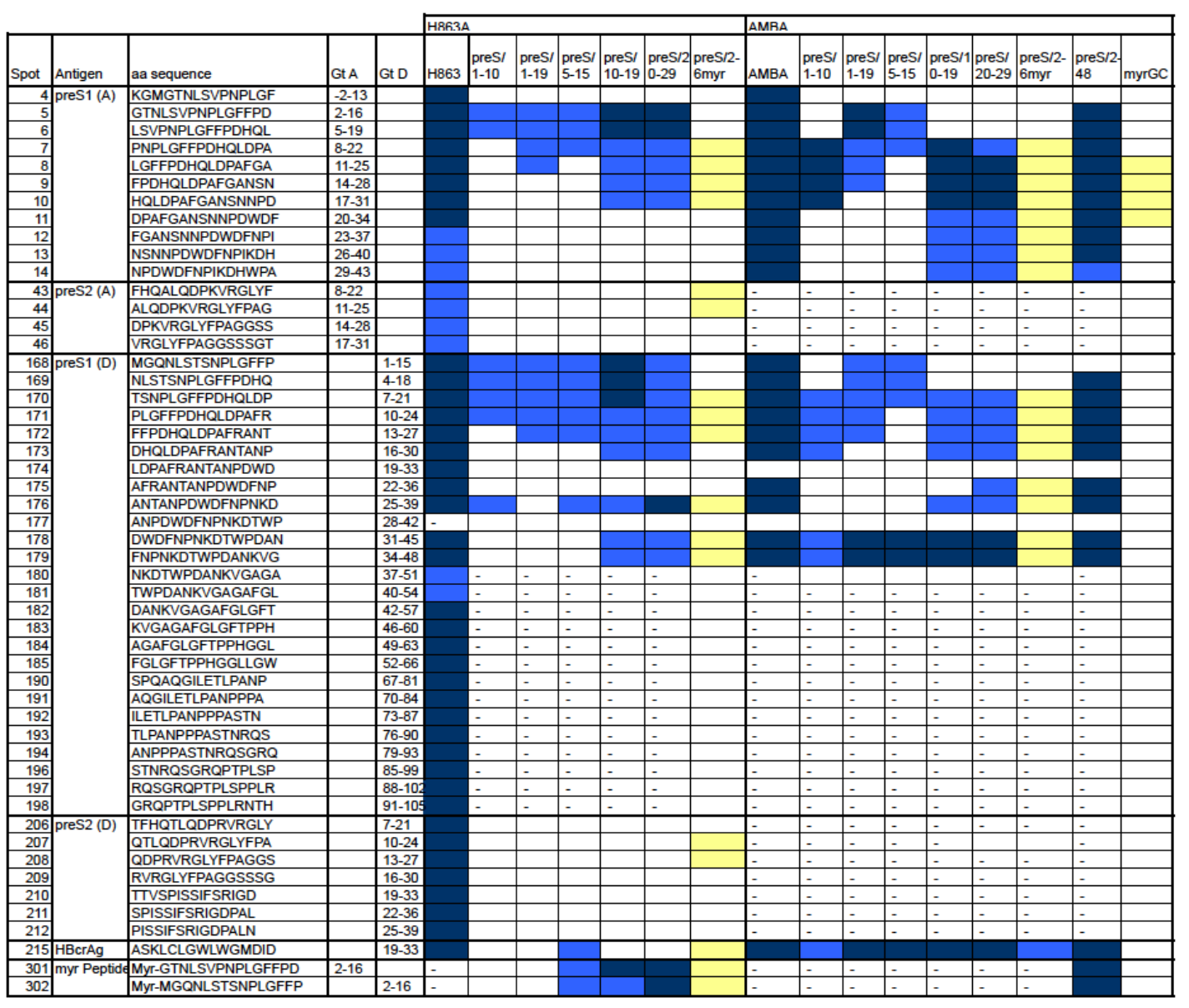

dark blue, strong responder; light blue, weak responder; yellow, signals too weak

Antibodies of AMBA and H863A sera were fractionated using peptide-coupled sepharose columns (performed at Prof. Dr. Stephan Urban's laboratory). Six preS1 peptides were used for fractionation, aa1-10, aa 1-19, aa 5-15, aa 10-19, aa 0-29, and myristoylated aa 2-6 (2-6 myr), in addition to myristoylated GC (myrGC) as control. The 6 antibody fractions of both sera were screened with the HBV microarray (figure 44, table 20). The eluted antibodies did not react as expected. Even the control myrGC-eluted antibodies reacted weakly with four peptides on the HBV microarray. Moreover, 2-6 myreluted antibodies detected peptides not included in respective sequence, probably due to a general stickiness of preS1 antibody to myristoylated peptides. The fractionation of these sera should be repeated. In conclusion, the HBV microarray was a powerful tool as a control for the quality of the fractionation experiment. This work was a part of the bachelor thesis of Angela Brand, University Hospital Heidelberg. 


\subsubsection{Identification of mimotopes of an HSV mAb, 2c using the 4608_RPL}

The $2 \mathrm{c} \mathrm{mAb}$ (provided by Prof. Dr. Michael Roggendorf, Institute of Virology, University Clinic, Essen) was generated by immunizing mice with HSV-1 strain 342. It is specific for glycoprotein B of HSV. It had been shown to mediate clearance of infection from the mucous membranes of mice and to prevent ganglionic infection. In vito, the 2c $\mathrm{mAb}$ inhibits the viral cell-to-cell spread as well as syncytium formation (Eis-Hubinger, Mohr et al. 1991; Eis-Hubinger, Schmidt et al. 1993). The target sequence of the 2c mAb is unknown and thought to be a discontinuous epitope. The $2 \mathrm{c}$ mAb was screened with the 4608_RPL. It recognized 32 peptides, 8 strongly and 24 weakly (figure 45, table 21). No common motif could be extracted. Currently, the mimotopes reacting with high affinity to the $2 \mathrm{cmAb}$ are used to immunize mice to obtain antibodies with respective properties.

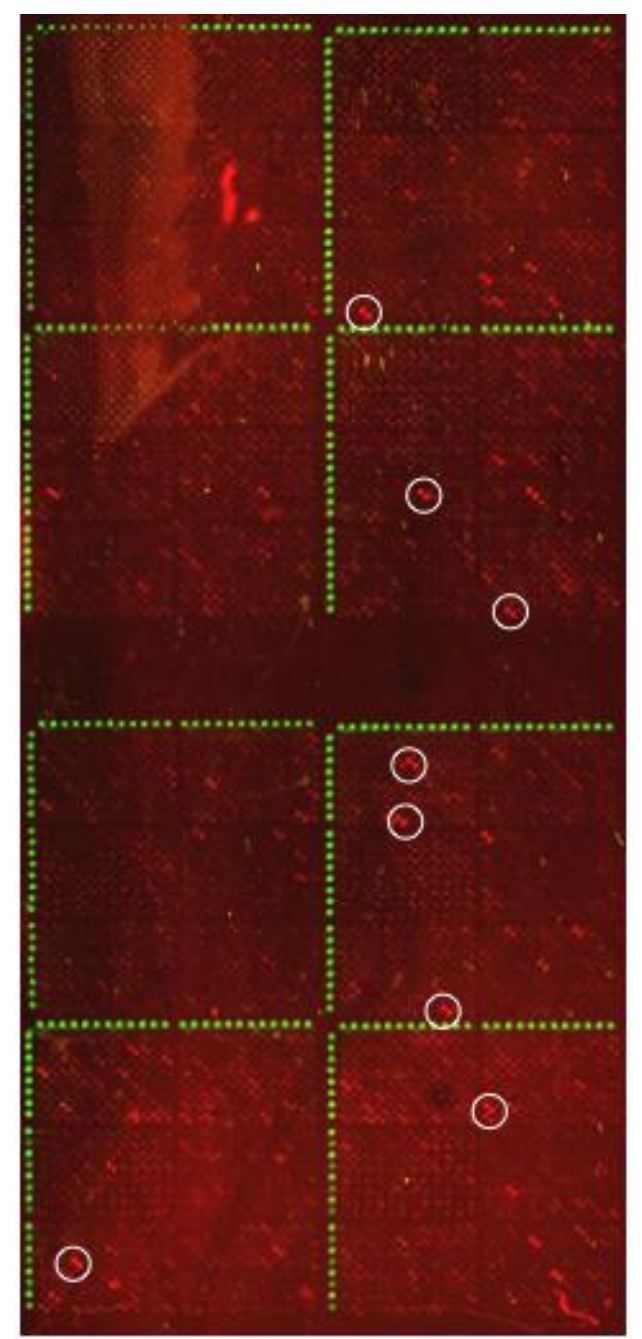

Figure 45: 2c mAb screened with 4608_RPL. The strong responders are circled in white. 
Table 21: Peptides reactive with the $2 \mathrm{c} \mathbf{m A b}$.

\begin{tabular}{|c|c|c|c|c|}
\hline No. & Spot No. & aa sequence & Reactivity & Remarks \\
\hline 1 & Q11H3 & LYAARSSDYFMCFDA & $S$ & \\
\hline 2 & Q19F8 & MWSGHTHAQDFYFNA & $S$ & \\
\hline 3 & Q24H3 & GGIFRGKPVYQEYHM & $S$ & Reacts with secondary antibody \\
\hline 4 & Q27C7 & VRDNITKQKDYFELD & $S$ & \\
\hline 5 & Q27H6 & YKWMDGYYHIAMHCF & S & \\
\hline 6 & Q35H10 & MTYCHVRYKDLNHEF & $S$ & \\
\hline 7 & Q40G1 & TWMIHVKPDCSYYMG & S & \\
\hline 8 & Q45D4 & KASESNYYCIQFSTD & $S$ & \\
\hline 9 & Q12D5 & EAEMFVLCCMSYYCT & $\mathrm{W}$ & \\
\hline 10 & Q12E1 & HAWFYCMYAGKFSTM & $\mathrm{W}$ & \\
\hline 11 & Q12G2 & WLMTNNDHYEWDDSY & $\mathrm{W}$ & \\
\hline 12 & Q18F8 & KKCNTWVNCHCYYDR & $\mathrm{W}$ & \\
\hline 13 & Q14C11 & TLCREIWCRYYYLRT & $\mathrm{W}$ & \\
\hline 14 & Q22H3 & YLIIHKMRIFARAFY & $\mathrm{W}$ & \\
\hline 15 & Q20C2 & DPRYRETQHHFHGDI & $\mathrm{W}$ & \\
\hline 16 & Q20F5 & RHKDYYCEMYNKEFH & $\mathrm{W}$ & \\
\hline 17 & Q20H8 & FPCCGMCNYDTYKQR & $\mathrm{W}$ & \\
\hline 18 & Q24E1 & KKAGVCMVSRMIRYY & $\mathrm{W}$ & \\
\hline 19 & Q24D7 & RHYIHYAAAERRFYN & $\mathrm{W}$ & Reacts with secondary antibody \\
\hline 20 & Q21B10 & QMDICVPNRAIGDDW & W & \\
\hline 21 & Q26A12 & VGINHYCQIVYTRYP & $\mathrm{W}$ & \\
\hline 22 & Q26H11 & AHHWNFYAQFRVRYY & $\mathrm{W}$ & \\
\hline 23 & Q26E3 & SRNSQCKGYMYFAVM & $\mathrm{W}$ & \\
\hline 24 & Q27C6 & WHYGKDHHYLFGAQG & $\mathrm{W}$ & \\
\hline 25 & Q27H5 & ERDFYHLCCLFYESQ & $\mathrm{W}$ & \\
\hline 26 & Q32A1 & NMYHEAWLYWEMNST & $\mathrm{W}$ & \\
\hline 27 & Q35F2 & ENTWNIWRRIYHVRW & $\mathrm{W}$ & \\
\hline 28 & Q36A3 & QSYFCEWKNRNTFDP & $\mathrm{W}$ & \\
\hline 29 & Q36A9 & SSDCASYFDVYAMSM & $\mathrm{W}$ & \\
\hline 30 & Q39F4 & RPYRSYHRRFMGWMD & $\mathrm{W}$ & Reacts with secondary antibody \\
\hline 31 & Q48B5 & CRYFQYYNNCLPPIM & $\mathrm{W}$ & \\
\hline 32 & Q48F7 & PSPFLFKSDQVYSKM & W & \\
\hline
\end{tabular}

$\mathrm{S}$, strong responder; $\mathrm{W}$, weak responder 


\section{Summary}

Mapping targets of antibodies - in particular neutralizing ones - is of great value for monitoring vaccination efficacy as well as for development of new vaccines and reagents for diagnostics. To this end, several methods (e.g. phage display libraries, peptide-based ELISA) have been used. These, however, suffer from cumbersome handling and the need for large amounts of sera, often pooled from many patients with the effect of blinding the serological analysis to individual variation. As shown here, these disadvantages can be overcome by miniaturization and parallelization.

In this study, HBV and HIVenv microarray chips with overlapping oligopeptides encompassing the full amino acid sequences of different HBV and HIV polypeptides were produced via SPOT synthesis (Frank 1992) and printed onto glass slides. In addition, a random peptide library composed of 4608 15-mers was prepared. The chips were used for analyzing mAbs and sera from HBV-infected and -vaccinated individuals as well as HIV-vaccinated monkeys.

Targets of all mAbs used in this study directed to linear sequence were identified using HIVenv and HBV microarray chips. Interestingly, using HIVenv chips, antibodies with erroneously assigned epitopes have been identified in the EVA program catalogue. Mimotopes of antibodies recognizing different types of epitopes, continuous of 4 aa in length (MA18/7, and EVA3047 mAbs), discontinuous (C20/02 mAb), and those with modified residues (Q19/10 mAb), were identified using the 4608_RPL. However, the 4608_RPL could not identify sequences of mAbs with continuous epitopes of 6, 9, or 12 aa in length, possibly because of the constrain being too high. Nevertheless, mimics of targets of these mAbs were detected.

Seventeen HBV epitopes were identified with sera from HBV-infected and/or vaccinated individuals using HBV microarrays. Seven of them were detected for the first time. The CKTCTT motif (aa 121-126 of SHBsAg) was only reactive with sera of humans inoculated with a yeast-derived HBV vaccine, whereas, sera of humans vaccinated with mammalian-derived vaccine did not identify epitopes on the HBV microarray. 
The HIVenv chips were used for screening monkey sera collected in three HIV/SIV vaccination experiments of the DPZ. In the E1, 8 rhesus monkeys were immunized with multigenic DNA prime/MVA boost vaccine, while in the second experiment E2, 6 rhesus (Stahl-Hennig, Suh et al. 2007) monkeys were immunized with DNA prime/adenovirus boost vaccine. In E3, another adenovirus/SIV construct was employed. Overall, 14 epitopes were identified. In E1, 11 epitopes were identified with a distribution between gp120 and gp41 of 8:3, while in E2 (8 epitopes), this ratio was 3:5. These results suggest that one and the same antigen, presented by two different vectors, can give rise to markedly different B-cell responses. Monkey sera from E3 did not recognise peptides on the HIVenv chip. Thus, epitopes identified with sera from E1 and E2 were due to HIV but not SIV immunization. Interestingly, three monkeys in E2 recognized a unique epitope (HIPRRIRQGLE, aa 842-852 of HIV gp41). This epitope was identified for the first time. In two-third of the monkeys, it had, to some extent, a lower peak of viremia after challenge with SHIV 89.6P. Perhaps recognition of this epitope mediates some protection. Nevertheless, more sera from vaccination experiments conducting the same regime must be tested.

Finally, the HBV and HIVenv microarray chips allowed for rapid (6 hours) and high-resolution mapping of B-cell continuous epitopes of HBV and HIV, respectively. The 4608_RPL is the starting point to develop a larger library that could serve as a universal tool to identify antibody targets (one chip serves all). 


\section{$5 \quad$ Bibliography}

Abbas, A. K., A. H. Lichtman, et al. (2010). Cellular and molecular immunology. Philadelphia, Saunders/Elsevier.

Ada, G. (2001). "Advances in immunology - Vaccines and vaccination." New England Journal of Medicine 345(14): 1042-1053.

Alberti, A., D. Cavalletto, et al. (1990). "Fine specificity of human antibody response to the PreS1 domain of hepatitis B virus." Hepatology 12(2): 199-203.

Alcami, A. and U. H. Koszinowski (2000). "Viral mechanisms of immune evasion." Trends in Microbiology 8(9): 410-418.

Avirutnan, P., E. Mehlhop, et al. (2008). "Complement and its role in protection and pathogenesis of flavivirus infections." Vaccine 26 Suppl 8: I100-107.

Baum, L. L. (2010). "Role of humoral immunity in host defense against HIV." Curr HIV/AIDS Rep 7(1): 11-18.

Benmira, S., V. Bhattacharya, et al. (2010). "An Effective HIV Vaccine: A Combination of Humoral and Cellular Immunity?" Curr HIV Res 8(6): 441-449.

Bonilla, F. A. and H. C. Oettgen (2010). "Adaptive immunity." J Allergy Clin Immunol 125(2 Suppl 2): S33-40.

Bremer, C. M., I. Sominskaya, et al. (2010). "N-terminal myristoylation-dependent masking of neutralizing epitopes in the preS1 attachment site of hepatitis B virus." J Hepatol, in press.

Brown, S. E., C. R. Howard, et al. (1984). "Determination of the affinity of antibodies to hepatitis B surface antigen in human sera." J Immunol Methods 72(1): 41-48.

Brown, S. E., C. Stanley, et al. (1986). "Antibody responses to recombinant and plasma derived hepatitis B vaccines." Br Med J (Clin Res Ed) 292(6514): 159-161.

Bruss, V., J. Hagelstein, et al. (1996). "Myristylation of the large surface protein is required for hepatitis B virus in vitro infectivity." Virology 218(2): 396-399.

Buchacher, A., R. Predl, et al. (1994). "Generation of human monoclonal antibodies against HIV-1 proteins; electrofusion and Epstein-Barr virus transformation for peripheral blood lymphocyte immortalization." AIDS Res Hum Retroviruses 10(4): 359-369.

Burton, D. R. (2002). "Antibodies, viruses and vaccines." Nat Rev Immunol 2(9): 706713.

Burton, D. R. and P. W. H. I. Parren (2000). "Vaccines and the induction of functional antibodies: Time to look beyond the molecules of natural infection?" Nature Medicine 6(2): 123-125. 
Burton, D. R. and I. A. Wilson (2007). "Square-dancing antibodies." Science 317(5844): 1507-1508.

Chai, N., H. E. Chang, et al. (2008). "Properties of subviral particles of hepatitis B virus." J Virol 82(16): 7812-7817.

Chang, J. J. and S. R. Lewin (2007). "Immunopathogenesis of hepatitis B virus infection." Immunol Cell Biol 85(1): 16-23.

Chaplin, D. D. (2010). "Overview of the immune response." J Allergy Clin Immunol 125(2 Suppl 2): S3-23.

Chen, Y. C., K. Delbrook, et al. (1996). "Discontinuous epitopes of hepatitis B surface antigen derived from a filamentous phage peptide library." Proc Natl Acad Sci U S A 93(5): 1997-2001.

Collett, J. R., E. J. Cho, et al. (2005). "Production and processing of aptamer microarrays." Methods 37(1): 4-15.

Costin, J. M., J. M. Rausch, et al. (2007). "Viroporin potential of the lentivirus lytic peptide (LLP) domains of the HIV-1 gp41 protein." Virol J 4: 123.

Cremer, N. E., C. K. Cossen, et al. (1982). "Evaluation and reporting of enzyme immunoassay determinations of antibody to herpes simplex virus in sera and cerebrospinal fluid." J Clin Microbiol 15(5): 815-823.

D'Mello, F., C. D. Partidos, et al. (1997). "Definition of the primary structure of hepatitis B virus (HBV) pre-S hepatocyte binding domain using random peptide libraries." Virology 237(2): 319-326.

Diamond, M. S. (2003). "Evasion of innate and adaptive immunity by flaviviruses." Immunol Cell Biol 81(3): 196-206.

Dikmans, A., U. Beutling, et al. (2006). "SC2: A novel process for manufacturing multipurpose high-density chemical microarrays." Qsar \& Combinatorial Science 25(11): 1069-1080.

Dranoff, G. (2004). "Cytokines in cancer pathogenesis and cancer therapy." Nat Rev Cancer 4(1): 11-22.

Eis-Hubinger, A. M., K. Mohr, et al. (1991). "Different mechanisms of protection by monoclonal and polyclonal antibodies during the course of herpes simplex virus infection." Intervirology 32(6): 351-360.

Eis-Hubinger, A. M., D. S. Schmidt, et al. (1993). "Anti-glycoprotein B monoclonal antibody protects $\mathrm{T}$ cell-depleted mice against herpes simplex virus infection by inhibition of virus replication at the inoculated mucous membranes." J Gen Virol 74 ( Pt 3): 379-385.

Emini, E. A., R. W. Ellis, et al. (1986). "Production and immunological analysis of recombinant hepatitis B vaccine." J Infect 13 Suppl A: 3-9.

Fields, G. B. and R. L. Noble (1990). "Solid phase peptide synthesis utilizing 9fluorenylmethoxycarbonyl amino acids." Int J Pept Protein Res 35(3): 161-214. 
Folgori, A., R. Tafi, et al. (1994). "A general strategy to identify mimotopes of pathological antigens using only random peptide libraries and human sera." EMBO J 13(9): 2236-2243.

Frahm, N., B. T. Korber, et al. (2004). "Consistent cytotoxic-T-lymphocyte targeting of immunodominant regions in human immunodeficiency virus across multiple ethnicities." J Virol 78(5): 2187-2200.

Frank, R. (1992). "Spot-Synthesis - an Easy Technique for the Positionally Addressable, Parallel Chemical Synthesis on a Membrane Support." Tetrahedron 48(42): 92179232.

Germaschewski, V. and K. Murray (1995). "Screening a monoclonal antibody with a fusion-phage display library shows a discontinuity in a linear epitope within PreS1 of hepatitis B virus." J Med Virol 45(3): 300-305.

Germaschewski, V. and K. Murray (1996). "Identification of polyclonal serum specificities with phage-display libraries." J Virol Methods 58(1-2): 21-32.

Glebe, D., M. Aliakbari, et al. (2003). "Pre-s1 antigen-dependent infection of Tupaia hepatocyte cultures with human hepatitis B virus." J Virol 77(17): 9511-9521.

Glebe, D. and S. Urban (2007). "Viral and cellular determinants involved in hepadnaviral entry." World J Gastroenterol 13(1): 22-38.

Glebe, D., S. Urban, et al. (2005). "Mapping of the hepatitis B virus attachment site by use of infection-inhibiting preS1 lipopeptides and tupaia hepatocytes." Gastroenterology 129(1): 234-245.

Gripon, P., J. Le Seyec, et al. (1995). "Myristylation of the hepatitis B virus large surface protein is essential for viral infectivity." Virology 213(2): 292-299.

Heermann, K. H., U. Goldmann, et al. (1984). "Large surface proteins of hepatitis B virus containing the pre-s sequence." J Virol 52(2): 396-402.

Heermann, K. H., F. Waldeck, et al. (1988). "Interaction between native human serum and the preS2 domain of hepatitis B virus surface antigen." J. Zuckerman, Editor, Viral Hepatitis and Liver Disease A. R. Liss( New York): 697-700.

Hellstrom, U. B., K. Madalinski, et al. (2009). "PreS1 epitope recognition in newborns after vaccination with the third-generation Sci-B-Vac vaccine and their relation to the antibody response to hepatitis B surface antigen." Virol J 6: 7.

Hilleman, M. R. (2002). "Realities and enigmas of human viral influenza: pathogenesis, epidemiology and control." Vaccine 20(25-26): 3068-3087.

Huang, X., J. J. Barchi, Jr., et al. (1997). "Glycosylation affects both the threedimensional structure and antibody binding properties of the HIV-1IIIB GP120 peptide RP135." Biochemistry 36(36): 10846-10856.

Imperiali, B. and K. W. Rickert (1995). "Conformational implications of asparaginelinked glycosylation." Proc Natl Acad Sci U S A 92(1): 97-101. 
Jiang, J. and C. Aiken (2007). "Maturation-dependent human immunodeficiency virus type 1 particle fusion requires a carboxyl-terminal region of the gp41 cytoplasmic tail." J Virol 81(18): 9999-10008.

Kolatkar, P. R., J. Bella, et al. (1999). "Structural studies of two rhinovirus serotypes complexed with fragments of their cellular receptor." EMBO J 18(22): 6249-6259.

Kurbanov, F., Y. Tanaka, et al. (2010). "Geographical and genetic diversity of the human hepatitis B virus." Hepatol Res 40(1): 14-30.

Laman, J. D., M. M. Schellekens, et al. (1992). "Variant-specific monoclonal and groupspecific polyclonal human immunodeficiency virus type 1 neutralizing antibodies raised with synthetic peptides from the gp120 third variable domain." J Virol 66(3): 1823-1831.

Lisowska, E. (2002). "The role of glycosylation in protein antigenic properties." Cell Mol Life Sci 59(3): 445-455.

Mahy, B. W. J. and V. Ter Meulen (2007). Topley and Wilson's microbiology and microbial infections. Virology. London, Hodder Arnold.

Mclain, L., C. Porta, et al. (1995). "Human-Immunodeficiency-Virus Type-1-Neutralizing Antibodies Raised to a Glycoprotein-41 Peptide Expressed on the Surface of a Plant-Virus." Aids Research and Human Retroviruses 11(3): 327-334.

McMahon, B. J. (2009). "The influence of hepatitis B virus genotype and subgenotype on the natural history of chronic hepatitis B." Hepatol Int 3(2): 334-342.

Meloen, R. H., W. C. Puijk, et al. (2000). "Mimotopes: realization of an unlikely concept." Journal of Molecular Recognition 13(6): 352-359.

Moore, J. P., Q. J. Sattentau, et al. (1994). "Probing the structure of the human immunodeficiency virus surface glycoprotein gp120 with a panel of monoclonal antibodies." J Virol 68(1): 469-484.

Mueller, M., S. Renzullo, et al. (2010). "Antigenic Characterization of Recombinant Hemagglutinin Proteins Derived from Different Avian Influenza Virus Subtypes." Plos One 5(2): - .

Otvos, L., Jr., J. Thurin, et al. (1991). "Glycosylation of synthetic peptides breaks helices. Phosphorylation results in distorted structure." Int J Pept Protein Res 38(5): 476482 .

Park, J. H., E. W. Cho, et al. (2000). "Determination of the protective effects of neutralizing anti-hepatitis B virus (HBV) immunoglobulins by epitope mapping with recombinant HBV surface-antigen proteins." Microbiol Immunol 44(8): 703710.

Patient, R., C. Hourioux, et al. (2009). "Morphogenesis of hepatitis B virus and its subviral envelope particles." Cell Microbiol 11(11): 1561-1570.

Plana, M., F. Garcia, et al. (2004). "Relevance of HIV-1-specific CD4+ helper T-cell responses during structured treatment interruptions in patients with CD4+ T-cell nadir above 400/mm3." J Acquir Immune Defic Syndr 36(3): 791-799. 
Plotkin, S. A. (2008). "Correlates of vaccine-induced immunity." Clinical Infectious Diseases 47(3): 401-409.

Qiu, X., P. Schroeder, et al. (1996). "Identification and characterization of a C(K/R)TC motif as a common epitope present in all subtypes of hepatitis B surface antigen." J Immunol 156(9): 3350-3356.

Reineke, U. (2004). "Antibody epitope mapping using arrays of synthetic peptides." Methods Mol Biol 248: 443-463.

Ren, F., A. Tsubota, et al. (2006). "A unique amino acid substitution, T126I, in human genotype $\mathrm{C}$ of hepatitis $\mathrm{B}$ virus $\mathrm{S}$ gene and its possible influence on antigenic structural change." Gene 383: 43-51.

Schaefer, S. (2007). "Hepatitis B virus genotypes in Europe." Hepatology Research 37: S20-S26.

Scholtissek, C. (1995). "Molecular evolution of influenza viruses." Virus Genes 11(2-3): 209-215.

Schroeder, H. W., Jr. and L. Cavacini (2010). "Structure and function of immunoglobulins." J Allergy Clin Immunol 125(2 Suppl 2): S41-52.

Shouval, D. (2003). "Hepatitis B vaccines." J Hepatol 39 Suppl 1: S70-76.

Slootstra, J. W., W. C. Puijk, et al. (1997). "Screening of a small set of random peptides: a new strategy to identify synthetic peptides that mimic epitopes." J Mol Recognit 10(5): 217-224.

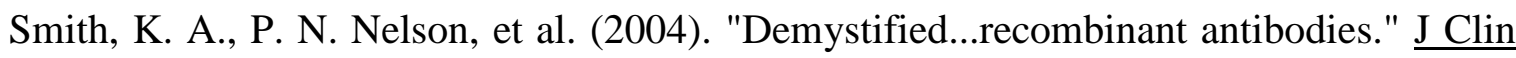
Pathol 57(9): 912-917.

Sobotta, D., I. Sominskaya, et al. (2000). "Mapping of immunodominant B-cell epitopes and the human serum albumin-binding site in natural hepatitis B virus surface antigen of defined genosubtype." J Gen Virol 81(Pt 2): 369-378.

Sominskaya, I., W. Paulij, et al. (2002). "Fine-mapping of the B-cell epitope domain at the $\mathrm{N}$-terminus of the preS2 region of the hepatitis B surface antigen." $\mathrm{J}$ Immunol Methods 260(1-2): 251-261.

Stahl-Hennig, C., S. Kuate, et al. (2007). "Atraumatic oral spray immunization with replication-deficient viral vector vaccines." J Virol 81(23): 13180-13190.

Stahl-Hennig, C., Y. S. Suh, et al. (2007). "Immunogenicity of a DNA prime and recombinant adenovirus boost regime significantly varies between rhesus macaques of Chinese and Indian origins." J Med Primatol 36(4-5): 195-205.

Stolte-Leeb, N., K. Bieler, et al. (2008). "Better protective effects in rhesus macaques by combining systemic and mucosal application of a dual component vector vaccine after rectal SHIV89.6P challenge compared to systemic vaccination alone." Viral Immunol 21(2): 235-246.

Thiriart, C., M. Francotte, et al. (1989). "Several antigenic determinants exposed on the gp120 moiety of HIV-1 gp160 are hidden on the mature gp120." J Immunol 143(6): 1832-1836. 
Tortorella, D., B. E. Gewurz, et al. (2000). "Viral subversion of the immune system." Annual Review of Immunology 18: 861-926.

Turvey, S. E. and D. H. Broide (2010). "Innate immunity." J Allergy Clin Immunol 125(2 Suppl 2): S24-32.

Valenzuela, P., A. Medina, et al. (1982). "Synthesis and assembly of hepatitis B virus surface antigen particles in yeast." Nature 298(5872): 347-350.

Vanderplasschen, A., M. Hollinshead, et al. (1997). "Antibodies against vaccinia virus do not neutralize extracellular enveloped virus but prevent virus release from infected cells and comet formation." J Gen Virol 78 ( Pt 8): 2041-2048.

Vigil, A., D. H. Davies, et al. (2010). "Defining the humoral immune response to infectious agents using high-density protein microarrays." Future Microbiol 5(2): 241-251.

Virgin, H. W., M. A. Mann, et al. (1994). "Protective Antibodies Inhibit Reovirus Internalization and Uncoating by Intracellular Proteases." Journal of Virology 68(10): 6719-6729.

von Brunn, A., M. Brand, et al. (1993). "Principal neutralizing domain of HIV-1 is highly immunogenic when expressed on the surface of hepatitis B core particles." Vaccine 11(8): 817-824.

Vossen, M. T., E. M. Westerhout, et al. (2002). "Viral immune evasion: a masterpiece of evolution." Immunogenetics 54(8): 527-542.

Weber, B. (2005). "Genetic variability of the S gene of hepatitis B virus: clinical and diagnostic impact." J Clin Virol 32(2): 102-112.

Wu, X., Z. Y. Yang, et al. (2010). "Rational design of envelope identifies broadly neutralizing human monoclonal antibodies to HIV-1." Science 329(5993): 856861.

Yinon, Y., D. Farine, et al. (2010). "Cytomegalovirus infection in pregnancy." J Obstet Gynaecol Can 32(4): 348-354.

Zhang, W. Y., Y. Wan, et al. (2001). "A mimotope of pre-S2 region of surface antigen of viral hepatitis B screened by phage display." Cell Res 11(3): 203-208.

Zhou, T. Q., L. Xu, et al. (2007). "Structural definition of a conserved neutralization epitope on HIV-1 gp120." Nature 445(7129): 732-737.

Zhou, Y. H., C. Wu, et al. (2009). "Vaccination against hepatitis B: the Chinese experience." Chin Med J (Engl) 122(1): 98-102. 


\section{Appendix (attached CD)}

6.1 Microarray Excel program

6.1.1 HBV miniarray

6.1.2 HBV microarray

6.1.3 HIVenv microarray

6.1.4 4608_RPL

6.2 Supplementary tables

6.3 Supplementary figures

6.4 Published article 


\section{$7 \quad$ List of publications}

Corinna M. Bremer, Irina Sominskaya, Dace Skrastina, Paul Pumpens, Ahmed Abd El Wahed, Ulrike Beutling, Ronald Frank, Hans-Joachim Fritz, Gerhard Hunsmann, Wolfram H. Gerlich and Dieter Glebe 'N-terminal myristoylation-dependent masking of neutralizing epitopes in the preS1 attachment site of hepatitis B virus." Journal of Hepatology, in print.

\section{List of presentations at congresses and meetings}

* is the presented Author

Beutling U., Städing K., Stradal T., Thiele S., Abd El Wahed A., Fritz H.-J., Hunsmann G. and Frank R*. Cellulose-Bound Peptide Miniarrays for Systematic Studies of PeptideProtein Interactions. The Proceedings of the 4th International Peptide Symposium in conjunction with the 7th Australian Peptide Conference and the 2nd Asia-Pacific International Peptide Symposium, 21-25 October, 2007, Cairns, Australia (oral presentation).

Abd El Wahed A. *, Beutling U., Frank R., Fritz H.-J., and Hunsmann G. Peptide miniarrays for the identification of hepatitis B virus epitopes. The XIV. International Congress of Virology, 10-15 August 2008, Istanbul, Turkey (oral presentation).

Ulrike Beutling*, Ahmed Abd El Wahed, Hans-Joachim Fritz, Gerhard Hunsmann, Kai Städing, Theresia Stradal and Ronald Frank. CELLULOSE-BOUND PEPTIDE MINIAND MICROARRAYS FOR LARGE SCALE PEPTIDE SCREENING APPLICATIONS. The 9th German Peptide Symposium, March 11 - 14, 2009, GeorgAugust-University Goettingen, Germany (poster presentation).

Ahmed Abd El Wahed*, Ulrike Beutling, Ronald Frank, Gerhard Hunsmann and HansJoachim Fritz. Rapid and accurate detection of HIV epitopes using HIVenv scanning 
chips prepared via SPOT synthesis. The 9th German Peptide Symposium, March 11 - 14, 2009, Georg-August-University Goettingen, Germany (oral presentation).

Corinna M. Bremer*, Irina Sominskaya, Dace Skrastina, Paul Pumpens, Ahmed Abd El Wahed, Hans-Joachim Fritz, Gerhard Hunsmann, Wolfram H. Gerlich and Dieter Glebe. Highly conserved and essential preS1 domain of hepatitis B virus (HBV) protected against binding of neutralising antibody by N-terminal myristoylation. 19. Annual Meeting of the German Society for Virology, 18-21. March 2009, Leipzig, Germany (oral presentation).

\begin{abstract}
Ahmed Abd El Wahed*, Ulrike Beutling, Corinna M. Bremer, Aurelia Zvirbliene, Dieter Glebe, Wolfram H. Gerlich, Ronald Frank, Hans-Joachim Fritz and Gerhard Hunsmann. Identification of HBV epitopes via a rapid microchip assay reveals large differences in the immune response to yeast-derived HBsAg and natural or mammalian cell-derived HBsAg. 2009 International Meeting The Molecular Biology of Hepatitis B Viruses. August 30 - September 2, 2009 Tours, Loire Valley, France (poster presentation).
\end{abstract}

Corinna M. Bremer*, Irina Sominskaya, Dace Skrastina. Paul Pumpens, Ahmed Abd El Wahed, Ulrike Beutling, Ronald Frank, Hans-Joachim Fritz, Gerhard Hunsmann, Wolfram H. Gerlich and Dieter Glebe. N-terminal myristoylation protects the highly conserved and essential preS1 domain of hepatitis B virus (HBV) against binding of neutralizing antibodies. 2009 International Meeting The Molecular Biology of Hepatitis B Viruses. August 30 - September 2, 2009 Tours, Loire Valley, France (poster presentation).

\footnotetext{
Ahmed Abd El Wahed*, Ulrike Beutling, Ronald Frank, Gerhard Hunsmann and HansJoachim Fritz. Hepatitis B virus (HBV) and Human immunodeficiency virus (HIV) antibodies detected by peptide microarrays. Advances in Microarray Technology congress, 25-26 May 2010, Dublin, Ireland (poster presentation).
} 
Ahmed Abd El Wahed*, Ulrike Beutling, Christiane Stahl-Hennig, Ronald Frank, Gerhard Hunsmann and Hans-Joachim Fritz. Peptide Microarray for Mapping HIVgp160 Epitopes after Vaccination of Rhesus Monkeys against HIV/SIV with Modified Vaccinia Ankara or Adenovirus Vectors. 4th Vaccine and ISV Annual Global Congress held in Vienna in 3-5 October 2010, Vienna, Austria (oral presentation). 


\section{Acknowledgments}

First of all I am greatly indebted for my work and success to our Merciful "Allah" Who gave me the ability to finish this work.

Great appreciation, profound gratitude and deepest thanks to Prof. Dr. HansJoachim Fritz and Prof. Dr. Gerhard Hunsmann for their kind supervision, valuable advice, encouragement, and pertinent suggestions during the course of this study as well as for the revision that enabled me to finish this work. I am indebted to them more than they know.

I would like to express my gratitude to Prof. Dr. Ali Ali Ibrahim El Kenawy, Head of Virology Department, Faculty of Veterinary Medicine, Mansoura University Egypt. Without his support, I would not be in Germany.

Many thanks go in particular to Dr. Ronald Frank and Ulrike Beutling, Department of Chemical Biology, HZI, Braunschweig, for teaching me the SPOT synthesis and microarray technologies, supplying the microarray chips, science discussion and the pleasure of working with them in this field. I am grateful in every possible way and hope to keep up our collaboration in the future.

I am very grateful to Dr. Gabriela Salinas-Riester and Lennart Opitz, DNA Microarray Facility, UMG Göttingen, for giving me the chance to use the Agilent microarray scanner and for helpful technical support.

I would like to thank Dr. Angela Uy, Institute for Medical Microbiology, UMG Göttingen, for supplying me with sera from HBV-infected and/or vaccinated individuals.

I owe my deepest gratitude to Dr. Christiane Stahl-Hennig, Infection Models Unit, DPZ, for supplying me with monkey serum samples from HIV/SIV immunization studies conducted at the DPZ, and for cooperation and discussions.

I am grateful to the EVA Programme, Center of AIDS Reagent, attached to NIBSC, UK, for supplying me with all HIV mAbs used in my study.

I would also like to express my gratitude to Dr. Klaus-Dieter Jentsch for giving me the chance to perform the filter membrane screening in his laboratory, and to Jutta Gloth and Andreas Kues for technical assistance. 
I am indebted to Prof. Dr. Wolfram Gerlich, Prof. Dr. Dieter Glebe, and Dr. Corinna M Bremer, University of Giessen, for providing me with mAbs, mice, and human sera against HBV.

I am especially grateful to Prof. Dr. Stephan Urban and Dr. Andreas Schulze, Otto-Meyerhof-Zentrum, University of Heidelberg, for providing anti-HB mice sera.

I am grateful to Prof. Dr. Camille Sureau, Institut National de la Transfusion Sanguine, Paris, for performing the HBV viral-like particle experiment.

I would like to thank Prof. Dr. Michael Roggendorf, Dr. Alexandra Schumann and Adalbert Krawczyk, Institute for Virology, University Hospital of Essen, University of Duisburg-Essen, for providing human sera from HBV-vaccinated individuals and $2 \mathrm{c}$ $\mathrm{mAb}$.

I convey a special acknowledgement to Karin Wolter, Erike Pitz, and Marita Kalck for their indispensable help dealing with travel funds, administration and bureaucratic matters during my stay in Germany.

Grateful thanks are also extended to all members of the Institute of Virology, UMG Göttingen, for their help and encouragement.

I would like to thank the Egyptian Ministry of Higher Education for supporting me in earning my PhD from Germany

Where would I be without my family? My parents deserve special mention for their constant support and prayers. Words fail me in expressing my appreciation to my wife, Engy, whose dedication, love and persistent confidence in me, has taken a load off my shoulders. 


\section{Curriculum Vitae}

Personal details:

Name

Date of birth

Place of birth

Marital status

Citizenship

School education:

\author{
Ahmed Abd El Wahed Aly Abou El Nasr \\ 03.11 .1980 \\ Port Said, Egypt \\ married, two daughters (born in 2008, and 2010) \\ Egyptian
}

General Secondary Education, Port Said Military Secondary School, Port Said, Egypt (degree 367/400)

\section{Academic background:}

2002

2006

From 2007
Bachelor of Veterinary Medical Science, Faculty of Veterinary Medicine, Mansoura University, Egypt

Master degree of Veterinary Medical Science, Faculty of Veterinary Medicine, Mansoura University, Egypt

Scholarship from the Egyptian Ministry of Higher Education to get the PhD from Germany $\mathrm{PhD}$ student at the Institute of Virology, UMG, Georg August University Goettingen, Germany under supervision of Prof. Dr. Hans-Joachim Fritz and Prof. Dr. Gerhard Hunsmann 
